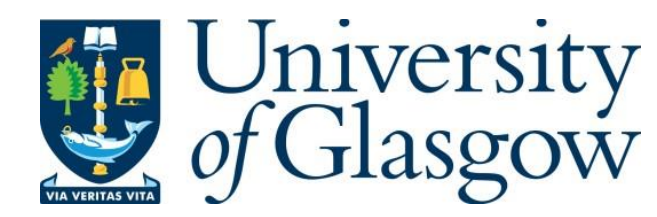

Philippopoulos, A., Varthalitis, P. and Vassilatos, V. (2017) Fiscal consolidation and its cross-country effects. Journal of Economic Dynamics and Control, 83, pp. 55-106. (doi:10.1016/j.jedc.2017.07.007)

There may be differences between this version and the published version. You are advised to consult the publisher's version if you wish to cite from it.

http://eprints.gla.ac.uk/145276/

Deposited on: 10 Jul 2018

Enlighten - Research publications by members of the University of Glasgow http://eprints.gla.ac.uk 


\section{Accepted Manuscript}

Fiscal consolidation and its cross-country effects

Apostolis Philippopoulos, Petros Varthalitis, Vanghelis Vassilatos

PII:

S0165-1889(17)30157-4

DOI:

10.1016/j.jedc.2017.07.007

Reference:

DYNCON 3458

To appear in:

Journal of Economic Dynamics \& Control

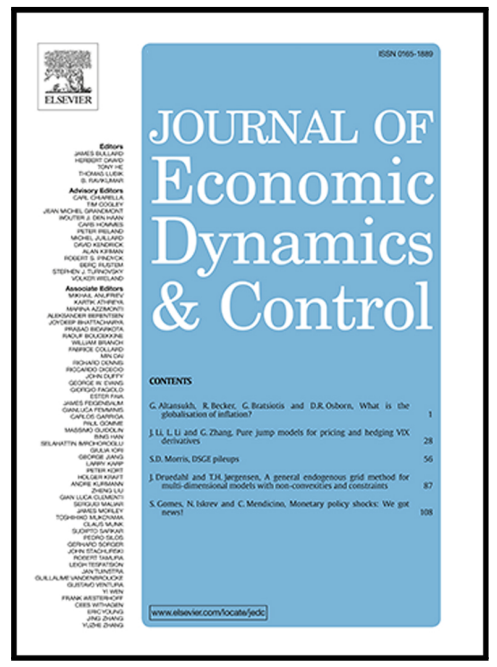

Received date:

8 July 2016

Revised date:

19 July 2017

Accepted date:

20 July 2017

Please cite this article as: Apostolis Philippopoulos, Petros Varthalitis, Vanghelis Vassilatos, Fiscal consolidation and its cross-country effects, Journal of Economic Dynamics \& Control (2017), doi: 10.1016/j.jedc.2017.07.007

This is a PDF file of an unedited manuscript that has been accepted for publication. As a service to our customers we are providing this early version of the manuscript. The manuscript will undergo copyediting, typesetting, and review of the resulting proof before it is published in its final form. Please note that during the production process errors may be discovered which could affect the content, and all legal disclaimers that apply to the journal pertain. 


\title{
Fiscal consolidation and its cross-country effects*
}

\author{
Apostolis Philippopoulos ${ }^{\dagger}$ \\ (Athens University of Economics and Business, and CESifo) \\ Petros Varthalitis \\ (Economic and Social Research Institute, and Trinity College Dublin) \\ Vanghelis Vassilatos \\ (Athens University of Economics and Business)

\begin{abstract}
We build a new Keynesian DSGE model consisting of two heterogeneous countries in a monetary union. We study how public debt consolidation in a country with high debt (like Italy) affects welfare in a country with solid public finances (like Germany). Our results show that debt consolidation in the high-debt country benefits the country with solid public finances over all time horizons, while, in Italy, debt consolidation is productive in the medium and long term. All this is with optimized feedback policy rules. On the other hand, fiscal consolidation hurts both countries and all the time, if it is implemented in an ad hoc way, like an increase in taxes. The least distorting fiscal mix from the point of view of both countries is the one which, during the early phase of pain, Italy cuts public consumption spending to address its debt problem and, at the same time, reduces income tax rates, while, once its debt has been reduced in the later phase, it uses the fiscal space to further cut income taxes.
\end{abstract} \\ July 31, 2017
}

Keywords: Debt consolidation, country spillovers, feedback policy rules, new Keynesian. JEL classification: E6, F3, H6

${ }^{*}$ We thank the coeditor, James Bullard, and two anonymous referees for many constructive comments. We thank Konstantinos Angelopoulos, Fabrice Collard, Harris Dellas, George Economides, Saqib Jafarey, Jim Malley, Dimitris Papageorgiou, Evi Pappa, Lefteris Roubanis and Elias Tzavalis for discussions. We thank Johannes Pfeifer for help with Dynare when this paper started. We have benefited from comments by seminar participants at the University of Bern, CESifo in Munich, University of Zurich, City University in London and the Athens University of Economics and Business. Any errors are ours. Petros Varthalitis clarifies that the views expressed here may differ from those of ESRI.

${ }^{\dagger}$ Corresponding author: Apostolis Philippopoulos, Department of Economics, Athens University of Economics and Business, Athens 10434, Greece. tel:+30-210-8203357. email: aphil@aueb.gr 


\section{Introduction}

Since the global shock of 2008, several eurozone periphery countries have been in a multiple crisis. In view of debt sustainability concerns and loss of confidence, these countries have been forced, among other things, to take restrictive fiscal policy measures which have further dampened demand in the short term. It is thus not surprising that fiscal consolidation has been one of the most debated policy areas over the past years. On the other hand, fiscal policy in eurozone center countries, like Germany, has been neutral. Nevertheless, the debt crisis in the periphery countries has also affected the German economy, which is another reminder of the importance of spillovers in an integrated area like the euro area. ${ }^{1}$

In this paper, we study how public debt consolidation in a country with high debt and sovereign premia affects welfare in other countries with solid public finances. In particular, we study how public debt consolidation in a country like Italy/affeets welfare in a country like Germany and how these cross-border effects depend on the fiscal policy mix chosen to bring public debt down. ${ }^{2}$

The setup is a new Keynesian DSGE model consisting of two heterogeneous countries forming a currency union. An international asset market allows private agents across countries to borrow from, or lend to, each other and the same market allows national governments to sell their bonds to foreign private agents. Regarding macroeconomic policy, being in a monetary union, there is a single monetary policy. On the other hand, the two countries are free to follow independent or national fiscal policies. Following most of the literature on debt consolidation (see below), we follow a rules-based approach to policy. Policy is conducted via "simple, implementable and optimized" feedback rules (see e.g. Schmitt-Grohé and Uribe, 2007). This means that the union-wide monetary policy is conducted via a standard Taylor rule for the nominal interest rate, while all the main national fiscal instruments (government consumption spending, government investment spending, transfer payments, and the tax rates on labor income, (capital income and consumption) can respond to the gap between public debt and target public debt as shares of output, as well as to the output gap. The values of feedback (monetary and fiscal) policy coefficients are computed optimally, so as to maximize a weighted average of households' expected discounted lifetime utility in the two countries;

\footnotetext{
${ }^{1}$ For the debt problem in the euroarea and fiscal policy in various member countries, see e.g. the EEAG Report on the European Economy $(2012,2017)$ by CESifo and EMU-Public Finances (2016) by the European Commission.

${ }^{2}$ Italy's (public and foreign) debt position, although sizeable in absolute terms, is not one of the worst in the euroarea. Greece, Portugal, Spain, Ireland and Cyprus, have been in a worse position; see e.g. the EEAG Report on the European Economy (2012) by CESifo. However, since these countries have received financial aid from the EC-ECB-IMF, we prefer to use Italy as our euro area periphery country.
} 
this can be thought of as a cooperative policy at international level. We will experiment with various public debt policy targets depending on whether national policymakers aim just to stabilize the economy around its status quo (defined as the solution consistent with the recent data), or whether they also want to move the economy to a new reformed steady state (defined as a solution with lower public debt than in the recent data). For comparison, we will also study exogenous fiscal consolidation scenarios resembing those recently observed in Italy.

We solve the above model numerically employing commonly used parameter values and fiscal policy data from Germany (called the domestic country) and Italy (called the foreign country). The steady state solution of this model can mimic relatively well the key features of the two countries over the euro years and, more importantly, the current account deficits in Italy financed by current account surpluses in Germany over the period 2001-2011. It is useful to stress that this is achieved simply by allowing for differences in fiscal policy and the degree of patience; the latter means that Italians have been 1ess patient than Germans during the euro period. In turn, we use this solution as a point of departure to study the dynamic evolution of endogenous variables in response to policy reforms, focusing on debt consolidation in the high-debt country, namely, Italy.

Our main results are as follows. First, as perhaps expected, had tax-spending policy in Italy remained unchanged as in the data averages over 2001-2011, the model would be dynamically unstable. In other words, some type of fiscal reaction (spending cuts and/or tax rises) to public debt imbalances was necessary for restoring dynamic stability.

Second, debt consolidation in the high-debt country (Italy) benefits the country with solid public finances (Germany) over all time horizons. By constrast, in Italy, namely the country that takes the consolidation measures, such a policy is productive only in the medium and long term. Thus, in Italy, although the benefits outweigh the costs when the criterion is lifetime utility, debt consolidation comes at a short-term pain relative to non-consolidation. To put it differently, fiscal consolidation in a high debt country is a common interest over longer horizons but, in shorter horizons, there seems to be a conflict of national interests. It is interesting to add that the medium- and long-term benefits from fiscal consolidation become more substantial for both countries when debt reduction is such that sovereign premia are also eliminated in the new reformed steady state; but such elimination requires an equalization of time discount factors, meaning an equal degree of patience, across countries in the new reformed steady state (see section 2.1 for details). All this holds with optimized feedback policy rules.

Third, the least distorting fiscal policy mix from the point of view of both countries is the one where, during the early phase of pain, Italy cuts government consumption spending to 
address its public debt problem and, at the same time, reduces (labor and capital) income tax rates to mitigate the short-term recessionary effects of these spending cuts, while, once its public debt has been reduced in the later phase, it uses the fiscal space created to further cut capital taxes. In other words, regarding the early phase of pain, Italy's public debt should be brought down by cuts in government consumption spending only (and not by cuts in government investment and transfer payments or by rises in various taxes), while, regarding the later phase of fiscal gain, the anticipation of cuts in capital taxes in the future, once debt consolidation has been achieved, plays a key role even in the short term. Use of public consumption spending is also recommended in Germany, where the policy aim is just cyclical stabilization. It is also interesting to report that, to the extent that policy reactions are chosen cooperatively, the higher the say of Germany in policy setting, the stronger the fiscal consolidation in Italy should be during the early period of pain. Again, all this holds with optimized feedback policy rules.

The fourth result is about exogenous data-mimicking policies, so it is a positive result. The implications of such policies are very different from the normative implications listed above. In particular, we experiment with an exogenous scenario of debt consolidation that resembles the policy actually implemented between 2012 and 2015; this means that, in Italy, the tax revenue to GDP ratio rises by around two percentage points, while the spending ratio remains practically unchanged, and, in Germany, fiscal policy is kept neutral. In this case, debt consolidation in Italy is harmful for both countries and across all time horizons, always relative to non-consolidation. Therefore, the way public debt is brought down is important.

Finally, the above results are robust to a number of extensions, namely, the introduction of non-Ricardian households, shocks to starting public debt, changes in the value of the public debt policy target, or flexible exchange rates. The policy recipes are also robust to the degree of international cooperation in policy decision-making. However, in a non-cooperative (Nash) policy regime, the absence of cooperation leads to a relatively small degree of fiscal consolidation in Italy; the idea is that countries free ride on other countries' debt stabilization efforts.

The literature closest to our work is the one on debt consolidation in multi-country open economy models and especially in currency union models; see e.g. Coenen et al. (2008), Forni et al. (2010), Clinton et al. (2011), Erceg and Lindé (2013) and Cogan et al. (2013). These papers have compared different ad hoc fiscal consolidation scenarios in a currency union. Here, by contrast, we compute optimized feedback policy rules for a rich menu of fiscal instruments 
allowed to be used simultaneously ${ }^{3}$ hence, we do not have to make any arbitrary assumptions about which instrument to use to react to economic conditions and/or how strong this reaction is (the latter also determines the optimal speed of fiscal consolidation). ${ }^{4}$ We also compare optimal to exogenous data-mimicking policy in light of the European debt crisis and thus emphasize the importance of the policy mix adopted. In addition, in what concerns the framework we work within, as far as we know, there have been no previous attempts to search for the best possible use of all main fiscal policy instruments in a new Keynesian DSGE model of a currency union consisting of two heterogeneous countries and, then, study the cross-border implications of fiscal consolidation measures taken by a high-debt country. Country heterogeneity takes the form of weak public finances and external debt in one country (e.g. Italy) and sound public finances and external assets in the other country (e.g. Germany) and this is reflected in sovereign premia. This type of heterogeneity is at the heart of the current debate in Europe and hence allows for a more realistic assessment of alternative consolidation policies. Finally, we also address how the political power of each country affects the chosen consolidation policies in a cooperative international setup, as well as the implications of the lack of such cooperation. ${ }^{5}$

The rest of the paper is organized as follows. Section 2 presents the model. The status quo solution is in section 3. Section 4 explains our policy experiments. The main results are in sections 5 and 6 . Section 7 studies other policy regimes. Section 8 closes the paper. An online appendix provides algebraic details and extra results.

\footnotetext{
${ }^{3}$ Papers that also compute optimized feedback policy rules in various economic environments include SchmittGrohé and Uribe (2005 and 2007), Beetsma and Jensen (2005), Kollmann (2008), Cantore et al. (2017) and Philippopoulos et al. $(2015,2016)$. Differences from these papers are discussed right below, while alternative approaches to policy decision-making are discussed in the last section (section 8).

${ }^{4}$ As is widely recognized (see e.g. Coenen et al., 2012, and D' Erasmo et al., 2016), the assumed size of feedback policy coefficients is an important factor behind the variation of results across models.

${ }^{5}$ Papers on debt consolidation in closed economy or small open economy models include Bi et al. (2013), Corsetti et al. (2013), Almeida et al. (2013), Benigno and Romei (2014), Benigno et al. (2014), Cantore et al. (2017) and Philippopoulos et al. (2015, 2016). Cantore et al. (2017) also study optimized simple rules, as we do here, but this is in a closed economy model, while Philippopoulos et al. (2016) focus on a small open economy. Beetsma and Jensen (2005) and Okano (2014) do compute optimal policies in a currency union but do not study debt consolidation. The literature on debt consolidation has built on the earlier literature on the fiscal-monetary policy interaction; see e.g. Leeper (1991), Schmitt-Grohé and Uribe (2005 and 2007), Beetsma and Jensen (2005), Kollmann (2008), Leith and Wren-Lewis (2008), Batini et al. (2009), Leeper et al. (2009), Kirsanova et al. (2009), Bi and Kumhof (2011) and Kirsanova and Wren-Lewis (2012).
} 


\section{A two-country model of a monetary union}

This section presents a New Keynesian DSGE model of a currency union consisting of two heterogeneous countries. ${ }^{6}$

\subsection{Informal description of the model}

In each country, there are households, firms and a national fiscal authority. In a monetary union, there is a single monetary authority. Households in each country save in the form of physical capital, domestic government bonds and internationally traded assets. The market for internationally traded assets allows private agents across countries to borrow from, or lend to, each other and it also allows national governments to sell their bonds to foreign private agents. ${ }^{7}$ International borrowing/lending takes place through a financialintermediary or bank and this intermediation requires a transaction cost proportional to the amount of the nation's debt. ${ }^{8}$ This cost creates a wedge between the borrowing and the lending interest rate, so that, when they participate in the international asset market, agents (private and public) of the debtor country face a higher interest rate than agents (private and public) of the creditor country. ${ }^{9}$ To the extent that the bank makes a profit, this profit is rebated lump-sum to households located in the creditor country.

Systematic borrowing and lending cannot occur in an homogeneous world. Some type of heterogeneity is needed. A popular way of producing borrowers and lenders has been to assume that agents differ in their patience to consume; specifically, the discount factor of lenders is higher than that of borrowers or, equivalently, borrowers are more impatient than lenders. ${ }^{10}$ Such differences in discount factors need to be combined with an imperfection in the capital market in order to get a well-defined solution; ${ }^{11}$ in our model, the capital market imperfection is the transaction cost of the loan. Therefore, the international transaction cost ensures, not only stationarity of foreign asset positions as is typically the case in the literature (see e.g.

${ }^{6}$ The model is similar to that in Economides et al (2016). However, here we study optimal debt consolidation policies within a currency union, while that paper compared a currency union to other regimes like a fiscal (transfer) union and without optimal policy.

7 See also Forni et al. (2010), Cogan et al. (2013), Erceg and Lindé (2013) and many others.

${ }^{8}$ Thus, as in e.g. Cúrdia and Woodford $(2010,2011)$ and Benigno et al (2014), we use the device of a financial intermediary. We could instead assume transaction costs incurred upon borrowers; see e.g. Forni et al. (2010), Cogan et al. (2013), Erceg and Lindé ( 2013).

${ }^{9}$ That is, here, differences in interest rates across countries are produced by transcation costs incurred by the bank. As is known such differences can be produced in various other ways (see subsection 2.5 below).

${ }^{10}$ See also e.g. Benigno et al. (2014). Kiyotaki and Moore (1997) also use a general equilibrium model with two types of agents, creditors and borrowers, who discount the future differently. Note that we could further enrich our model so as the discount factors are formed endogenously.

${ }^{11}$ See also e.g. Doepke and Zilibotti (2008) and Benigno et al. (2014). 
Schmitt-Grohé and Uribe, 2003), but also allows for a well-defined solution with different discount factors across different countries.

The solution of this model will imply that one country (Germany) is a net lender and the other (Italy) is a net borrower in the international asset market and that interest rates are higher in the net debtor country. That is, as said in the Introduction, the relatively impatient Italians finance their current account deficits by borrowing funds from the patient Germans who run current account surpluses. This scenario is also consistent with the literature on the interpretation of current accounts, in the sense that systematic low saving rates and current account deficits are believed to reflect relatively low patience (see e.g. Choi et al., 2008).

On other dimensions, the model is a standard new Keynesian currency union model. ${ }^{12}$ In particular, each country produces an array of differentiated goods and, in both countries, firms act monopolistically facing Calvo-type nominal fixities. Nominal fixities can give a real role to monetary and exchange rate policy, at least in the transition path. In a monetary union, we assume a single monetary policy but independent/national fiscal policies. Policy (both monetary and fiscal) is conducted by optimized state-contingent policy rules.

The rest of this section models the above story. We will present the domestic country. The structure of the foreign country will be analogous except otherwise said. A star will denote the counterpart of a variable in the foreign country.

\subsection{Households}

This subsection presents the problem of households in the domestic country. There are $N$ identical households indexed by $i=1,2, \ldots, N$. Similarly, in the foreign economy. For simplicity, population in both countries, $N$ and $N^{*}$, is constant over time and the two countries are of equal size, $N=N^{*}$.

\subsubsection{Consumption bundles}

The quantity of each variety $h$ produced at home by domestic firm $h$ and consumed by each domestic household $i$ is denoted as $c_{i, t}^{H}(h)$. Using a Dixit-Stiglitz aggregator, the composite of domestic goods consumed by each domestic household $i, c_{i, t}^{H}$, consists of $h$ varieties and is given by: ${ }^{13}$

$$
c_{i, t}^{H}=\left[\sum_{h=1}^{N}\left[c_{i, t}^{H}(h)\right]^{\frac{\phi-1}{\phi}}\right]^{\frac{\phi}{\phi-1}}
$$

\footnotetext{
${ }^{12}$ See Okano (2014) for a review of the related literature dating back to Galí and Monacelli $(2005,2008)$.

${ }^{13} \mathrm{As}$ in e.g. Blanchard and Giavazzi (2003), we work with summations rather than with integrals.
} 
where $\phi>0$ is the elasticity of substitution across goods produced in the domestic country.

Similarly, the quantity of each imported variety $f$ produced abroad by foreign firm $f$ and consumed by each domestic household $i$ is denoted as $c_{i, t}^{F}(f)$. Using a Dixit-Stiglitz aggregator, the composite of imported goods consumed by each domestic household $i, c_{i, t}^{F}$, consists of $f$ varieties and is given by:

$$
c_{i, t}^{F}=\left[\sum_{f=1}^{N}\left[c_{i, t}^{F}(f)\right]^{\frac{\phi-1}{\phi}}\right]^{\frac{\phi}{\phi-1}}
$$

In turn, having defined $c_{i, t}^{H}$ and $c_{i, t}^{F}$, $i$ 's consumption bundle, $c_{i, t}$, is defined as:

$$
c_{i, t}=\frac{\left(c_{i, t}^{H}\right)^{\nu}\left(c_{i, t}^{F}\right)^{1-\nu}}{\nu^{\nu}(1-\nu)^{1-\nu}}
$$

where $\nu$ is the degree of preference for domestic goods (if $\nu>1 / 2$, there is a home bias).

\subsubsection{Consumption expenditure, prices and terms of trade}

Domestic household $i$ 's total consumption expenditure is:

$$
P_{t} c_{i, t}=P_{t}^{H} c_{i, t}^{H}+P_{t}^{F} c_{i, t}^{F}
$$

where $P_{t}$ is the consumer price index $(\mathrm{CPI}), P_{t}^{H}$ is the price index of home tradables, and $P_{t}^{F}$ is the price index of foreign tradables (expressed in domestic currency).

Each domestic household's total expenditure on home goods and foreign goods are:

$$
\begin{aligned}
& P_{t}^{H} c_{i, t}^{H}=\sum_{h=1}^{N} P_{t}^{H}(h) c_{i, t}^{H}(h) \\
& P_{t}^{F} c_{i, t}^{F}=\sum_{f=1}^{N} P_{t}^{F}(f) c_{i, t}^{F}(f)
\end{aligned}
$$

where $P_{t}^{H}(h)$ is the price of each variety $h$ produced at home and $P_{t}^{F}(f)$ is the price of each variety $f$ produced abroad, both denominated in domestic currency.

We assume that the law of one price holds meaning that each tradable good sells at the same price at home and abroad. Thus, $P_{t}^{F}(f)=S_{t} P_{t}^{H *}(f)$, where $S_{t}$ is the nominal exchange rate (where an increase in $S_{t}$ implies a depreciation) and $P_{t}^{H *}(f)$ is the price of variety $f$ produced abroad denominated in foreign currency. Note that the terms of trade are defined as $\frac{P_{t}^{F}}{P_{t}^{H}}\left(=\frac{S_{t} P_{t}^{H *}}{P_{t}^{H}}\right)$, while the real exchange rate is defined as $\frac{S_{t} P_{t}^{*}}{P_{t}}$. In a currency union, we set $S_{t} \equiv 1$ at all $t$. 


\subsubsection{Household's optimization problem}

Each household $i$ acts competitively to maximize expected discounted lifetime utility, $V_{0}$ :

$$
V_{0} \equiv E_{0} \sum_{t=0}^{\infty} \beta^{t} U\left(c_{i, t}, n_{i, t}, m_{i, t}, g_{t}\right)
$$

where $c_{i, t}$ is $i$ 's consumption bundle as defined above, $n_{i, t}$ is $i$ 's hours of work, $m_{i, t}$ is $i$ 's real money holdings, $g_{t}$ is per capita utility-enhancing public goods and services provided by the government, $0<\beta<1$ is domestic agents' discount factor, and $E_{0}$ is a rational expectations operator.

For our numerical solutions, the period utility function will be (see also e.g. Galí, 2008):

$$
u_{i, t}\left(c_{i, t}, n_{i, t}, m_{i, t}, g_{t}\right)=\frac{c_{i, t}^{1-\sigma}}{1-\sigma}-\chi_{n} \frac{n_{i, t}^{1+\varphi}}{1+\varphi}+\chi_{m} \frac{m_{i, t}^{1-\mu}}{1-\mu}+\chi_{g} \frac{g_{t}^{1-\zeta}}{1-\zeta}
$$

where $\chi_{n}, \chi_{m}, \chi_{g}, \sigma, \varphi, \mu, \zeta$ are standard preference parameters, $1 / \sigma$ is the elasticity of substitution between consumption at two points in time and $1 / \varphi$ is the Frisch labour elasticity.

The period budget constraint of each household $i$ in the domestic country written in real terms (i.e. nominal variables are divided by the domestic CPI, $P_{t}$ ) is:

$$
\begin{gathered}
\left(1+\tau_{t}^{c}\right)\left[\frac{P_{t}^{H}}{P_{t}} c_{i, t}^{H}+\frac{P_{t}^{F}}{P_{t}} c_{i, t}^{F}\right]+\frac{P_{t}^{H}}{P_{t}} x_{i, t}+b_{i, t}+m_{i, t}+\frac{S_{t} P_{t}^{*}}{P_{t}} f_{i, t}^{h}= \\
=\left(1-\tau_{t}^{k}\right)\left[r_{t}^{k} \frac{P_{t}^{H}}{P_{t}} k_{i, t-1}+\widetilde{\omega}_{i, t}\right]+4\left(1-\tau_{t}^{n}\right) w_{t} n_{i, t}+R_{t-1} \frac{P_{t-1}}{P_{t}} b_{i, t-1}+ \\
+\frac{P_{t-1}}{P_{t}} m_{i, t-1}+Q_{t-1} \frac{S_{t} P_{t}^{*}}{P_{t}} \frac{P_{t-1}^{*}}{P_{t}^{*}} f_{i, t-1}^{h}-\tau_{i, t}^{l}+\pi_{i, t}
\end{gathered}
$$

where $x_{i, t}$ is $i$ 's investment in domestic physical capital, $b_{i, t}$ is the real value of $i$ 's end-of-period domestic government bonds, $m_{i, t}$ is $i$ 's end-of period real domestic money holdings, $f_{i, t}^{h}$ is the real value of $i$ 's end-of-period internationally traded assets denominated in foreign currency (if $f_{i, t}^{h}<0$, it denotes private foreign debt), $r_{t}^{k}$ is the real return to $k_{i, t-1}$ which is $i$ 's beginningof-period domestic physical capital, $\widetilde{\omega}_{i, t}$ denotes $i$ 's real dividends received by domestic firms, $w_{t}$ is the real wage rate, $R_{t-1} \geq 1$ denotes the gross nominal return to domestic government bonds between $t-1$ and $t, Q_{t-1} \geq 1$ denotes the gross nominal return to international assets between $t-1$ and $t, \tau_{i, t}^{l}$ is real taxes/transfers (if positive, it denotes lump-sum taxes paid to the government; if negative, it denotes transfers received by the government), $\pi_{i, t}$ is real profits distributed in a lump-sum fashion to each domestic household by the financial intermediary and $0 \leq \tau_{t}^{c}, \tau_{t}^{k}, \tau_{t}^{n}<1$ are tax rates on consumption, capital income and labour income respectively. 
The law of motion of $i$ 's physical capital is:

$$
k_{i, t}=(1-\delta) k_{i, t-1}+x_{i, t}-\frac{\xi}{2}\left(\frac{k_{i, t}}{k_{i, t-1}}-1\right)^{2} k_{i, t-1}
$$

where $0<\delta<1$ is a depreciation rate and $\xi \geq 0$ is a parameter capturing adjustment costs.

Details on the household's problem, its first-order conditions and implications for the price bundles are in Appendix 1.

\section{$2.3 \quad$ Firms}

This subsection presents the problem of firms in the domestic economy. There are $N$ domestic firms indexed by $h=1,2, \ldots, N$. Each firm $h$ produces a differentiated tradable good of variety $h$ under monopolistic competition and Calvo-type nominal fixities.

\subsubsection{Demand for the firm's product}

Demand for each product $h$, denoted as $y_{t}^{H}(h)$, is (see Appendix 2 for details):

$$
y_{t}^{H}(h)=\left[\frac{P_{t}^{H}(h)}{P_{t}^{H}}\right]^{-\phi^{\prime}} Y_{t}^{H}
$$

where $Y_{t}^{H}$ denotes total demand in the domestic country.

\subsubsection{Firm's optimization problem}

Real profits of each domestic firm $h$ are defined as:

$$
\widetilde{\omega}_{t}(h) \equiv \frac{P_{t}^{H}(h)}{P_{t}} y_{t}^{H}(h)-\frac{P_{t}^{H}}{P_{t}} r_{t}^{k} k_{t-1}(h)-w_{t} n_{t}(h)
$$

where $k_{t-1}(h)$ and $n_{t}(h)$ denote capital and labor inputs chosen by firm $h$ at $t$.

Maximization is subject to the demand function, (11), and the production function:

$$
y_{t}^{H}(h)=A_{t}\left[k_{t-1}(h)\right]^{\alpha}\left[n_{t}(h)\right]^{1-\alpha}
$$

where $A_{t}$ is total factor productivity (TFP), whose motion is defined below, and $0<\alpha<1$ is a technology parameter.

In each period, each firm $h$ faces an exogenous probability $\theta$ of not being able to reset its price. A firm $h$, which is able to reset its price at time $t$, chooses its price $P_{t}^{\#}(h)$ to maximize the sum of discounted expected nominal profits for the next $k$ periods in which it may have to keep its price fixed. 
Details on the firm's problem and its first-order conditions are in Appendix 2.

\subsection{Government budget constraint}

The period budget constraint of the consolidated government sector in the domestic country expressed in real and per capita terms is (see Appendix 3 for details):

$$
\begin{aligned}
& b_{t}+\frac{S_{t} P_{t}^{*}}{P_{t}} f_{t}^{g}+m_{t}=R_{t-1} \frac{P_{t-1}}{P_{t}} b_{t-1}+Q_{t-1} \frac{S_{t} P_{t}^{*}}{P_{t}} \frac{P_{t-1}^{*}}{P_{t}^{*}} f_{t-1}^{g}+\frac{P_{t-1}}{P_{t}} m_{t-1}+ \\
& \quad+\frac{P_{t}^{H}}{P_{t}} g_{t}-\tau_{t}^{c}\left(\frac{P_{t}^{H}}{P_{t}} c_{t}^{H}+\frac{P_{t}^{F}}{P_{t}} c_{t}^{F}\right)-\tau_{t}^{k}\left(r_{t}^{k} \frac{P_{t}^{H}}{P_{t}} k_{t-1}+\widetilde{\omega}_{t}\right)-\tau_{t}^{n} w_{t} n_{t}-\tau_{t}^{l}
\end{aligned}
$$

where $b_{t}$ is the end-of-period domestic real public debt held by domestic households, $f_{t}^{g}$ is the end-of-period domestic real public debt held by foreign households and expressed in foreign prices, ${ }^{14}$ and $m_{t}$ is the end-of-period stock of real money balances. Also, $g_{t}, c_{t}^{H}, c_{t}^{F}, k_{t-1}, \widetilde{\omega}_{t}, n_{t}$ are respectively government purchases of goods and services, households' consumption of the domestic good, households' consumption of the imported good, households' physical capital holdings, households' dividends and household's work hours. Finally, $\tau_{t}^{c}, \tau_{t}^{k}, \tau_{t}^{n}$ and $\tau_{t}^{l}$ have been defined above.

Equivalently, if we define total nominal public debt in the domestic country as $D_{t} \equiv$ $B_{t}+S_{t} F_{t}^{g}$, so that in real and per capita terms $d_{t} \equiv b_{t}+\frac{S_{t} P_{t}^{*}}{P_{t}} f_{t}^{g}$, we have $b_{t} \equiv \lambda_{t} d_{t}$ and $\frac{S_{t} P_{t}^{*}}{P_{t}} f_{t}^{g} \equiv\left(1-\lambda_{t}\right) d_{t}$, where $0 \leq \lambda_{t} \leq 1$ denotes the fraction of domestic public debt held by domestic private agents and $0 \leq 1-\lambda_{t} \leq 1$ is the fraction of domestic public debt held by foreign private agents.

In each period, one of the fiscal instruments $\left(\tau_{t}^{c}, \tau_{t}^{k}, \tau_{t}^{n}, g_{t}, \tau_{t}^{l}, \lambda_{t}, d_{t}\right)$ follows residually to satisfy the government budget constraint. We assume, except otherwise said, that this role is played by the end-of-period total public debt, $d_{t} \cdot{ }^{15}$

\footnotetext{
${ }^{14}$ Since the returns to bonds held by domestic agents and the same bonds held by foreign agents can differ, our modelling assumes implicitly that the bond market can be segmented.

${ }^{15}$ We treat the share of public debt held by foreign private agents, $\left(1-\lambda_{t}\right)$, as an exogenous variable. In our model, there is a single international asset subject to a single transaction cost. Thus, since we do not allow for separate international asset markets (one for private and one for public), we need an extra assumption to get a solution and this is provided by treating $\lambda_{t}$ as an exogenous variable in each country (it will be set as in the data average). Alternatively, we could assume that private agents in each country can separately invest in foreign private assets and foreign government bonds (rather than in a single international asset). But, as is known, this modelling would lead to a non-well specified system (a kind of portfolio indeterminacy), except if one is willing to assume different transaction costs in different asset markets. In the latter case, portfolio shares could be determined but their solution would depend on the parameterization of the associated transaction cost function. This would not be different from treating $\lambda_{t}$ exogenously in the first place.
} 


\subsection{World financial intermediary}

We use a simple and popular model of financial frictions (see e.g. Uribe and Yue, 2006, Cúrdia and Woodford, 2010 and 2011, and Benigno et al., 2014). International borrowing, or lending, takes place through a financial intermediary or bank. This intermediary is located in the home country. It plays a traditional role only, collecting deposits from lenders and lending the funds to borrowers.

In particular, the bank raises funds from domestic private agents, $\left(f_{t}^{h}-f_{t}^{g}\right)$, at the rate $Q_{t}$ and lends to foreign agents, $\left(f_{t}^{* g}-f_{t}^{* h}\right)$, at the rate $Q_{t}^{*}{ }^{16}$ In addition, the bank faces operational costs, which are increasing and convex in the volume of the loan, $\left(f_{t}^{* g}-f_{t}^{* h}\right)$. The profit of the bank is revenue minus cost where revenue is net of transaction costs. Thus, the profit written in real and per capita terms in the domestic country is given by (details are in Appendix 4):

$$
\pi_{t}=Q_{t-1}^{*}\left[\frac{P_{t-1}}{P_{t}}\left(f_{t-1}^{* g}-f_{t-1}^{* h}\right)-\frac{P_{t}^{H}}{P_{t}} \frac{P_{t-1}^{H}}{P_{t}^{H}} \frac{\psi}{2}\left(f_{t-1}^{* g}-f_{t-1}^{* h}\right)^{2}\right]-Q_{t-1} \frac{S_{t} P_{t}^{*}}{P_{t}} \frac{P_{t-1}^{*}}{P_{t}^{*}}\left(f_{t-1}^{h}-f_{t-1}^{g}\right)
$$

where $\frac{\psi}{2}\left(f_{t-1}^{* g}-f_{t-1}^{* h}\right)^{2}$ is a real and per capita cost function and $\psi \geq 0$ is a parameter (see subsection 3.1 below for its value). The first term in the brackets on the RHS is the bank's return on the loan net of transaction costs, while the last term is payments to the savers.

At each $t$, the bank chooses the volume of its loan taking $Q_{t}$ and $Q_{t}^{*}$ as given. The optimality condition is (details are in Appendix 4):

$$
Q_{t-1}^{*}=\frac{Q_{t-1} \frac{S_{t}}{S_{t-1}}}{1-\frac{P_{t-1}^{H}}{P_{t-1}} \psi\left(f_{t-1}^{* g}-f_{t-1}^{* h}\right)}
$$

where, in a currency union, $S_{t} \equiv 1$; thus, $Q_{t}^{*}>Q_{t}$ which means that borrowers pay a sovereign premium.

It needs to be said that the implied property in equation (16) - namely, that the interest rate, at which the country borrows from the rest of the world, is increasing in the nation's total foreign debt - is supported by a number of empirical studies (see e.g. EMU-Public Finances,

\footnotetext{
${ }^{16}$ Here $f_{t}^{h} \equiv \frac{\sum_{i=1}^{N} f_{i, t}^{h}}{N}$, where $f_{i, t}^{h} \equiv \frac{F_{i, t}^{h}}{P_{t}^{*}}$ is each household $i$ 's foreign assets denominated in foreign currency, and $f_{t}^{g} \equiv \frac{F_{t}^{g}}{P_{t}^{*} N}$ is real and per capita public foreign debt (i.e. public debt held by foreign agents) in the domestic country; similarly in the foreign country. Then, if it so happens that $\left(f_{t}^{h}-f_{t}^{g}\right)$ is positive, it denotes net foreign assets in the home country and if it so happens that $\left(f_{t}^{* g}-f_{t}^{* h}\right)$ is positive, it denotes net foreign liabilities in the foreign country. In equilibrium, $\left(f_{t}^{* g}-f_{t}^{* h}\right)+\frac{S_{t} P_{t}^{*}}{P_{t}}\left(f_{t}^{g}-f_{t}^{h}\right)=0$. Appendix 4 provides details.
} 
2012, by the European Commission). It should also be said that a similar type of endogeneity of the country premium can be produced by several other models, including models of default risk. ${ }^{17}$

\subsection{Monetary and fiscal policy}

We now specify monetary and fiscal policy rules.

\subsubsection{Single monetary policy rule in a monetary union}

If we had flexible exchange rates, the exchange rate would be an endogenous variable and the two countries' nominal interest rates, $R_{t}$ and $R_{t}^{*}$, could be free to be set independently by the national monetary authorities, say, to follow national Taylor-type rules (see section 7 for flexible exchange rates). Here, by contrast, to mimic the eurozone regime, we assume that only one of the nominal interest rates, say $R_{t}$, can follow a Taylor-type rule, while $R_{t}^{*}$ is an endogenous variable replacing the exchange rate which becomes an exogenous policy variable (this modelling, where the union's central bank uses one of national governments' interest rates as its policy instrument, is similar to that in e.g. Galí and Monacelli, 2008, and Benigno and Benigno, 2008). ${ }^{18}$

In particular, we assume a single monetary feedback policy rule of the form:

$$
\begin{array}{r}
\log \left(\frac{R_{t}}{R}\right)=\phi_{\pi}\left(\eta \log \left(\frac{\Pi_{t}}{\Pi}\right)+(1-\eta) \log \left(\frac{\Pi_{t}^{*}}{\Pi^{*}}\right)\right)+ \\
+\phi_{y}\left(\eta \log \left(\frac{y_{t}^{H}}{y^{H}}\right)+(1-\eta) \log \left(\frac{y_{t}^{* H}}{y^{* H}}\right)\right)
\end{array}
$$

where $\phi_{\pi} \geq 0$ and $\phi_{y} \geq 0$ are respectively feedback monetary policy coefficients on price inflation and the output gap, $0 \leq \eta \leq 1$ is the political weight given to the domestic country relative to the foreign country (see subsection 3.1 below for the value of this parameter) and variables without time subscripts denote policy targets (in the case of monetary policy, the policy targets are simply the steady state values of the corresponding variables).

${ }^{17}$ Default risk reflects the fear of de jure, or outright, repudiation of debt obligations, but also the fear of de facto default via inflation or new wealth taxes with retroactive effect (see Alesina et al., 1992, for an early study and D' Erasmo et al., 2016, for a recent study). As Corsetti et al. (2013) point out, there are two modelling approaches to sovereign default. The first approach models it as a strategic choice of the government (see e.g. Eaton and Gersovitz, 1981, Arellano, 2008, D' Erasmo et al., 2016, and many others). The second approach assumes that default occurs when debt exceeds an endogenous fiscal limit (see e.g. Bi, 2012, and many others). In our paper, we abstract from issues related to default.

${ }^{18}$ For various ways of modelling monetary policy in a monetary union, see e.g. Dellas and Tavlas (2005) and Collard and Dellas (2006). 


\subsubsection{National fiscal policy rules}

Countries can follow independent fiscal policies. As in the case of monetary policy above, we focus on simple feedback rules meaning that national fiscal authorities react to a small number of easily observable macroeconomic indicators. In particular, in each country, we allow all the main spending-tax policy instruments, namely, the ratio of real government spending on goods and services to real GDP, defined as $s_{t}^{g}$, the ratio of real government transfers to real GDP, denoted as $s_{t}^{l}$, and the tax rates on consumption, capital income and labor income, $\tau_{t}^{c}, \tau_{t}^{k}$ and $\tau_{t}^{n}$, to react to the public debt-to-GDP ratio as deviation from a target value, as well as to the output gap, according to simple linear rules: ${ }^{19}$

$$
\begin{gathered}
s_{t}^{g}-s^{g}=-\gamma_{l}^{g}\left(l_{t-1}-l\right)-\gamma_{y}^{g}\left(y_{t}^{H}-y^{H}\right) \\
s_{t}^{l}-s^{l}=\gamma_{l}^{l}\left(l_{t-1}-l\right)+\gamma_{y}^{l}\left(y_{t}^{H}-y^{H}\right) \\
\tau_{t}^{c}-\tau^{c}=\gamma_{l}^{c}\left(l_{t-1}-l\right)+\gamma_{y}^{c}\left(y_{t}^{H}-y^{H}\right) \\
\tau_{t}^{k}-\tau^{k}=\gamma_{l}^{k}\left(l_{t-1}-l\right)+\gamma_{y}^{k}\left(y_{t}^{H}-y^{H}\right) \\
\tau_{t}^{n}-\pi^{n}=\gamma_{l}^{n}\left(l_{t-1}-l\right)+\gamma_{y}^{n}\left(y_{t}^{H}-y^{H}\right)
\end{gathered}
$$

where $l_{t-1}$ is the beginning-of-period government liabilities as share of GDP (defined right below), $\gamma_{l}^{q}$ and $\gamma_{y}^{q} \geq 0$, for $q \equiv(g, l, c, k, n)$, are respectively feedback fiscal policy coefficients on public liabilities and the output gap, and variables without time subscripts denote policy targets (see/subsection 4.1 below for definition of fiscal policy targets). It should be recalled that a negative value of $s_{t}^{l}$ denotes transfers, so a positive $\gamma_{l}^{l}$ means that transfers fall when public liabilities rise above their target.

From the government budget constraint, public liabilities at the end of period $t$ expressed in real and per capita terms are (see Appendix 3 for details):

\footnotetext{
${ }^{19}$ For similar rules, see e.g Schmitt-Grohé and Uribe (2007) and Cantore et al. (2017). See also EMU-Public Finances (2011) by the European Commission and D' Erasmo et al. (2016) for fiscal reaction functions used in practice and their role in public debt sustainability.
} 


$$
l_{t} \equiv \frac{R_{t} \lambda_{t} d_{t}+Q_{t} \frac{S_{t+1}}{S_{t}}\left(1-\lambda_{t}\right) d_{t}}{\frac{P_{t}^{H}}{P_{t}} y_{t}^{H}}
$$

Fiscal policy in the foreign country is modelled similarly.

\subsection{Exogenous variables and shocks}

We now specify the rest of the exogenous variables, $A_{t}, A_{t}^{*}, \lambda_{t}, \lambda_{t}^{*}$ and $\frac{S_{t+1}}{S_{t}}$. Starting with TFP in the two countries, $A_{t}$ and $A_{t}^{*}$, we assume stochastic $A R(1)$ processes of the form:

$$
\begin{aligned}
& \log \left(A_{t}\right)=\left(1-\rho^{a}\right) \log (A)+\rho^{a} \log \left(A_{t-1}\right)+\varepsilon_{t}^{\alpha} \\
& \log \left(A_{t}^{*}\right)=\left(1-\rho^{* a}\right) \log \left(A^{*}\right)+\rho^{* a} \log \left(A_{t-1}^{*}\right)+\varepsilon_{t}^{* \alpha}
\end{aligned}
$$

where $0<\rho^{a}, \rho^{* a}<1$ are persistence parameters, variables without time subscript denote steady state values and $\varepsilon_{t}^{a} \sim N\left(0, \sigma_{a}^{2}\right), \varepsilon_{t}^{* a} \sim N\left(0, \sigma_{a}^{* 2}\right)$.

The fiscal policy variables, $\left\{\lambda_{t}, \lambda_{t}^{*}\right\}_{t=0}^{\infty}$, are assumed to be constant and equal to their data average values in all $t$. Finally, as said, in a regime of a currency union, we set $S_{t} \equiv 1$ in all $t$.

In other words, we assume that stochasticity comes from shocks to TFP only (we report however that our main results do not depend on this).

\subsection{Equilibrium system in the status quo economy}

We now combine the above to get the equilibrium system for any feasible policy. This is defined to be a sequence of allocations, prices and policies such that: (i) households maximize utility; (ii) a fraction $(1-\theta)$ of firms maximize profits by choosing an identical price $P_{t}^{\#}$, while a fraction $\theta$ just set prices at their previous period level; (iii) the international bank maximizes its profit (iv) all constraints, including the government budget constraint and the balance of payments, are satisfied; (v) all markets clear, including the international asset market; (vi) policy instruments are set by feedback rules.

This equilibrium system is presented in detail in Appendix 5. It consists of 61 equations in 61 variables, $\left\{V_{t}, y_{t}^{H}, c_{t}, c_{t}^{H}, c_{t}^{F}, n_{t}, x_{t}, k_{t}, f_{t}^{h}, m_{t}, T T_{t}, \Pi_{t}, \Pi_{t}^{H}, \Theta_{t}, \Delta_{t}, w_{t}, m c_{t}, \widetilde{\omega}_{t}, r_{t}^{k}, d_{t}, \Pi_{t}^{*}\right.$, $z_{t}^{1}, z_{t}^{2}, \pi_{t}, q_{t}, Q_{t}, l_{t}, V_{t}^{*}, y_{t}^{* H}, c_{t}^{*}, c_{t}^{H *}, c_{t}^{F *}, n_{t}^{*}, x_{t}^{*}, k_{t}^{*}, f_{t}^{h *}, m_{t}^{*}, \Pi_{t}^{H *}, \Theta_{t}^{*}, \Delta_{t}^{*}, w_{t}^{*}, m c_{t}^{*}, \widetilde{\omega}^{*}$, $\left.r_{t}^{* k}, d_{t}^{*}, z_{t}^{1 *}, z_{t}^{2 *}, Q_{t}^{*}, l_{t}^{*}, R_{t}, s_{t}^{g}, s_{t}^{l}, \tau_{t}^{c}, \tau_{t}^{k}, \tau_{t}^{n}, R_{t}^{*}, s_{t}^{g *}, s_{t}^{l *}, \tau_{t}^{c *}, \tau_{t}^{k *}, \tau_{t}^{n *}\right\}_{t=0}^{\infty}$. This is for given the exogenous variables, $\left\{A_{t}, A_{t}^{*}, \lambda_{t}, \lambda_{t}^{*}, S_{t}\right\}_{t=0}^{\infty}$, as defined in subsection 2.7 , the values of 
feedback policy coefficients as defined in subsection 2.6 (these values will be chosen optimally) and initial conditions for the state variables.

\subsection{Plan of the rest of the paper}

Our main goal in this paper is to evaluate the implications of various hypothetical and actual debt consolidation policies. We will therefore work as follows. First, using commonly employed parameter values and fiscal data from Germany and Italy, we will numerically solve the above model. This is in the next section (section 3). In turn, to the extent that the steady state solution of this model is empirically relevant (meaning that it can mimic the data averages over the euro area period of study), we will use this solution - defined as the status quo - as a point of departure in order to evaluate the implications of various debt consolidation policies. A description of policy experiments and a discussion of the solution methodology are in section 4, while numerical solutions are in sections 5,6 and 7 .

\section{Data, parameteres and solution of the status quo model}

This section solves numerically the above model by using annual data from Germany and Italy over the period 2001-2011. We start in 2001 because this year marked the introduction of the euro and we stop at 2011 because the year 2012 marked the beginning of fiscal consolidation efforts in Italy (see e.g. EMU-Public Finances, 2015, by the European Commission).

\subsection{Parameter values and fiscal policy variables}

The baseline parameter values and the data averages of fiscal policy variables, used in the numerical solution of the above model, are listed in Tables $1 \mathrm{a}$ and $1 \mathrm{~b}$ respectively. The time unit is meant to be a year. The two countries can differ only in their discount factors (see $\beta$ and $\beta^{*}$ in Table 1a) and fiscal policy variables (see the fiscal policy instruments in Table 1b). In all other respects, the two countries are assumed to be symmetric. Interestingly, as said above, these two differences will prove to be enough to give a steady state solution close to the data averages during 2001-2011.

Regarding parameter values, the model's key parameters are the discount factors in the two countries, $\beta$ and $\beta^{*}$, and the cost coefficient driving the wedge between the borrowing and the lending interest rate, $\psi$. The values of these parameters are calibrated to match the real interest rates and the net foreign asset position of the two countries in the time period under consideration. In particular, the values of $\beta$ and $\beta^{*}$ follow from the Euler equations in the two 
countries which, at the steady state, are reduced to:

$$
\begin{gathered}
\beta Q / \Pi=1 \\
\beta^{*} Q^{*} / \Pi^{*}=1
\end{gathered}
$$

where $Q / \Pi$ and $Q^{*} / \Pi^{*}$ are gross real interest rates in the two countries (see Appendix 5 for detailed definitions of all variables). Since $Q / \Pi<Q^{*} / \Pi^{*}$ in the data over the period under consideration, it follows $\beta=0.9833>\beta^{*}=0.9780$. That is, the Germans are more patient than the Italians.

In turn, the optimality condition of the bank, (16), written at the steady state, is:

$$
Q^{*}=\frac{Q}{1-\frac{P^{H}}{P} \psi\left(f^{* g}-f^{* h}\right)}
$$

from which the value of the parameter $\psi$ is calibrated.

All other parameter values, as listed in Table 1a, are the same across countries and are set at values commonly used in related studies. We start by setting the value of the political weight, $\eta$, at the "neutral" value of 0.5 (a sensitivity analysis regarding this parameter is in section 6 below). We report that our main results are robust to changes in these values (see section 6 below for further details). Thus, although our numerical simulations below are not meant to provide a rigorous quantitative study, they illustrate the qualitative dynamic features of the model in a realistic way. 
Table 1a: Baseline parameter values

\begin{tabular}{|c|c|c|c|}
\hline Parameter & Home & Foreign & Description \\
\hline$a, a^{*}$ & 0.3 & 0.3 & share of physical capital in production \\
\hline$\nu, \nu^{*}$ & 0.5 & 0.5 & home goods bias in consumption \\
\hline$\mu, \mu^{*}$ & 3.42 & 3.42 & money demand elasticity in utility \\
\hline$\delta, \delta^{*}$ & 0.1 & 0.1 & capital depreciation rate \\
\hline$\phi, \phi^{*}$ & 6 & 6 & price elasticity of demand \\
\hline$\varphi, \varphi^{*}$ & 1 & 1 & inverse of Frisch labour elasticity \\
\hline$\sigma, \sigma^{*}$ & 1 & 1 & inverse of elasticity of substitution in consumptio \\
\hline$\theta, \theta^{*}$ & 0.2 & 0.2 & price rigidity parameter \\
\hline$\chi_{m}, \chi_{m}^{*}$ & 0.001 & 0.001 & preference parameter related to money) balances \\
\hline$\chi_{n}, \chi_{n}^{*}$ & 5 & 5 & preference parameter related to work effort \\
\hline$\chi_{g}, \chi_{g}^{*}$ & 0.1 & 0.1 & preference parameter related to public spending \\
\hline$\xi, \xi^{*}$ & 0.01 & 0.01 & adjustment cost parameter of physical capital \\
\hline$\zeta, \zeta^{*}$ & 1 & 1 & public spending elasticity in utility \\
\hline$\eta$ & 0.5 & 0.5 & political weight in union-wide policies \\
\hline$\beta, \beta^{*}$ & 0.9833 & 0.9780 & time discount factor \\
\hline$\psi$ & 0.072 & - & cost parameter in international borrowing \\
\hline$\sigma_{\alpha}, \sigma_{\alpha^{*}}$ & 0.01 & 0.01 & tandard deviation of TFP \\
\hline$\rho^{\alpha}, \rho^{\alpha^{*}}$ & 0.92 & & persistence of TFP \\
\hline
\end{tabular}

Regarding fiscal policy variables in the two countries as defined in subsection 2.6.2 above, the steady state government spending-to-GDP ratios and tax rates are set to their average values in the data in Germany and Italy over 2001-2011 (see Table 1b). In particular, as a measure of $s^{g}$ and $s^{* g}$, which serve as arguments in households' utility function and hence are typically thought of as public consumption, we use data on total government spending on goods and services, ${ }^{20}$ while, we use data on transfer payments as a measure of $s^{l}$ and $s^{* l}$, which enter households' budget constraints. As tax rates, $\tau^{c}, \tau^{* c}, \tau^{k}, \tau^{* k}, \tau^{n}$ and $\tau^{* n}$, we use the associated effective tax rates (or what Eurostat calls implicit tax rates).

\footnotetext{
${ }^{20}$ We could use data on government consumption spending only to measure $s^{g}$ and $s^{* g}$; this is not important to our results. In subsection 6.4 below, we will augment the model by giving different roles to government consumption and government investment spending.
} 
Table 1b: Fiscal policy variables (2001-2011 data averages)

\begin{tabular}{llll}
\hline \hline Variable & Home & Foreign & Description \\
\hline \hline$\tau^{c}, \tau^{* c}$ & 0.1934 & 0.1756 & consumption tax rate \\
\hline$\tau^{k}, \tau^{* k}$ & 0.2041 & 0.3118 & capital income tax rate \\
\hline$\tau^{n}, \tau^{* n}$ & 0.3833 & 0.421 & labour income tax rate \\
\hline$s^{g}, s^{* g}$ & 0.2131 & 0.2423 & government purchases of goods/services as share of GDP \\
\hline$s^{l}, s^{* l}$ & -0.2039 & -0.2163 & government transfers payments as share of GDP \\
\hline$\lambda, \lambda^{*}$ & 0.52 & 0.61 & share of public debt held by domestic agents \\
\hline \multicolumn{4}{c}{ Note: The data source is Eurostat. }
\end{tabular}

\subsection{Steady state solution in the status quo model}

The equilibrium system was defined in subsection 2.8 and the assoeiated steady state follows simply if we assume that variables do not change over time (details are at the end of Appendix 5). Table 2 presents the steady state solution when parameters and policy instruments are set at the values in Tables 1a-b. It is worth pointing out that, since policy instruments react to deviations of macroeconomic indicators from their steady state values, feedback policy coefficients do not play any role in steady state, solutions. In this steady state solution, the residually determined public financing variable is public debt in both countries. Table 2 also presents some key ratios in the German and Italian data and, as can be seen, the respective ratios implied by the steady state solytion are close to their values in the data. In particular, the solution can mimic rather well the data averages of public debt-to-GDP ratios and foreign debt-to-GDP ratios in the two countries over 2001-2011.

This steady state solution will serve as a point of departure. That is, in what follows, we will depart from this solution to study the implications of various policy experiments. We report (and this is confirmed below) that an exogenous reduction in public debt stimulates output and improves welfare in both countries; this can provide a first justification for our fiscal consolidation experiments. 
Table 2: Status quo steady state solution

\begin{tabular}{|c|c|c|c|c|c|}
\hline Variables & Description & Home & Data & Foreign & Data \\
\hline$u, u^{*}$ & utility & 0.0376 & - & 0.0315 & - \\
\hline$y^{H}, y^{H *}$ & output & 0.3912 & - & 0.3543 & - \\
\hline$c, c^{*}$ & consumption & 0.2314 & - & 0.2278 & - \\
\hline$n, n^{*}$ & hours worked & 0.3116 & - & 0.3063 & - \\
\hline$k, k^{*}$ & capital & 0.6655 & - & 0.4976 & 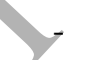 \\
\hline$w, w^{*}$ & real wage rate & 0.6976 & - & 0.7085 & - \\
\hline$r^{k}, r^{k *}$ & real return to capital & 0.1470 & & 0.1780 & - \\
\hline$Q^{*}-Q$ & interest rate premium & - & & 0.0055 & 0.0055 \\
\hline$\frac{c}{y^{H} T T^{1-\nu}}, \frac{c^{*}}{y^{H *} T T_{t}^{\nu^{*}-1}}$ & $\begin{array}{l}\text { consumption as } \\
\text { share of GDP }\end{array}$ & & & 0.6752 & - \\
\hline$\frac{k}{y^{H}}, \frac{k^{*}}{y^{H *}}$ & capital as share of $G$ & 1.7009 & - & 1.4045 & - \\
\hline$\frac{d}{T T^{\nu-1} y^{H}}, \frac{d^{*}}{T T^{1-\nu^{*}} y^{* H}}$ & $\begin{array}{l}\text { total public debt } \\
\text { as share of GDP }\end{array}$ & & 0.6861 & 1.0871 & 1.08 \\
\hline$\frac{\left(\frac{(1-\lambda) d}{\left.T T^{\nu-1}-T T_{t}^{\nu^{*}} f^{h}\right)}\right.}{y^{H}}, \frac{\frac{\left(1-\lambda^{*}\right) d^{*}}{T T^{1-\nu-\nu^{*}}-f^{* h}}}{T T_{t}^{\nu} y^{* H}}$ & $\begin{array}{l}\text { total foreign debt } \\
\text { as share of GDP* }\end{array}$ & -0.2109 & -0.2501 & 0.2114 & 0.2109 \\
\hline
\end{tabular}

Notes: Parameters and policy variables as in Tables 1a-b.

\subsection{Transition dynamics and determinacy}

It is well recognized that the interaction between fiscal and monetary policy, and, in particular, the magnitude of the associated feedback policy coefficients in the policy rules, are crucial to determinacy (see e.g. Leith and Wren-Lewis, 2008). This is also the case in our paper. In particular, when we assume that fiscal policy instruments remain constant at their data average values in Table $1 \mathrm{~b}$ without any reaction to public debt and there is no interest rate policy reaction to inflation, the model, when approximated around the status quo steady state solution, exhibits dynamic instability meaning that there is no convergence to the steady state solution reported above. In other words, policy can guarantee a unique transition path, only when at least one fiscal policy instrument in each country $\left(s_{t}^{g}, s_{t}^{l}, \tau_{t}^{c}, \tau_{t}^{k}, \tau_{t}^{n}\right.$ and $s_{t}^{g *}, s_{t}^{l *}, \tau_{t}^{c *}$, $\left.\tau_{t}^{k *}, \tau_{t}^{n *}\right)$ reacts to public liabilities. The magnitude of these reactions lies within a range of critical minimum and maximum non-zero values. These critical values differ across different fiscal policy instruments. And all this holds when monetary policy satisfies the so-called Taylor principle, meaning that the single nominal interest rate reacts aggressively to inflation. This will also be confirmed by the results for optimized policy rules below. By contrast, fiscal and 
monetary policy reaction to the output gap has not been found to be crucial for determinacy. Further details regarding ranges of feedback policy coefficients guaranteeing local determinacy are available upon request. In sum, determinacy requires stabilizing fiscal reaction to inherited public debt and monetary reaction to inflation; this holds in all cases studied below.

\section{Description of policy experiments and solution strategy}

This section defines our policy experiments and explains the solution strategy. Numerical results will then be presented in sections 5,6 and 7. In our main thought experiment, we will depart from the status quo steady state solution (in other words, the initial values of the predetermined variables will be those found by the steady state solution in Table 2) and compute the equilibrium transition path as we travel towards a new reformed steady state (the key policy reforms are defined in subsection 4.1). Additional policy scenarios, used mainly for comparison, are defined in subsection 4.2. The values of feedback coefficients of monetary and fiscal policy instruments used in the transition from the status quo steady state to a new steady state will be chosen optimally (this is explained in subsection 4.3). Transition dynamics will be driven by extrinsic TFP shocks in both countries and by policy reforms in the high-debt country, except otherwise said. ${ }^{21}$

\subsection{National fiscal policies and reforms in the main policy experiment}

In our main thought experiment, motivated by the facts discussed in the opening paragraph of the Introduction, we focus on two different types of fiscal action, one for each country.

\subsubsection{Fiscal policy scenario in the domestic country with solid public finances}

The domestic country (defined to be Germany) is assumed to follow a neutral fiscal policy. In other words, we assume that the domestic country does not take any active fiscal consolidation measures but it just stabilizes the public debt-to-GDP ratio at its average level, where the latter, namely the public debt target in the country's feedback policy rules, is defined to be the steady state value of the public debt-to-GDP ratio as determined residually by the withinperiod government budget constraint. That is, in this country, we depart from, and end up at, the same tax-spending position, which is as in the average data in Germany (however, as explained below, the new steady state solution will differ from the status quo solution because

\footnotetext{
${ }^{21}$ We have also experimented with asymmetric shocks (for instance, shocks in one country only), or no shocks at all, and the main results do not change. Thus, our main results will be driven by policy (debt consolidation) reforms in the high-debt country.
} 
of fiscal consolidation in the foreign country). This is usually called "debt accommodation" in the related literature (see Wren-Lewis, 2010).

Specifically, fiscal policy in the domestic country is defined as follows: (a) All exogenously set tax-spending national policy instruments remain at the same value (data average value) in both the status quo steady state and the new steady state. (b) Along the transition to the new steady state, all tax-spending national policy instruments are allowed to react to deviations from policy targets in a optimized way (see subsection 4.3 below), where the policy targets are the endogenously determined new steady state values. (c) All the time, namely, both during the transition and in the steady state, the public debt serves as the residually determined public financing instrument closing the within-period government budget constraint.

To understand this scenario, imagine that the economy is hit by a temporary adverse shock to TFP as modelled in equations (24)-(25). This, as the impulse response functions can show, leads at impact to a contraction in output and a rise in the public debt-to-output ratio. Then, the policy questions are which tax-spending policy instrument to use over time, and how strong the reaction of those policy instruments to deviations from targets should be, in order to minimize cyclical volatility.

\subsubsection{Fiscal policy scenario in the foreign country with weak public finances}

The role of fiscal policy in the foreign country (defined to be Italy) is twofold: to stabilize the economy against the same shocks as above and, at the same time, to improve resource allocation by bringing down its public debt-to-GDP ratio over time. This is typically called "debt consolidation" in the related literature (see Wren-Lewis, 2010).

Specifically, in our main thought experiment, fiscal policy in the foreign country (i.e. Italy) is defined as follows: (a) In the new reformed steady state, the country's output share of public debt is exogenously set at the target value of $90 \%$ (recall that it was around $110 \%$ of GDP in the status quo steady state solution in subsection 3.2). ${ }^{22}$ Actually, we will study two subcases here: one in which sovereign premia may remain in this reformed steady state, as determined endogenously by equation (28), similarly to the status quo model; and one in which, not only public debt is reduced to $90 \%$, but also sovereign premia are eliminated in the new reformed steady state, meaning that now we also impose $Q=Q^{*}$ in equation (28). Obviously, the second case, the one without premia, is more ambitious. Modelling details are provided in

\footnotetext{
${ }^{22}$ We choose the target value of $90 \%$ simply because this is consistent with evidence provided by e.g. Reinhart and Rogoff (2010) and Checherita-Westphal and Rother (2012) that, in most advanced economies, the adverse effects of public debt arise when it is around 90-100\% of GDP. We report that our main results are not sensitive to this value. For instance, we have experimented with a debt target value of $70 \%$ or $60 \%$ and the results are qualitatively the same.
} 
the next subsection right below. (b) In this new reformed steady state, since the country's public debt has been reduced and thus fiscal space has been created relative to the status quo, fiscal spending can be increased and/or tax rates can be cut, depending on which fiscal policy instrument is assumed to follow residually to close the government budget constraint. This is known as the long-term fiscal gain from debt consolidation. Here, we will report results only for the case in which the fiscal space created by debt reduction is used to reduce the capital tax rate; ${ }^{23}$ this has been found to be the most efficient way of making use of the fiscal space created and is consistent with the Chamley-Judd well known normative result that the limiting capital tax rate should be zero. To put it differently, our solutions confirm, as in most of the literature, that the impact of debt consolidation depends on expectations about how the fiscal space will be used in the future and it is expectations of a cut in the capital tax rate that appear to have a long-lasting beneficial effect on investment and output. (c) Along the transition to the new reformed steady state, the national tax-spending policy instruments are allowed to react to deviations from policy targets in a optimized way (see subsection 4.3 below). Given that the new debt policy target is set at a value lower than in the status quo (i.e. we depart from $110 \%$ but the policy target in Italy's feedback fiscal policy rules is 90\%), this requires lower public spending, and/or higher tax rates, during the early phase of the transition period. This is known as the short-term fiscal pain of debt consolidation. ${ }^{24}$

\subsubsection{Equilibrium system in the reformed economy: modelling issues}

The equilibrium system and modelling details are in Appendix 6. As explained in that Appendix, the case in which premia are allowed in the new steady state is similar to the status quo regime in terms of modelling except that in the reformed economy the debt policy target is $90 \%$. On the other hand, the case in which we also set $Q=Q^{*}$ in the new steady state is more demanding. In particular, elimination of premia, or equivalently equalization of interest rates, $Q=Q^{*}$, means that the international capital market becomes perfect so that agents can borrow and lend at the same interest rate internationally. For this to happen,

\footnotetext{
${ }^{23}$ Results with other instruments are available upon request.

${ }^{24}$ It is well recognized that debt consolidation implies a tradeoff between short-term pain and medium-term gain; see e.g. Coenen et al. (2008) and Clinton et al. (2011). During the early phase of the transition, debt consolidation comes at the cost of higher taxes and/or lower public spending. In the medium- and long-run, a reduction in the debt burden allows, other things equal, a cut in tax rates, and/or a rise in public spending. Thus, one has to value the early costs of stabilization vis-a-vis the medium- and long-term benefits from the fiscal space created. It is also recognized that the implications of fiscal reforms, like debt consolidation, depend heavily on the public financing policy instrument used, namely, which policy instrument adjusts endogenously to accommodate the exogenous changes in fiscal policy; see e.g. Leeper et al. (2009). In the case of debt consolidation, such implications are expected to depend both on which policy instrument bears the cost of adjustment in the early period of adjustment and on which policy instrument is expected to reap the benefit, once consolidation has been achieved.
} 
however, and as discussed in subsection 2.1 above, the discount factors need also to be equalized across countries. Namely, without financial frictions, the agents should become equally patient eventually. Thus, $\beta^{*}$ needs to become equal to $\beta$ at the new steady state (although this is not required along the transition). To model this, in a relatively neutral way, we assume that the discount factor in Italy, $\beta^{*}$, follows over time the $\operatorname{AR}(1)$ process:

$$
\beta_{t}^{*}=\rho^{\beta^{*}} \beta_{t-1}^{*}+\left(1-\rho^{\beta^{*}}\right) \beta
$$

where the initial value is the value used in the status quo solution (see Table 1a) while the value in the new reformed steady state is set as in Germany (see Table 1a again). ${ }^{25}$ It is important to stress that, in case premia are eliminated in the new steady state so that $\beta^{*}=\beta$, we will choose the autoregressive parameter, $\rho^{\beta^{*}}$, optimally, alongside all other feedback policy parameters, so as not to force results in one direction or another. In general, $\rho^{\beta^{*}}$ can be thought of as capturing some form of cultural change relative to the status quo, as discussed by e.g. Becker and Mulligan (1997) and Doepke and Zilibotti (2008).

\subsection{Other fiscal policy scenarios studied}

In addition to the above defined main experiment, and for reasons of comparison, we will also study two other policy scenarios:

First, the case in which, other things equal, Italy does not take any active fiscal consolidation measures. That is, acting like Germany, it just departs from, and returns to, the same tax-spending position (which is the status quo steady state). This case of non-consolidation typically serves as a benchmark to evaluate the possible merits of fiscal consolidation. Note that again feedback policy coefficients will be chosen optimally.

Second, we study an exogenous case in which fiscal variables in Italy and Germany mimic their values in the actual data between 2012 and 2015 (see e.g. EMU-Public Finances, 2015, p. 15, by the European Commission). In practice, any fiscal consolidation in Italy, during that period, was achieved by an increase in total tax revenues as share of GDP by around 2 percentage points, while total public spending to GDP share remained more or less unchanged. ${ }^{26}$ At the same time, in Germany, fiscal policy was kept neutral meaning no changes. To implement this scenario, in our simulations, we appropriately adjust the feedback policy coefficients on

\footnotetext{
${ }^{25}$ The exact numerical value we use for steady state $\beta^{*}$ is not important to our main results. But we do need $\beta^{*}=\beta$ to get a well-defined steady state solution to the extent that we do not have premia in this new steady state.

${ }^{26}$ In Italy, tax revenues as share of GDP were $45.6 \%$ in 2011 and this increased to $47.8 \%$ in 2012 and to $48.2 \%$ in 2015 .
} 
public debt in the fiscal policy rules in the two countries, so as the generated values of fiscal variables (total tax revenues and public spending as shares of GDP) are close to those in the data during the first four years (namely, 2012-5) after departure from the status quo solution in Table 2. Thus, under this scenario, policy reaction is not chosen optimally; instead, the fiscal feedback policy coefficients are adjusted so as to mimic the actual policy in the period 2012-5. The monetary authority's reaction to weighted inflation in the two countries, $\phi_{\pi}$, is also set exogenously at, say, 2 (we report that results for this exogenous case are not sensitive to this value to the extent that $\phi_{\pi}>1$, which is the so-called Taylor principle). Further details and results of this ad hoc scenario are in subsection 5.2.

\subsection{Optimized policy rules, solution methodology and welfare comparison}

The single monetary authority can choose the feedback policy coefficients on inflation and output in the two countries in its single rule for the nominal interest rate (see equation 17 above), while each national fiscal authority can choøse the feedback policy coefficients on national public debt and output in its rules for public spending and tax rates (see equations 18-22 above for each country).

We start with defining the welfare objective of policymakers.

\subsubsection{Welfare objective of policymakers}

There can be many institutional scenarios regarding the degree of cooperation between the single monetary authority and the two national fiscal authorities, ranging from full cooperation to zero cooperation. In this paper, we mainly focus on a scenario of full cooperation at policy level (however in section 7 below we also study Nash equilibria). Apart from computational simplicity, we focus on this scenario because, these days, most macroeconomic measures, and especially fiscal consolidation measures, are taken under the advice, or coordination, of the European Union and the ECB.

In particular, we assume that all monetary and fiscal feedback policy coefficients are chosen jointly and simultaneously so as to maximize a weighted average of households' expected discounted lifetime utility in the two countries defined as:

$$
W_{t}=\eta V_{t}+(1-\eta) V_{t}^{*}
$$

where $0 \leq \eta \leq 1$ is the political weight of the domestic country vis-a-vis the foreign country, i.e. the higher is $\eta$, the higher the say of Germany in policy-making (see also equation (17) above), and $V_{t}$ and $V_{t}^{*}$ are as defined in equation (7) above for each country. As said, we start 
with the neutral case $\eta=0.5$, but we will experiment with various values of $\eta$ in section 6 .

\subsubsection{Computation of optimized feedback policy rules}

Except for the ad hoc scenario discussed in subsection 4.2, we compute the welfare-maximizing values of feedback policy coefficients in the policy rules (this is what Schmitt-Grohé and Uribe, 2005 and 2007, call optimized policy rules). The welfare criterion is to maximize the conditional welfare of the two households as defined in (30) above, where conditionality refers to the initial conditions chosen; the latter are given by the status quo solution in Table 2 above, which is close to the data averages over 2001-2011. To this end, following Schmitt-Grohé and Uribe (2004), we take a second-order approximation to both the equilibrium conditions and the welfare criterion. ${ }^{27}$ Specifically, we first compute a second-order approximation of both the conditional welfare and the decentralized equilbrium around the associated steady state, as functions of feedback policy coefficients using Dynare and, in turn, we use a matlab function (such as fminsearch.m) to compute the values of the feedback policy coefficients that maximize this approximate system (Dynare and matlab routines are available upon request). In this exercise, if necessary, the feedback policy coefficients are restricted to be within some prespecified ranges so as to deliver determinacy. All this is with, and without, debt consolidation, where the case without consolidation will serve as a benchmark,

Regarding the zero lower bound (ZLB) for the nominal interest rate, we work as in e.g. Schmitt-Grohé and Uribe (2007), which means that, when necessary, we simply place additional restrictions on the range of feedback policy coefficients in the Taylor rule, $\phi_{\pi}$ and $\phi_{y}$ in equation (17), so that the gross nominal interest rates do not violate the ZLB, in other words, $R_{t}, Q_{t}, R_{t}^{*}, Q_{t}^{*}>1$. We report that only in the case of flexible exchange rates, studied in subsection 72 below, such additional restrictions will be required (details for this case are postponed until then). In all other cases, at least under the parameterizations used, the ZLB is not violated, the main reason seems to be that our initial conditions feature relatively high debt and relatively high nominal interest rates, which are, in turn, gradually reduced by optimally chosen debt consolidation policies in the transition. ${ }^{28}$

\footnotetext{
${ }^{27}$ We focus on second-order accurate approximate solutions because, when the model is stochastic, first-order approximations can give spurious results when used to compare the welfare under alternative policies (see e.g. the review in Galí, 2008, pp. 110-111). We report that we have also experimented with non-approximate solutions in the deterministic case and the main results do not change.

${ }^{28}$ By contrast, the initial conditions in Erceg and Lindé (2013) are consistent with a deep output contraction, produced by (among other things) a big adverse TFP shock, which, in combination with the assumed feedback policy coefficients, leads to sharp policy interest rate cuts in order to keep output near potential and inflation near target. In our paper, both in the baseline parameterization and in the sensitivity tests in sections 6 and 7 , this possibility does not arise, except in the flexible exchange rate regime discussed below. For a methodology paper on the ZLB, see e.g. Fernández-Villaverde et al. (2015).
} 


\subsubsection{Welfare comparison of alternative policy regimes}

Comparisons of alternative policy regimes will be in terms of welfare, namely, expected lifetime discounted utility. Welfare differences will then be expressed in terms of consumption equivalents. The case without debt consolidation will serve as the benchmark in these welfare comparisons (except otherwise stated).

\section{Main results}

We work as explained in the previous section. In other words, we depart from the status quo steady state solution in Table 2 and travel towards a new reformed steady state. In this new steady state, in Italy, under debt consolidation, public debt has been cut at $90 \%$ and the resulting fiscal space is used to finance a decrease of the capital tax rate, while, by contrast, in Germany, tax-spending policy instruments remain as in the status quo steady state. Along the transition to this new steady state, the debt policy target in Italy's feedback fiscal policy rules is set at $90 \%$ and, except in the case of the ad hoc policy scenario, all feedback policy coefficients are optimally chosen.

Ideally, we would like to study the case in which all feedback policy coefficients are chosen optimally and at the same time. Namely, when the single monetary authority reacts to both inflation and output (see the rule in subsection 2.6.1) and each national fiscal authority reacts to both public debt and output (see the rules in subsection 2.6.2). However, when all feedback policy coefficients are simultaneously chosen optimally, the optimization problem becomes too heavy to be computed (since 18 feedbacks have to be chosen). Therefore, we will start with the case in which all national fiscal policy instruments are allowed to react to the public debt gap only and the single monetary policy instrument is allowed to react to the weighted sum of national inflation rates only, while (fiscal and monetary) policy reaction to output gaps will be exogenously added in section 6 below.

\subsection{Debt/consolidation with optimized policy rules}

In the reformed economy with debt consolidation in Italy, the debt policy target is 0.9. Thus, in the steady state of this economy, we set the Italian public debt to GDP ratio, $\frac{d^{*}}{T T^{1-\nu^{*}} y^{* H}}$, at this target value, 0.9 , and allow the capital tax rate, $\tau^{k *}$, to follow residually. As said in subsection 4.1, we distinguish two cases of this scenario: one in which sovereign premia are allowed in the reformed steady state (the results are in subsection 5.1.1) and a more ambitious one where such premia are eliminated (the results are in subsection 5.1.2). 


\subsubsection{Allowing for sovereign premia in the steady state of the reformed economy}

In this case, the endogenously determined steady state capital tax rate, $\tau^{k *}$, falls from 0.31 (in the data) to $0.292 .{ }^{29}$ Table 3 reports the values of the optimized feedback policy coefficients (see notes of Table 3) and hence the associated policy mix, as well as the resulting level of expected discounted lifetime utility (see the last column in Table 3). In addition, we report results over shorter time horizons (see the first three columns). ${ }^{30}$ This is in both countries. Numbers in parentheses report welfare levels in the benchmark case without debt consolidation in Italy, other things equal (this is the first scenario discussed in subsection 4.2). Welfare gains/losses of debt consolidation vis-a-vis no debt consolidation are in terms of percentage consumption equivalents, where a positive number means a gain vis-a-vis the case without debt consolidation and vice versa for a negative number.

Table 3: Welfare over different time horizons with, and without, debt consolidation in Italy (with premia in the reformed steady state)

\begin{tabular}{ccccc}
\hline \hline & 2 periods & 4 periods & 20 periods & lifetime \\
\hline \hline \multirow{2}{*}{ Home (Germany) } & $\begin{array}{c}0.1304 \\
(0.0811)\end{array}$ & $\begin{array}{c}0.2373 \\
(0.1589)\end{array}$ & $\begin{array}{c}0.7681 \\
(0.6802)\end{array}$ & $\begin{array}{c}2.4843 \\
(2.3889)\end{array}$ \\
\hline welfare gain/loss & 0.0169 & 0.0163 & 0.0049 & 0.0016 \\
\hline \multirow{2}{*}{ Foreign (Italy) } & 0.0418 & 0.126 & 0.6221 & 1.5846 \\
& $(0.068)$ & $(0.1339)$ & $(0.5732)$ & $(1.5340)$ \\
\hline \multirow{2}{*}{ welfare gain/loss } & -0.0089 & -0.0016 & 0.0029 & 0.0011 \\
\hline
\end{tabular}

Notes: (i) Optimized policy coefficients $\phi_{\pi}=1.1, \gamma_{l}^{g}=0.1188, \gamma_{l}^{c}=0.244, \gamma_{l}^{* g}=0.587$, $\gamma_{l}^{l}=\gamma_{l}^{* l}=\gamma_{l}^{* c}=\gamma_{l}^{k}=\gamma_{l}^{* k}=\gamma_{l}^{n}=\gamma_{l}^{* n}=0$.(ii) We set $\eta \equiv 0.5$. (iii) Results without debt consolidation in parentheses. (iv) Welfare gains/losses in terms of consumption equivalents.

In terms of policy reaction, the values of the optimized feedback policy coefficients, as reported in the notes of Table 3, imply that the interest rate policy instrument should react aggressively to weighted inflation, $\phi_{\pi}=1.1>1$, which is according to the Taylor principle, while national fiscal reactions to public debt should be achieved by government consumption spending and consumption taxes in Germany and by government consumption spending only in Italy. Obviously, government consumption spending reaction to public debt should be stronger

\footnotetext{
${ }^{29}$ Modelling details and the full steady state solution are in Appendix 6 .

${ }^{30}$ The welfare criterion for the choice of feedback policy coefficients is the maximization of expected discounted lifetime utilities, as defined in equation (30) above. Thus, when we report welfare results for shorter time horizons, we use these lifetime optimal feedbacks to obtain the discounted utility of different time periods.
} 
in Italy (the debt consolidating country) than in Germany (the debt accomodating country); that is, $0.1188=\gamma_{l}^{g}<\gamma_{l}^{* g}=0.587$. Notice that both countries should not use any income taxes for debt accomodation (in Germany) or debt consolidation (in Italy); in other words, the optimal values of the associated feedback policy coefficients in the rules for the capital and labor income tax rates are all zero in both countries, $\gamma_{l}^{k}=\gamma_{l}^{* k}=\gamma_{l}^{n}=\gamma_{l}^{* n}=0$. Intuitively, since Italy goes for debt consolidation, which requires relatively big cuts in public spending and/or big tax rises, it is better to avoid the use of fiscal instruments that are particularly distorting like tax rates. Germany, on the other hand, just stabilizes cyclical debt fluctuations, which does not require big changes in fiscal instruments, so this can also be achieved by the use of consumption taxes. But, in both countries, it is a bad idea to use income taxes, the most distorting fiscal instruments, to address public debt problems. Notice also that neither country finds it optimal to use transfer payments to stabilize its public debt. That is, the optimized values of both $\gamma_{l}^{l}$ and $\gamma_{l}^{* l}$ in the policy rules for transfers are zero. This is because, although cuts in transfer payments are less damaging to output than cuts in government consumption spending in the short term, the intertemporal welfare cost of debt consolidation is smaller with cuts in government consumption spending than it would be in a package where consolidation would take place via cuts in transfers (see subsection 5.3 below for details).

In terms of welfare implications of debt consolidation, expressed as said above in terms of consumption equivalents, the respective signs in Table 3 imply that debt consolidation in Italy hurts Italians in the short term, but there are welfare gains in the medium and long term. By contrast, Germany gains all the time from debt consolidation in Italy. The mechanism behind these results is again discussed in subsection 5.3 below where we present response functions.

Notice, however, that the size of welfare effects from debt consolidation is relatively small in Table 3 and this applies especially to the case of Italy, which is the debt consolidating country (for instance, a value of 0.0011 for lifetime gain means that consumption rises by $0.11 \%$ in each period in Italy). Such a welfare effect looks to be "small" at least when it is compared to the welfare effects of e.g. Lucas (1990), who has found a lifetime welfare gain of around 0.027 or $2.7 \%$, when dapital taxes are eliminated in the USA. This is why we will also consider a more ambitious consolidation scenario right below.

Before we move on, Table 4 reports the implications for fiscal policy variables as a result of the above policy. Numbers are expressed as absolute changes relative to the corresponding values in the status quo steady state solution. In other words, a value of -0.0665 means that public consumption spending, as share of GDP, should fall by around 6.65 percentage points relative to its value in the status quo steady state solution. 
Table 4: Resulting government spending and tax revenues as shares of GDP

\begin{tabular}{ccccc}
\hline \hline & $\begin{array}{c}2 \text { periods } \\
\text { average }\end{array}$ & $\begin{array}{c}4 \text { periods } \\
\text { average }\end{array}$ & $\begin{array}{c}10 \text { periods } \\
\text { average }\end{array}$ & $\begin{array}{c}20 \text { periods } \\
\text { average }\end{array}$ \\
\hline \hline $\begin{array}{c}\text { Gov. consumption to GDP } \\
\text { in Germany }\end{array}$ & 0.0078 & 0.0059 & 0.0013 & 0 \\
\hline $\begin{array}{c}\text { Gov. consumption to GDP } \\
\quad \text { in Italy }\end{array}$ & -0.0665 & -0.0367 & -0.0172 & -0.0093 \\
\hline $\begin{array}{c}\text { Tax revenues to GDP } \\
\text { in Germany }\end{array}$ & -0.0092 & -0.0069 & -0.0014 & 0.0004 \\
\hline $\begin{array}{c}\text { Tax revenues to GDP } \\
\text { in Italy }\end{array}$ & 0.0014 & -0.0009 & -0.0025 & -0.0033 \\
\hline
\end{tabular}

Notes: (i) See notes in Table 3. (ii) Numbers are expressed as absolute changes relative to the corresponding values in the status quo steady state solution.

\subsubsection{Eliminating sovereign premia in the steady state of the reformed economy}

We now consider the more ambitious case in which, not only public debt is reduced to $90 \%$ but also sovereign premia are eliminated in the new reformed steady state. ${ }^{31}$ Results are reported in Tables 5 and 6 . The difference between Tables 5 and 6 on one hand, and Tables 3 and 4 on the other hand, is that in Tables 5 and 6 we also eliminate sovereign premia in the steady state of the reformed economy.

Comparison of Tables 5 and 3 reveals that the qualitative results do not change. On the other hand, welfare implications are bigger now. In particular, Germany's discounted utilities are all higher in Table 5 than in Table 3 . Also, the elimination of premia benefits Italy more in the long run (in Table 3, discounted lifetime utility was 1.5846 , while it is 2.765 in Table 5) but this comes at a higher cost in the short term (Italy's discounted utilities over the first 2, 4 and 20 periods are lower in Table 5 than in Table 3). Intuitively, a more ambitious policy leads to higher payoffs in the medium and long term but it also means bigger sacrifices in the short term. Subsection 5.3 below discusses the mechanism behind these welfare results.

\footnotetext{
${ }^{31}$ Modelling details and the full steady state solution are in Appendix 6 .
} 
Table 5: Welfare over different time horizons with, and without, debt consolidation in Italy (without premia in the reformed steady state)

\begin{tabular}{ccccc}
\hline \hline & 2 periods & 4 periods & 20 periods & lifetime \\
\hline \hline \multirow{2}{*}{ Domestic (Germany) } & 0.1424 & 0.2751 & 1.0543 & 2.8979 \\
& $(0.0811)$ & $(0.1589)$ & $(0.6802)$ & $(2.3889)$ \\
\hline welfare gain/loss & 0.0210 & 0.0243 & 0.0212 & 0.0085 \\
\hline \multirow{2}{*}{ Foreign (Italy) } & -0.0421 & -0.0099 & 0.4585 & 2.765 \\
& $(0.068)$ & $(0.1339)$ & $(0.5732)$ & $(1.534)$ \\
\hline welfare gain/loss & -0.0345 & -0.0296 & -0.0067 & 0.0208 \\
\hline Notes: (i) Optimized policy coefficients $\phi_{\pi}=1.103, \gamma_{l}^{g}=0.014, \gamma_{l}^{* q}=0.5619$,
\end{tabular}

$\gamma_{l}^{l}=\gamma_{l}^{* l}=\gamma_{l}^{c}=\gamma_{l}^{* c}=\gamma_{l}^{k}=\gamma_{l}^{* k}=\gamma_{l}^{n}=\gamma_{l}^{* n}=0$ and $\rho^{\beta^{*}}=0$. (ii) We set $\eta \equiv 0.5$. (iii) Results without debt consolidation in parentheses. (iv) Welfare gains/losses in terms of consumption equivalents.

Table 6: Resulting government spending and tax revenues as shares of GDP

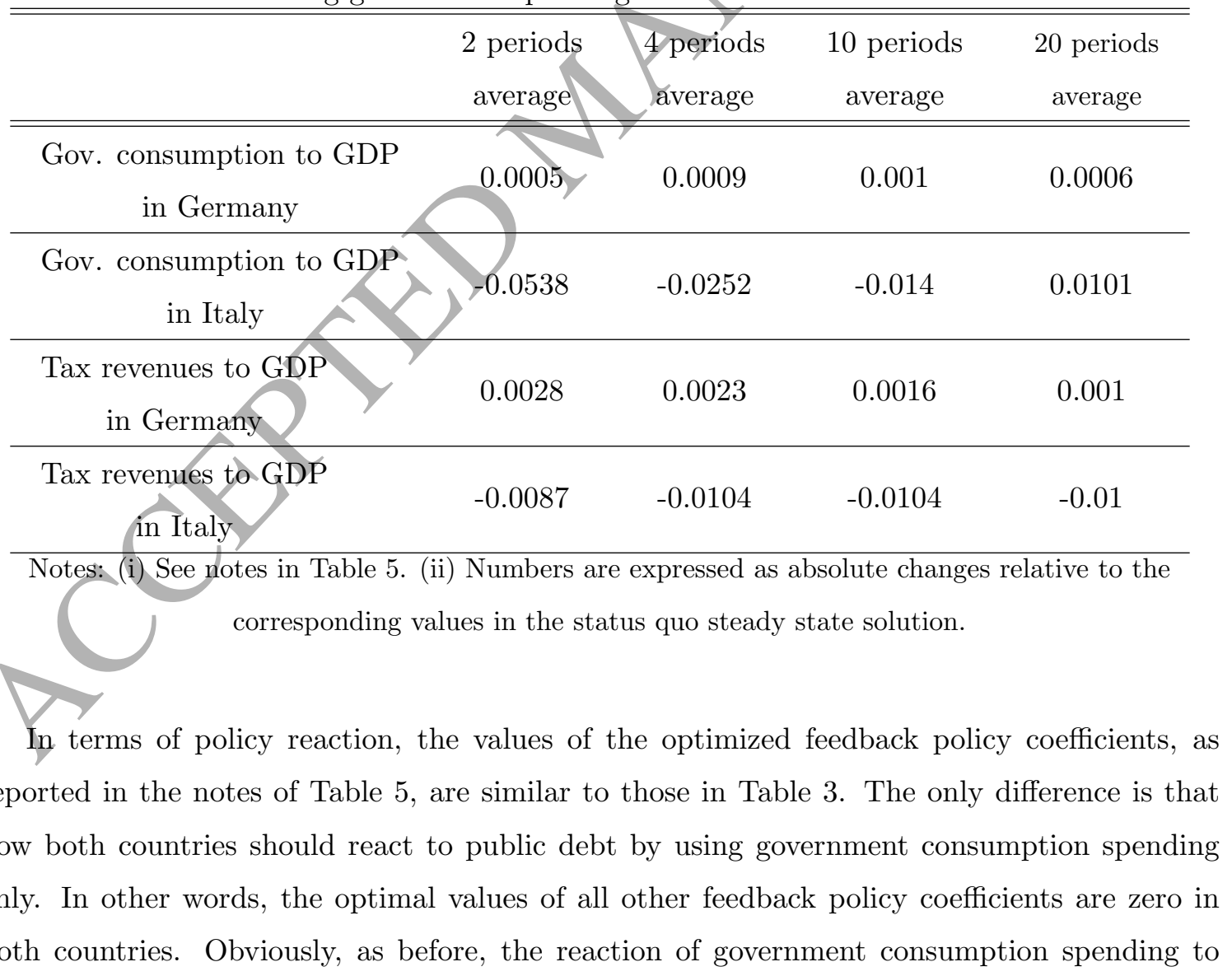


public debt should be stronger in Italy (the debt consolidating country) than in Germany (the debt accomodating country); that is, $0.014=\gamma_{l}^{g}<\gamma_{l}^{* g}=0.5619$ in Table 5.

Besides, it is important to notice, as reported in the notes of Table 5, that the optimally chosen value of the persistence parameter in the $\mathrm{AR}(1)$ process for Italy's discount factor, $\rho^{\beta^{*}}$, is practically zero meaning that it would be optimal for Italians to adopt the patience of Germans and this should be done as soon as possible. Although we realize that cultural characteristics, like the degree of patience, can change very slowly, we believe that this is a useful normative result.

\subsection{Debt consolidation with exogenous data-mimicking policy}

Here, we study the scenario described in subsection 4.2. Namely, we repeat the same policy experiment as in subsection 5.1.1, except that, now, debt reduction to 0.9 in Italy is achieved by ad hoc changes in fiscal policy variables, which are similar to those actually implemented in the post-2011 period. We also assume that there can be risk premia in the new reformed steady state, which is as in subsection 5.1.1, and that the fiscal space created by debt reduction in Italy is used to finance an increase in transfer payments at steady state, rather than a decrease in capital tax rates as in the optimal cases. ${ }^{32}$

Results are reported in Tables 7 and 8. These two tables should be compared to Tables 3 and 4 (optimized policy with premia in the steady state) or to Tables 5 and 6 (optimized policy without premia in the steady state). Inspection of the results in Tables 7 and 8, and comparison with the previous ones, reveals that consolidation in Italy is now harmful for both countries and across all time intervals.

Therefore, the way public debt is brought down is important. Bringing public debt down in an exogenous way, similar to the one actually followed by Italy (i.e. mainly an increase in tax revenues) proves to be welfare-deteriorating all the time and for both countries vis-a-vis the case without debt consolidation and, naturally, is welfare inferior relative to the normative case where fiscal reaction policy is chosen optimally (meaning an optimally chosen cut in public consumption spending). In other words, there is room for considerable improvement in European policies in view of the current debt crisis. A discussion of the reasons behind these results is provided in the next subsection.

\footnotetext{
${ }^{32}$ In the exogenous case, we assume that the fiscal space is used to finance higher transfer payments simply because, in most DSGE models with exogenous policy, it is transfers that usually serve as the residually determined fiscal policy instrument in steady state. We report however that our qualitative results do not depend on this. For instance, we have also experimented with the case in which it is the capital tax rate that takes advantage of the fiscal space as we did in the optimal cases studied in subsection 5.1. The welfare inferiority of the exogenous case gets smaller but it is still there; it is now driven by ad hoc policies in the transition only.
} 
Table 7: Welfare over different time horizons with, and without, debt consolidation in Italy (exogenous policy as implied by the data)

\begin{tabular}{ccccc}
\hline \hline & 2 periods & 4 periods & 20 periods & lifetime \\
\hline \hline \multirow{2}{*}{ Domestic (Germany) } & 0.0745 & 0.1411 & 0.5688 & 2.1645 \\
& $(0.0811)$ & $(0.1589)$ & $(0.6802)$ & $(2.3889)$ \\
\hline welfare gain/loss & -0.0022 & -0.0037 & -0.0062 & -0.0062 \\
\hline \multirow{2}{*}{ Foreign (Italy) } & 0.0677 & 0.1276 & 0.5083 & 1.4092 \\
& $(0.068)$ & $(0.1339)$ & $(0.5732)$ & $(1.534)$ \\
\hline welfare gain/loss & -0.0004 & -0.0013 & -0.0038 & -0.0027
\end{tabular}

Notes: (i) Ad-hoc policy coefficients $\phi_{\pi}=2, \gamma_{l}^{g}=0.05, \gamma_{l}^{* g}=0, \gamma_{l}^{c}=\gamma_{l}^{k}=\gamma_{l}^{n}=0$, $\gamma_{l}^{* c}=\gamma_{l}^{* k}=\gamma_{l}^{* n}=0.08$, (ii) We set $\eta \equiv 0.5$. (iii) Results without debt consolidation in parentheses. (iv) Welfare gains/losses in terms of consumption equivalents.

Table 8: Resulting government spending and tax revenues as shares of GDP

\begin{tabular}{|c|c|c|c|c|}
\hline & 2 perio & $\begin{array}{l}4 \text { periods } \\
\text { average }\end{array}$ & $\begin{array}{c}10 \text { periods } \\
\text { average }\end{array}$ & $\begin{array}{c}20 \text { periods } \\
\text { average }\end{array}$ \\
\hline & & 0 & 0 & 0 \\
\hline Gov. spending & 0 & 0 & 0 & 0 \\
\hline $\begin{array}{c}\text { Tax revenues to GDP } \\
\text { in Germany }\end{array}$ & 0 & 0 & 0 & 0 \\
\hline $\begin{array}{c}\text { Tax revenues to GDP } \\
\text { in Italy }\end{array}$ & 0.023 & 0.0205 & 0.0155 & 0.01 \\
\hline
\end{tabular}

Notes: (i) See notes in Table 7. (ii) Numbers are expressed as absolute changes relative to the corresponding values in the status quo steady state solution. 


\subsection{Response functions and discussion of the main mechanisms}

To understand the logic behind the above welfare results, we now present the associated response functions. Figure 1 plots the simulated paths of the main fiscal policy instruments and the resulting public debt-to-GDP ratio in the foreign country (Italy), which is the country that undertakes the debt consolidation measures; these paths are shown in levels (i.e. percentage points). ${ }^{33}$ Figure 2 plots the paths of the main macroeconomic variables in the two countries; these paths are shown as percentage deviations from their status quo steady state values/except from net exports, $N E$ and $N E^{*}$, which are presented as shares of GDP). Figure 3 shows the paths of various price indices in the two countries; these paths are shown in levels. All response functions are computed from first-order approximations around the associated new reformed steady state when transition dynamics are driven by debt consolidation measures only.

The red line shows the case with optimized feedback policy rules as studied in subsection 5.1.1. The blue line shows the case in which the fiscal policy instruments are set as implied by the data as explained in subsection 5.2. The green horizontal straight line shows the initial, status quo value of the corresponding variable as reported in Table $2 .{ }^{34}$ In other words, the simulations shown in red are implemented as the transition from the status quo steady state in Table 2 to the new reformed steady state in Italy with a lower public debt than in the status quo (from $110 \%$ to $90 \%$ ) and hence with a lower capital tax rate, while, along the transition, all national fiscal policy instruments in both countries are allowed to react optimally to the public debt gap. On the other hand, the simulations shown in blue color plot the sub-optimal case in which, although again the Italian public debt is brought down to $90 \%$ in the new reformed steady state, this is achieved by following the exogenous data-mimicking policy mix studied in subsection 5.2 (as can be seen in Figure 1, this implies a short-term rise in all three tax rates by around 1.5 percentage point relative to their status quo values).

\footnotetext{
${ }^{33}$ Recall that, under optimized rules, only government consumption spending should be used, while, under ad hoc policy, debt consolidation has been achieved by higher taxes.

${ }^{34}$ In the welfare results reported in the tables, we also had temporary TFP shocks. Here, in these response functions, we switch off these shocks so that transition dynamics is driven by policy reforms in the high-debt country only. This allows us to see more clearly the main mechanisms behind various debt consolidation policies. Notice that without shocks, the steady state solution (the green line) is also the solution without debt consolidation used as the benchmark in our welfare comparisons in the tables. In Appendix 7.1, we provide the same response functions except that there we also include a temporary adverse shock to Italy's TFP, so that the non-consolidation case exhibits transition dynamics too. The main messages remain the same.
} 
Figure 1: Response functions of public debt to GDP and fiscal instruments in Italy (in levels)
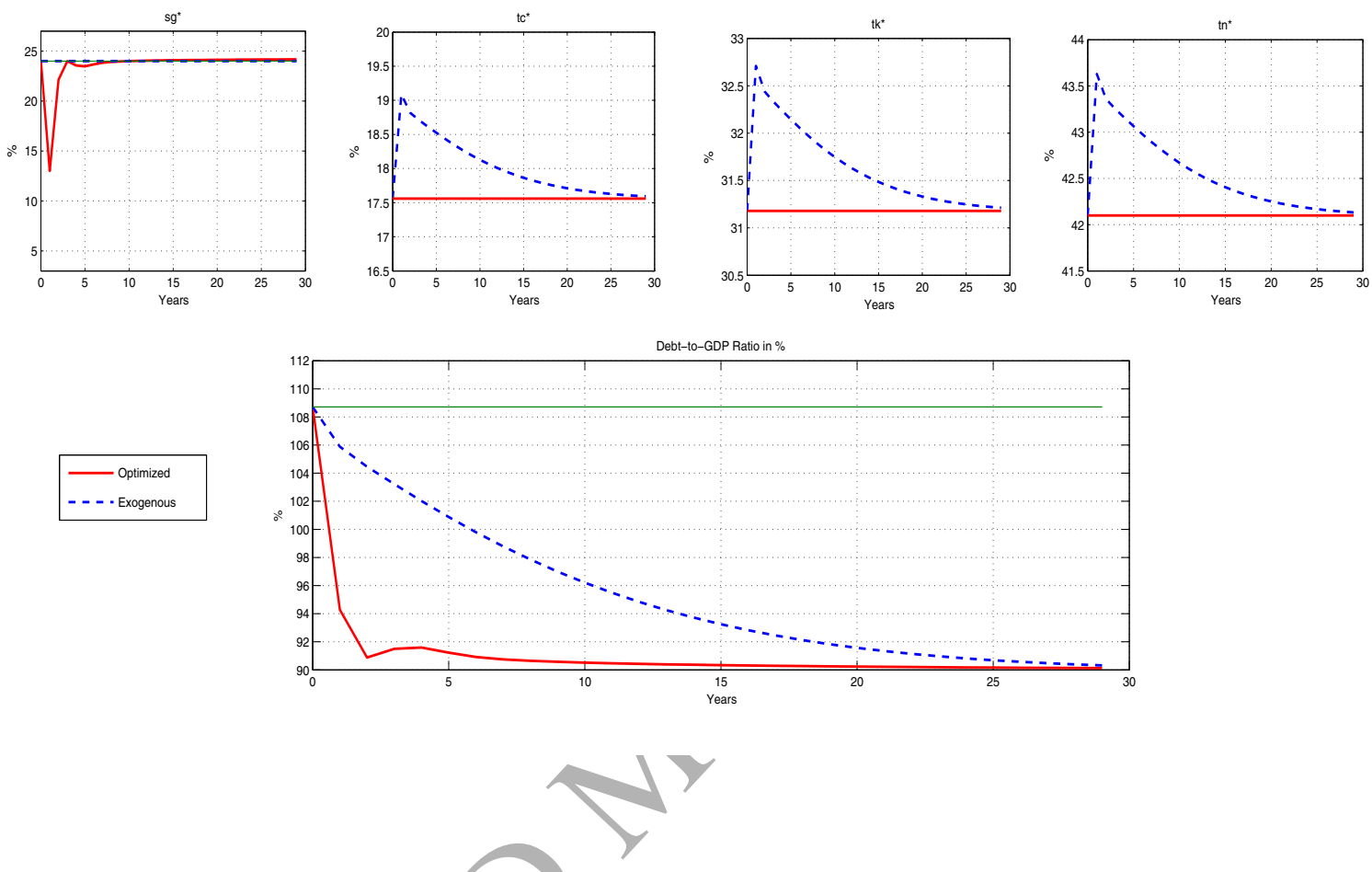

Regarding fiscal policy, inspection of the response functions for Italy's fiscal instruments in Figure 1 illustrates that, under optimized policy rules, only public consumption spending should fall on impact to bring public debt down, while, the blue lines show the rise in the three effective tax rates in the case of the ad hoc data-mimicking policy. As a consequence, the speed of adustment is faster under optimized rules (in the first three years, the public debt to GDP ratio is reduced from 109\% to $92 \%$ under optimal policy, while, under exogenous policy, it is reduced to $102 \%$ only; also, the debt target value, $90 \%$, is reached after ten years under optimal policy, while it takes 27 years under exogenous policy). In other words, when we use a relatively little distorting instrument, like a cut in government consumption spending, it is welfare-enhancing to front-load the fiscal adjustment, even if this comes at the cost of a relatively big output contraction on impact (see the red line for $y^{* H}$ in Figure 2). 
Figure 2: Response functions of main macro variables in Germany and Italy (in percentage deviations from status-quo steady state)
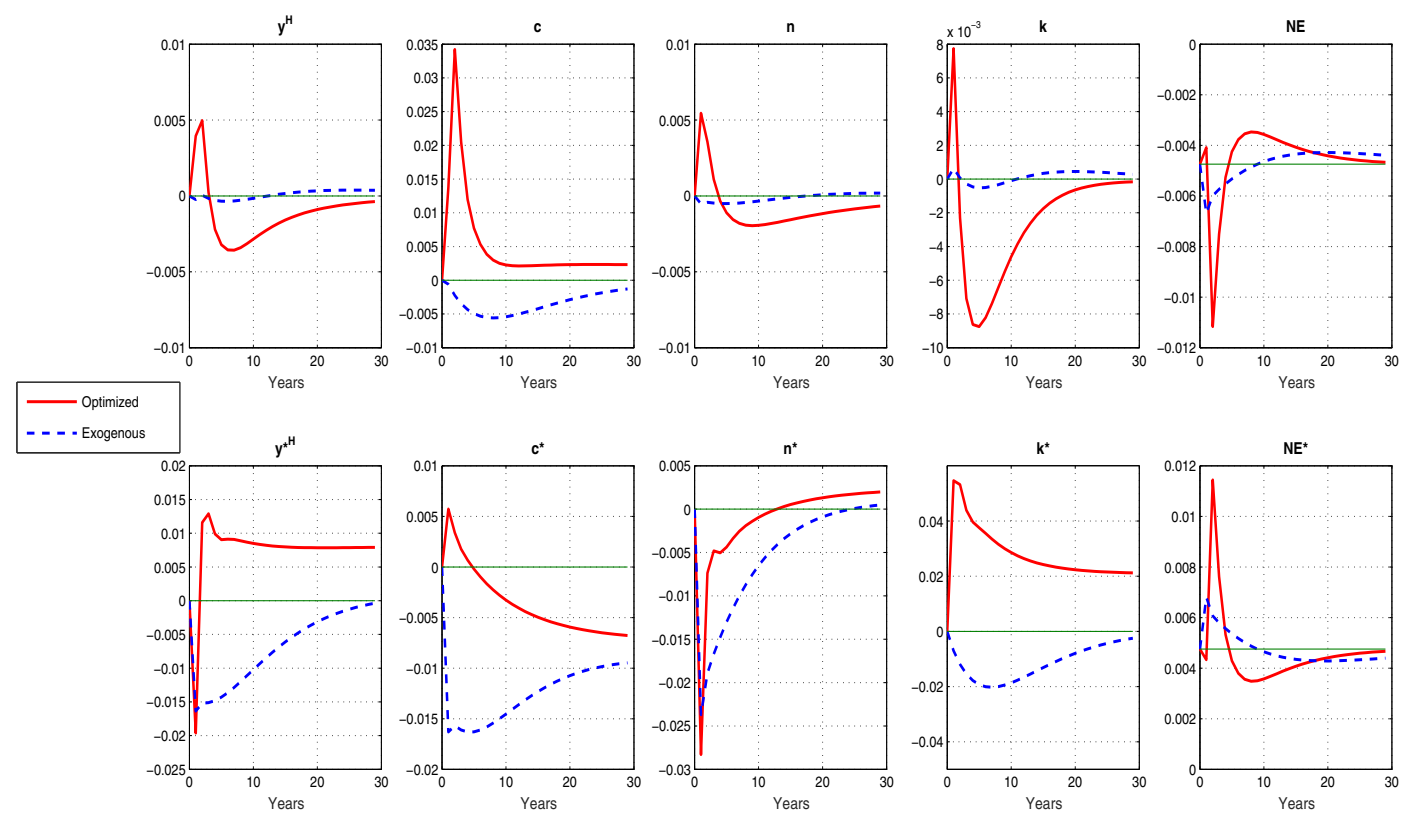

Regarding interest rates and relative prices as well as their macro effects, Figure 3 confirms that nominal interest rates, $R$ and $R^{*}$, as well as real interest rates, $\frac{R}{\Pi}$ and $\frac{R^{*}}{\Pi^{*}}$, both fall over time as a result of debt consolidation (strictly speaking, the real interest rates fall after a sharp jump on impact). The anticipation of lower real interest rates over time is good for capital accumulation in the whole currency union area. In Italy, the crowding-in of capital is further strengthened by the anticipation of lower capital tax rates in the new reformed steady state. These effects are behind the different behavior of $k$ and $k^{*}$ over time (see the red lines for $k$ and $k^{*}$ in Figure 2). In turn, in Italy, a higher $k^{*}$ implies a higher marginal product of labour so that work hours rise too after a fall in the short term (see the red line for $n^{*}$ in Figure 2) and the combination of more capital and more labor leads to more output produced, $y^{* H}$, over time. Notice also the clear co-movement of capital, $k$, work hours, $n$, and output, $y^{H}$, in Germany. The improvement in the terms of trade in favor of Italy, as shown by the red line for $T T$ in Figure 3, results in an immediate increase in Italian net exports, $N E^{*}$, and so a fall in Germany's $N E$, as shown by the red lines in Figure 2. Finally, comparing this optimal case to the ad hoc case, notice that the fall in interest rates (nominal and real) is bigger and lasts longer under optimal than under ad hoc policy and that Italy's terms of trade do not improve 
under the ad hoc case (see red and blue lines in Figure 3).

Regarding consumption, it rises in both countries in the short term as a result of optimized fiscal consolidation in Italy (see the red lines for $c$ and $c^{*}$ in Figure 2). This is mainly driven by the anticipation of lower real interest rates across the whole currency area over time, which induces households to bring forward their spending plans (the standard intertemporal substitution effect) and hence crowds in consumption plans in the short term. In Italy, there is an additional wealth effect on consumption, as agents anticipate that their net-of-tax wealth will increase thanks to the decrease in the public debt burden and the associated fall in taxes in the new steady state. ${ }^{35}$ After the initial rise, $c$ and $c^{*}$ start falling in the medium term, as the real interest rates start rising relatively to their initial cuts. Notice that the positive effect on initial consumption is stronger and more lasting in Germany (and this results in higher welfare, as also shown in Tables 3 and 5). This happens mainly because consumption in Italy, $c^{*}$, has to make room for higher investment and exports, as discussed above; however, eventually $c^{*}$ will be higher in the new reformed steady state than in the status quo steady state. ${ }^{36}$ Finally, comparing this optimized case to the ad hoc case, consumption suffers in both countries under the ad hoc scenario (see the blue lines for $c$ and $c^{*}$ in Figure 2) and this partly explains the welfare inferiority of the ad hoc regime. Looking at the response functions, this can be explained by a number of developments; for instance, in the ad hoc case, the fall in real interest rates is not so strong, there is no anticipation of a cut in distorting income taxes in the long run and the initial recession lasts longer.

All the above shape the dynamics of output. The simulations in Figure 2 show that Italian output falls sharply on impact (this is the direct effect of the cut in public spending), but it manages to recover fast under optimal policy for the reasons explained right above (this is illustrated by the red line for $y^{* H}$ in Figure 2). German output is affected in the opposite direction from Italy's (see the red line for $y^{H}$ in Figure 2); namely, in the transition to the new steady state, $y^{H}$ first rises and then falls (although this fall is small quantitatively) as Italian output starts rising. ${ }^{37}$ As discussed above, the main reasons behind the (small) fall in output

${ }^{35}$ Thus, in this consolidation scenario, consumption and leisure both rise in Italy in the short term relative to non-consolidation. This means that the welfare cost of debt consolidation in the early periods reported in Table 3 is due to the cut in public spending. If public spending is not valued in the utility function, consolidation is welfare superior to non-consolidation even in the short term (see also subsection 6.4 below). In the scenario in Table 5, the early welfare cost of consolidation is higher because consumption also falls in the short term in Italy (see below for this scenario).

${ }^{36}$ See the solutions for $c^{*}$ in Table 2 above (status quo steady state) and in Tables A1 and A2 in the Appendix (steady state solutions with debt consolidation in Italy).

${ }^{37}$ Table 2 in the main text reports the status quo steady state solution, while Tables A1 and A2 in the Appendix report the steady state solutions with debt consolidation in Italy. As can be seen, $y^{H}$ in Tables A1 and A2 is higher than, or equal to, $y^{H}$ in Table 2. 
in Germany in the medium term, after the positive effect from lower interest rates in the short term, are the decrease in its exports (see $N E$ and $N E^{*}$ in Figure 2), and the fact that Italy gets the lion's share in new capital accumulation (see $k$ and $k^{*}$ in Figure 2) along the transition path to the new steady state. Finally, comparing this optimized case to the ad hoc case, there is a long-lasting recession under the ad hoc tax-based scenario (see the blue line for $y^{* H}$ in Figure 2). Thus, an optimally chosen fiscal package, based on cuts in consumption spending, can make the output cost of fiscal adjustment temporary and relatively small. ${ }^{38}$ 39

Figure 3: Response functions of main price indices in Germany and Italy (in leyels)
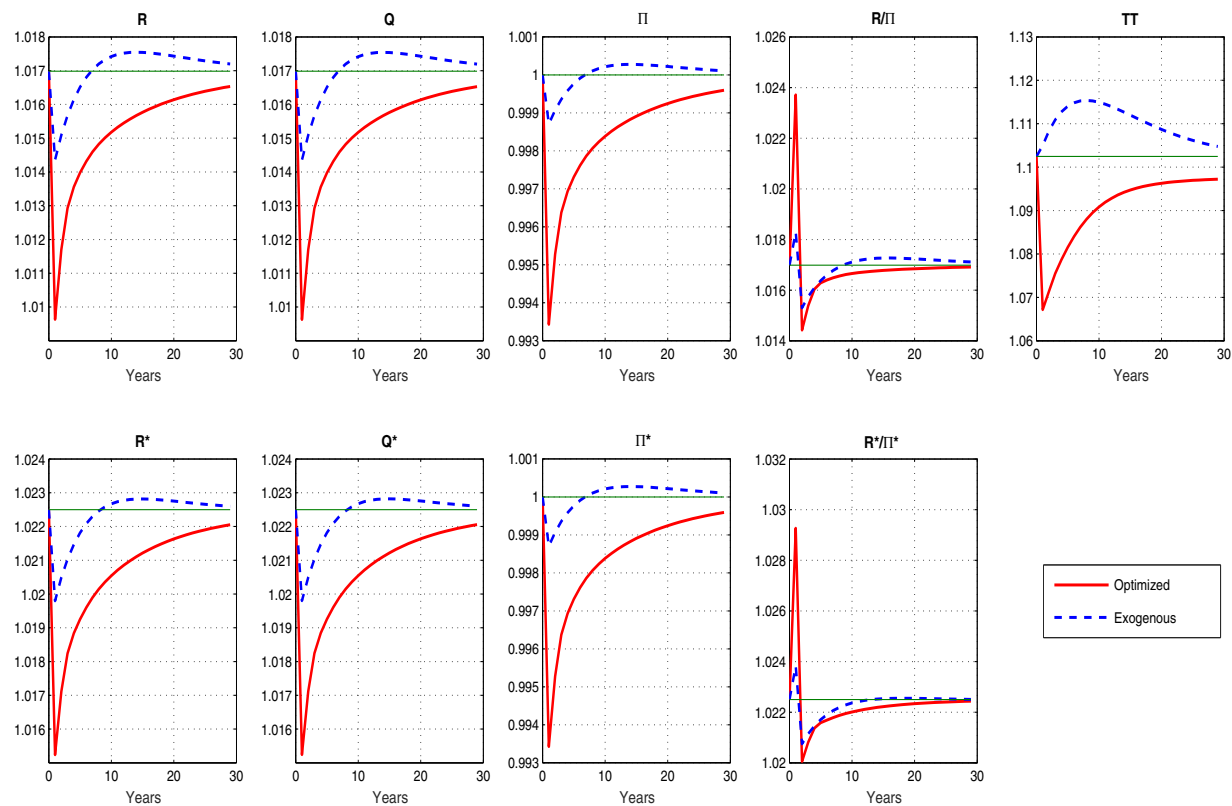

Before we close this section, we briefly report two other results. First, recall that we have

\footnotetext{
${ }^{38} \mathrm{We}$ have also experimented with other ad hoc cases, like a relatively sharp increase in tax rates and a relatively small decrease in public spending. Then, if the criterion is output in Italy, $y^{* H}$ (in particular, how deep is the contractionary impact of consolidation at short horizons and how long this contraction lasts), then the best scenario is the optimal one (as shown in Figure 1, this scenario translates into a strong cut in public spending on impact), next is the one with a mild decrease in public spending which causes a milder contraction on impact but more long-lasting than the optimal case, then comes the data-mimicking scenario which generates a persistent contraction, and finally is the case with a sharp rise in tax rates which produces a sharp output contraction. Response functions are available upon request.

${ }^{39}$ Erceg and Lindé (2013) find that, in a currency union, a tax-based consolidation depresses output by less than a spending-based consolidation in the short term. That is, although we get similar results at longer horizons, our results differ at short horizons. This difference in the short term can be due to model differences, to the way countries are assumed to differ or to the fact that they employ exogenous values for the feedback policy coefficients.
} 
also studied the more ambitious case in which, not only public debt is reduced, but also premia are eliminated, in the new reformed steady state (see subsection 5.1.2). The main difference of this more ambitious case ${ }^{40}$ from the case in which premia remain in the new reformed steady state (this was the case illustrated in Figures 1-3) is that, under the former, the crowd-in of capital is much stronger in Italy and this leads to a rise in work hours and even a rise in this country's output from the very start. In other words, our simulations can support the debated argument made by e.g. Giavazzi and Pagano (1990), Alesina and Perotti (1997) or Alesina and Ardagna (1998) that fiscal contractions are output-expansionary even in the short term, ${ }^{41}$ only when such contractions are accompanied by cultural changes and in particular in the degree of patience in the country that undergoes debt consolidation. Also, in this more ambitious case, the cross-border beneficial effect on Germany's consumption is more permanent than in Figure 2. Second, recall that in all cases with optimized rules studied so far, it has not been optimal to use cuts in transfer payments to bring public debt down during the transition. To understand why, we have also examined the case in which debt consolidation would take place via ad hoc cuts in government transfers. ${ }^{42}$ As the response functions show, such cuts, although they allow Italy to avoid the short-term fall in output observed when debt consolidation takes place via cuts in government consumption spending, they lead to lower private consumption, lower capital and lower leisure over time. This makes the transfer-cut package welfare-inferior to the optimized case in which debt consolidation takes place via cuts in government consumption spending. Notice that, under transfer cuts, consumption falls because real interest rates (after a temporary fall on impact) rise, which creates an adverse intertemporal substitution effect. Relatively high real interest rates also explain the crowing-out of capital. All this translates to the zero feedback coefficients on debt in the optimized rule for transfers, and the positive ones in the optimized rule for government consumption (see Tables 3 and 5 above).

\section{Sensitivity analysis and extensions}

We now check the robustness of our results. We will focus on changes in the two countries' political power (subsection 6.1), reaction to the output gap (subsection 6.2), shocks to initial debt when consolidation efforts start (subsection 6.3), the introduction of government investment (subsection 6.4) and the addition of non-Ricardian households (subsection 6.5). Following usual practice, we will study one change at a time. Before we present results for these richer

\footnotetext{
${ }^{40}$ To save on space, the response functions of this more ambitious case are presented in Appendix 7.2

${ }^{41}$ See also Coenen et al. (2008) and EEAG Report (2014, chapter 3) for this argument.

${ }^{42}$ To save on space, the response functions of this ad hoc case are presented in Appendix 7.3.
} 
cases, we report that the above results are robust to changes in all other parameter values listed in Table 1a above, at least within reasonable ranges.

Since the welfare benefits of debt consolidation have been found to be stronger in the case in which premia are also eliminated in the steady state of the reformed economy (see the results in Tables 5 and 6 ), in what follows, we work with this case when we refer to consolidation. We report, however, that the qualitative results are the same when the comparison is relative to the less ambitious policy experiment in Tables 3 and 4 where premia can remain in the new reformed steady state.

\subsection{Does political power matter?}

So far, we have restricted ourselves to the "politically correct" case in which the two countries shared equal power in policy decision making. That is, we have set the weight $\eta$ in equation (30) at the neutral value of 0.5 . The higher is $\eta$, the more Germany matters to policy decisionmaking in this equation. New results in the range $0.5 \leq \eta<1$ are reported in Tables 9 and 10. To save on space, we focus again on the best policy mix found, namely, when both Italy and Germany use public consumption spending in the transition phase, while Italy cuts capital taxes once its fiscal consolidation has been implemented.

First of all, observe that welfare differences are quantitatively small as $\eta$ changes. This should be expected since here we compare results under optimized rules. Keeping this in mind, the main messages are as follows. Table 9 implies that the higher the say of Germany in policy decision making, the better off Germany, and the worse off Italy, become. This is as expected. Table 10 implies that the higher the say of Germany, the stronger the fiscal consolidation in Italy. This is shown by the monotonic positive effect of $\eta$ on the magnitude of the feedback fiscal policy coefficient on public debt in Italy, $\gamma_{l}^{g *}$ (the other optimized feedback policy coefficients remain practically zero, as in the previous section).

Table 9: Effect of political weight on lifetime utility

\begin{tabular}{cccc}
\hline \hline weight & world $E_{0} W_{0}$ & home $E_{0} V_{0}$ & foreign $E_{0} V_{0}^{*}$ \\
\hline \hline$\eta=0.5$ & 2.8315 & 2.8979 & 2.765 \\
\hline \hline$\eta=0.6$ & 2.8460 & 2.9009 & 2.7635 \\
\hline$\eta=0.7$ & 2.8598 & 2.9012 & 2.7634 \\
\hline$\eta=0.8$ & 2.8735 & 2.9027 & 2.7565 \\
\hline$\eta=0.9$ & 2.8887 & 2.9042 & 2.7488
\end{tabular}

Notes: The weight in the Taylor rule is kept at 0.5 (not important). 
Table 10: Effect of political weight on feedback policy coefficients

\begin{tabular}{cccc}
\hline \hline political weight & $\begin{array}{c}\text { monetary } \\
\text { reaction } \\
\text { to inflation }\end{array}$ & $\begin{array}{c}\text { home fiscal } \\
\text { reaction } \\
\text { to debt }\end{array}$ & $\begin{array}{c}\text { foreign fiscal } \\
\text { reaction } \\
\text { to debt }\end{array}$ \\
\hline$\eta=0.5$ & $\phi_{\pi}=1.1$ & $\gamma_{l}^{g}=0.014$ & $\gamma_{l}^{* g}=0.5619$ \\
\hline$\eta=0.6$ & $\phi_{\pi}=1.1$ & $\gamma_{l}^{g}=0.015$ & $\gamma_{l}^{* g}=0.6389$ \\
\hline$\eta=0.7$ & $\phi_{\pi}=1.1$ & $\gamma_{l}^{g}=0.014$ & $\gamma_{l}^{* g}=0.6454$ \\
\hline$\eta=0.8$ & $\phi_{\pi}=1.1$ & $\gamma_{l}^{g}=0.016$ & $\gamma_{l}^{* g}=0.7636$ \\
\hline$\eta=0.9$ & $\phi_{\pi}=1.1$ & $\gamma_{l}^{g}=0.014$ & $\gamma_{l}^{* g}=0.8607$ \\
\hline
\end{tabular}

\subsection{Allowing for reaction to the output gap}

So far we have allowed for optimal reaction to inflation only (on the part of the single monetary authority) and to public debt only (on the part of national fiscal authorities). That is, we have not allowed monetary and/or fiscal policy instruments to react optimally to the output gap too. As explained above, this has been for computationalreasons only. Nevertheless, although we cannot allow at the same time all feedback policy coefficients in subsections 2.6.1 and 2.6.2 to be chosen optimally, we can at least experiment with various exogenously set values of national feeback fiscal reaction to the output gap. Monetary policy reaction to inflation and national fiscal policy reactions to public debt are optimally chosen as above (while again we set $\phi_{y}=0$ for the central bank). ${ }^{43}$

Table 11 reports the implications for expected discounted lifetime utility in the two countries, when Italy uses its income (capital and labor) tax rates in a counter-cyclical way, meaning that these two distorting tax rates decrease when the output gap is negative and the opposite when the output gap is positive, while the rest of the experiment remains as in subsection 5.1.2. In particular, in Table 11, we ad hoc set $\gamma_{l}^{* k}=\gamma_{l}^{* n} \equiv 0.5$ in the rules for the capital and labor tax rates in Italy (we report that our qualitative results do not depend on the particular values assumed for these two feedback coefficients). Comparison of Table 11 to, for instance, Table 5 implies two results: First, welfare rises in Table 11 relative to Table 5. Second, and more interesting, Table 11 implies a clear assigment of policy instruments to policy targets during the transition phase: public consumption spending should be cut to address the public debt gap and, at the same time, capital and labor tax rates should also be reduced to mitigate

\footnotetext{
${ }^{43}$ Monetary policy reaction to output, $\phi_{y}>0$, is bad for welfare. That is, as $\phi_{y}$ rises, welfare deteriorates in both countries. See also e.g. Schmitt-Grohé and Uribe (2007) and Philippopoulos et al. (2015) in closed economies.
} 
the recessionary effects of debt consolidation.

Table 11: Welfare over different time horizons with, and without, debt consolidation in Italy (plus ad-hoc reaction to output gap via income taxes in Italy)

\begin{tabular}{ccccc}
\hline \hline & 2 periods & 4 periods & 20 periods & lifetime \\
\hline \hline \multirow{2}{*}{ Home (Germany) } & 0.1407 & 0.2742 & 1.0709 & 2.9080 \\
& $(0.0811)$ & $(0.1589)$ & $(0.6802)$ & $(2.3889)$ \\
\hline welfare gain/loss & 0.0204 & 0.0241 & 0.0221 & 0.0087 \\
\hline \multirow{2}{*}{ Foreign (Italy) } & -0.0322 & -0.0048 & 0.4841 & 2.7750 \\
& $(0.068)$ & $(0.1339)$ & $(0.5732)$ & $(1.534)$ \\
\hline welfare gain/loss & -0.0336 & -0.0286 & -0.0052 & 0.0277 \\
\hline
\end{tabular}

Notes: (i) Optimized policy coefficients $\phi_{\pi}=1.1, \gamma_{l}^{g}=0.014, \gamma_{l}^{* g}=0.4942$,

$\gamma_{l}^{l}=\gamma_{l}^{c}=\gamma_{l}^{k}=\gamma_{l}^{n}=\gamma_{l}^{* l}=\gamma_{l}^{* c}=\gamma_{l}^{* k}=\gamma_{l}^{* n}=0$ and $\rho^{\beta^{*}}=0$ (ii) We set $\gamma_{l}^{* k}=\gamma_{l}^{* n} \equiv 0.5$ and $\eta \equiv 0.5$ (iii) Results without debt consolidation in parentheses. (iv) Welfare gains/losses are in terms of consumption equivalents.

\subsection{Shocks to initial debt}

Now we shock the initial public debt in Italy so as to rise from $110 \%$ to, say, $130 \%$. All the rest remains as in section 5 above. The new results are reported in Table 12. Qualitatively, the results are as in Tables 3 or 5 . Notice however that, with a higher public debt initially, the fiscal pain is bigger than in the preyious tables. 
Table 12: Welfare over different time horizonswith, and without, debt consolidation in Italy

\begin{tabular}{ccccc}
\hline \hline \multicolumn{5}{c}{ (with a higher initial debt) } \\
\hline \hline Home (Germany) & 0.1775 & 0.3449 & 1.2575 & 3.1538 \\
& $(0.0811)$ & $(0.1589)$ & $(0.6802)$ & $(2.3889)$ \\
\hline welfare gain/loss & 0.0332 & 0.0392 & 0.0329 & 0.0129 \\
\hline Foreign (Italy) & -0.0839 & -0.0605 & 0.3765 & 2.6945 \\
& $(0.068)$ & $(0.1339)$ & $(0.5732)$ & $(1.534)$ \\
\hline welfare gain/loss & -0.0502 & -0.0394 & -0.011 & 0.0196 \\
\hline Notes: (i) Optimized policy coefficients $\phi_{\pi}=1.1, \gamma_{l}^{g}=0.014, \gamma_{l}^{* g}=0.443$, \\
$\gamma_{l}^{l}=\gamma_{l}^{c}=\gamma_{l}^{k}=\gamma_{l}^{n}=\gamma_{l}^{* l}=\gamma_{l}^{* c}=\gamma_{l}^{* k}=\gamma_{l}^{* n}=0$ and $\rho^{\beta^{*}}=0 .($ ii) We set $\eta$ 户 0.5 . (iii) Results \\
without debt consolidation in parentheses. (iv) Welfare gains/losses are in terms of consumption \\
equivalents.
\end{tabular}

\subsection{The role of government spending}

So far we have assumed that government purchases of goods and services played a utilityenhancing role. Specifically, these purchases served as an argument in households' utility function and this utility-enhancing effect was measured by the preference parameter $\chi_{g} \geq 0$ in equation 8 (which has been set at 0.1 so far) - In this subsection, we first check the sensitivity of our results to changes in the value of $\chi_{g}$ and then enrich the model by also allowing for a productivity-enhancing role of public,spending.

Regarding utility-enhancing government spending, we report that we have started with $\chi_{g}=0$ and then experimented with various positive values. Our qualitative results for the optimal policy mix do not change. On the other hand, when $\chi_{g}$ gets higher than 0.3 , the optimal reaction of public government spending to public debt imbalances becomes weaker meaning a smaller cut in public spending. At the other extreme, when $\chi_{g}$ is close to zero, the cut in public spending (chosen for debt consolidation) does not hurt welfare so that debt consolidation becomes welfare superior to non-debt consolidation even in the short term (compare this to the results in Table 3 where $\chi_{g}=0.1$ ). These are intuitive results.

Regarding productivity-enhancing government spending, we now assume that government activities can also serve an an input to private production. In particular, we augment the firm's production function in equation (13) to:

$$
y_{t}^{H}(h)=A_{t}\left(g_{t}^{i}\right)^{\varkappa}\left[k_{t-1}(h)\right]^{\alpha}\left[n_{t}(h)\right]^{1-\alpha}
$$


where $g_{t}^{i}$ denotes per capita productivity-enhancing government spending on goods and services and $0 \leq \varkappa \leq 1$ is a technology parameter. ${ }^{44}$ Notice that, for simplicity, and as in e.g. Baxter and King (1993), we maintain the assumption of CRS over private inputs.

As we have done so far with other types of public spending, we set $g_{t}^{i}=s_{t}^{i} y_{t}^{H}$, where $s_{t}^{i}$ is the ratio of real government investment to real GDP. ${ }^{45}$ This new fiscal instrument is allowed to follow the feedback rule:

$$
s_{t}^{i}-s^{i}=-\gamma_{l}^{i}\left(l_{t-1}-l\right)-\gamma_{y}^{i}\left(y_{t}^{H}-y^{H}\right)
$$

where $\gamma_{l}^{i}, \gamma_{y}^{i} \geq 0$ are new feedback policy coefficients. Note that we have similar equations for the foreign country and the feedback policy coefficients are again chosen optimally.

Details of the new model, the new government budget constraint and the resulting final equilibrium system are in Appendix 8. Here, we just report that the main results do not change and that the optimized values of the feedback polícy coeffcients on public liabilities in both countries, $\gamma_{l}^{i}$ and $\gamma_{l}^{* i}$, are found to be zero in all experiments. ${ }^{46}$ That is, it is not optimal to use an instrument like government investment, which practically determines the effective TFP, for debt consolidation. Debt consolidation should be left to less distorting fiscal policy instruments, like government consumption spending.

\subsection{Does agent heterogeneity mattér?}

So far we have assumed that households are identical within each country. Although it might be true that debt consolidation is a uniform reform across agents, agents are heterogeneous so that even an aggregate reform, or shock, can affect them differently. There can be many types of agent heterogeneity. Here, we focus on a particular type that has been common in this literature. We distinguish between "Ricardian" households, defined as those who have access to financial and capital markets and own the country's firms, and "non-Ricardian" households, who have no access to financial markets and do not own physical or financial capital. We assume that the fraction of Ricardian households is $0<\nu_{r} \leq 1$ and the fraction of non-Ricardian ones is $0 \leq \nu_{n r}=1-\nu_{r}<1$, and similarly in the foreign country.

\footnotetext{
${ }^{44}$ Note that we use public investment (which is a flow) rather than public capital (which is a stock) in the production function. This is for simplicity only (our qualitative results do not depend on this).

${ }^{45}$ Thus, we now distinguish between utility-enhancing government purchases of goods and services (whose output share is $s_{t}^{g}$ ) and productivity-enhancing ones (whose output share is $s_{t}^{i}$ ), where the former are measured by government consumption spending and the latter by government investment spending in the data.

${ }^{46}$ Following Baxter and King (1993) and most of the related literature, in the baseline parameterization, we start with $\varkappa$ equal to 0.05 , which is also close to the GDP share of public investment in the data. We report that our results are not sensitive to this value. Note that as above we switch off the reaction to output gap for computational reasons.
} 
Details of the new model, the behavior of the new non-Ricardian agents and the resulting final equilibrium system are in Appendix 8. Here, we only report some numerical results. To get these results, we set $\nu_{r}=\nu_{n r}=0.5 .{ }^{47}$ We also need to recalibrate the new model so as to bring it again close to the data. ${ }^{48}$ Using all this, we get the numerical results reported in Table 13, which is like Table 5 above. ${ }^{49}$ In Table 13, in each cell, we report results for the two types of households distinguished by a slash, i.e. in the first cell, 0.6575 is the two-period discounted utility of the Ricardian agent and 0.075 is that of the non-Ricardian household in the home country. The same applies to all cells.

Table 13: Welfare over different time horizons with, and without, debt consolidation in Italy with Ricardian and non-Ricardian agents (without premia in the reformed steady state)

\begin{tabular}{|c|c|c|c|c|}
\hline & 2 periods & 4 periods & 20 periods & lifetime \\
\hline Home & $0.657 / 0.070$ & $1.287 / 0.143$ & 57 & $18.053 / 1.496$ \\
\hline (Germany) & $(0.578 / 0.022)$ & $(1.138 / 0.044)$ & $.002 / 0.204)$ & $(17.483 / 0.690)$ \\
\hline $\begin{array}{c}\text { welfare } \\
\text { gain/loss }\end{array}$ & $0.0272 / 0.0164$ & & $0.0259 / 0.02$ & $0.0096 / 0.0136$ \\
\hline Foreign & $0.437 /-0.010$ & $0.946 \gamma-0.002$ & $4.690 / 0.273$ & $17.679 / 1.451$ \\
\hline (Italy) & $(0.572 /-0.007)$ & $(1.119 /-0.013)$ & $(4.727 / 0.006)$ & $(13.153 /-0.144)$ \\
\hline $\begin{array}{c}\text { welfare } \\
\text { gain/loss }\end{array}$ & $44 !$ & $00351 / 00023$ & $-0.002 / 0.0151$ & $0.0785 / 0.027$ \\
\hline
\end{tabular}
$\gamma_{l}^{l}=\gamma_{l}^{c}=\gamma_{l}^{k}=\gamma_{l}^{n}=\gamma_{l}^{* l}=\gamma_{l}^{* c}=\gamma_{l}^{* k}=\gamma_{l}^{* n}=0$ and $\rho^{\beta^{*}}=0$. (ii) We set $\eta \equiv 0.5$. (iii) Results without debt consølidation in parentheses. (iv) Welfare gains/losses in terms of consumption equivalents.

Inspection of the results in Table 13 reveals that the main messages do not change. Namely, focusing on welfare gains/losses which are in consumption equivalents, debt consolidation implies a short term cost for both types of agents in the country that undergoes consolidation

${ }^{47}$ This is a value close to that used by Erceg and Lindé (2013). Priftis and Vogel (2016), and several other studies by the ECB cited in their paper, set $\nu_{r}=0.6$. We report that our main results do not change within the range $0.45<\nu_{r} \leq 1$.

${ }^{48}$ In particular, we recalibrate the risk premium parameter and lump-sum transfers/taxes in the two countries so as to hit net foreign debt and public debt as shares of GDP in the data. Thus, we set $\psi=0.071, s^{l}=-0.187$ and $s^{* l}=-0.1905$. The new steady state solution, which should be compared to that in Table 2 , is presented in Appendix 8.

${ }^{49}$ The welfare criterion in each country is now a weighted average of the welfare of the two income groups, where as weights we use their population fractions; thus, $V_{t} \equiv \nu_{r} V_{r, t}+\left(1-\nu_{r}\right) V_{n r, t}$ in the domestic economy and $V_{t}^{*} \equiv \nu_{r}^{*} V_{r, t}^{*}+\left(1-\nu_{r}^{*}\right) V_{n r, t}^{*}$ in the foreign economy, where the functions are defined in Appendix 8. 
(Italy), while both types of agents benefit across all time windows in the other country (Germany). In Italy, Ricardian households or "the rich" seem to suffer more from debt consolidation than non-Ricardian households or "the poor" in the near term (this is in terms of both consumption and leisure), but they eventually benefit more when the criterion is lifetime utility, as debt consolidation crowds-in capital at longer horizons (see subsection 5.3 above) and the latter is owned by Ricardian households only. Also, relative to the results in Table 5, notice that the optimal reaction of public spending to debt imbalances is bigger now (it is $\gamma_{l}^{* 9}=0.7499$, while it was $\gamma_{l}^{* g}=0.5619$ in Table 5), which means that Italy should go for a sharper cut in public spending on impact relative to the case with a representative household. Based on the related simulation results, our interpretation is that, since now the government also cares about non-Ricardian households whose main source of income is income from labor, it finds it optimal to front-load the fiscal adjustment so as to make the loss in employment, or work hours, as temporary as possible. ${ }^{50}$

Notice that again it is not optimal to use cuts in transfer payments for debt consolidation (see the optimized values of the feedbacks in the notes of Table 13). This happens not only for the reasons discussed at the very end of subsection 5.3, but also because now, with household heterogeneity, transfer payments do not appear only in the government budget constraint (see the equilibrium system presented in Appendix 8); in other words, cuts in transfers are now more distorting than in the case of the representative household. We also report that the main results do not change when we assume agent-specific transfers (see Appendix 8 for modelling details). For instance, when we assume, other things equal, that the per capita transfer given to the non-Ricardian household is higher than the transfer given to the Ricardian household, nonRicardian households get better off, and Ricardian households get worse off, but the optimal policy mix does not change..$^{51}$

Before we move on, and as we also say in the closing section below, we recognize that the distributional implications of debt consolidation is an important issue on its own so the above experiments obviously do not exhaust its study.

\footnotetext{
${ }^{50}$ The short-term fall in employment is more persistent in the single agent case (see Figure 2 above) than in the present scenario and this applies in particular to the employment of non-Ricardian households whose fall is very temporary. The new response functions are available upon request.

${ }^{51}$ We have also experimented with the case in which, in the new reformed steady state, the fiscal space, created by a lower debt burden, is used to finance transfers targeted to non-Ricardians (namely, these transfers play the role of the residual fiscal instrument in this steady state solution). Again, non-Ricardians get better off but this is not Pareto improving. All these numerical results are availabe upon request.
} 


\section{Other policy regimes: Non-cooperative policies and flexible exchange rates}

We finally consider two different policy regimes from those studied so far. In subsection 7.1, we study non-cooperative (Nash) policies. In subsection 7.2 , we consider what would have happened under flexible exchange rates. Again, we study one change at a time.

\subsection{Non-cooperative (Nash) policies}

So far, we have studied a fully cooperative policy scenario (recall the discussion in subsection 4.3.1 above). We now study the case in which the single monetary authority and the two national fiscal authorities do not cooperate with each other.

Since this is a more demanding problem computationally than its counterpart under cooperation (with cooperation, we had to compute only one policy optimization problem), we focus on the following case. Working again with optimized feedback policy rules (as we have done so far), we assume that the single monetary authority chooses its feedback reaction to weighted inflation in the two countries and, at the same time, the two national fiscal auhorities choose their feedback reactions to their own public liabilities, and all this is modelled as a non-cooperative (Nash) game among these three policymakers. More specifically, (i) the single monetary authority chooses $\phi_{\pi}$ in its nominal interest rate policy rule (see equation 17) to maximize the union's welfare, $W_{t}=\eta V_{t}+(1-\eta) V_{t}^{*}$ (see equation 30) for given national fiscal policies, (ii) the domestic country's government chooses the vector $\gamma \equiv\left\{\gamma_{l}^{g}, \gamma_{l}^{l}, \gamma_{l}^{c}, \gamma_{l}^{k}, \gamma_{l}^{n}\right\}$ in its fiscal policy rules (see equations 18 to 22 ) to maximize the welfare of the domestic household, $V_{t}$ (see equation 7 ) for given monetary and foreign fiscal policy, and (iii) the foreign country's government chooses the vector $\gamma^{*} \equiv\left\{\gamma_{l}^{* g}, \gamma_{l}^{* l}, \gamma_{l}^{* c}, \gamma_{l}^{* k}, \gamma_{l}^{* n}\right\}$ in its fiscal policy rules (which are like equations 18 to 22 ) to maximize the welfare of its own household, $V_{t}^{*}$ (which is like equation 7), for given monetary and domestic fiscal policy. In doing so, all three policy authorities are constrained by the world equilibrium system (see subsection 2.8) which was for given policy coefficients. To compute this Nash game, we work similarly to Mendoza and Tesar (2005), who, however, solve for the optimal level of capital tax rates rather than for the optimal magnitude of feedback coefficients in the assumed policy rules. ${ }^{52}$ Results for the Nash

\footnotetext{
${ }^{52}$ More formally, (i) the single monetary authority chooses $\phi_{\pi}$, which gives the reaction function $\Phi_{\pi}\left(\gamma, \gamma^{*}\right)$ where $\Phi_{\pi}=\arg \max W\left(\phi_{\pi} \mid \gamma, \gamma^{*}\right)$, (ii) the domestic country's government chooses $\gamma$, which gives the reaction function $\Gamma\left(\phi_{\pi}, \gamma^{*}\right)$ where $\Gamma=\underset{\gamma}{\arg \max } V\left(\gamma \mid \phi_{\pi}, \gamma^{*}\right)$, and (iii) the foreign country's government chooses $\gamma^{*}$, which gives the reaction function, $\Gamma^{*}\left(\phi_{\pi}^{\gamma}, \gamma\right)$ where $\Gamma^{*}=\underset{\gamma^{*}}{\arg \max } W\left(\gamma^{*} \mid \phi_{\pi}, \gamma\right)$. In doing so, all three policy authorities are constrained by the world equilibrium system which was for given policy feedbacks. The Nash numerical
} 
policy game, using the same parameterization as above, are reported in Table 14. Numbers in parentheses report welfare levels in the benchmark case with cooperation summarized by Table 5, other things equal. Welfare gains/losses of Nash vis-a-vis cooperation are in terms of percentage consumption equivalents; a negative number means a loss vis-a-vis the case with cooperation and vice versa with a positive number.

Table 14: Nash versus cooperative policies (without premia in the reformed steady state)

\begin{tabular}{ccccc}
\hline \hline & 2 periods & 4 periods & 20 periods & lifetime \\
\hline \hline \multirow{2}{*}{ Domestic (Germany) } & 0.1356 & 0.2673 & 1.0507 & 2.8785 \\
& $(0.1424)$ & $(0.2751)$ & $(1.0543)$ & $(2.8979)$ \\
\hline welfare gain/loss & -0.0023 & -0.0016 & -0.0002 & -0.0003 \\
\hline \multirow{2}{*}{ Foreign (Italy) } & -0.0353 & -0.0110 & 0.4694 & 2.7541 \\
& $(-0.0421)$ & $(-0.0099)$ & $(0.4585)$ & $(2.765)$ \\
\hline welfare gain/loss & 0.0023 & -0.0002 & 0.0006 & -0.0002 \\
\hline
\end{tabular}

Notes: (i) Optimized policy coefficients under $\operatorname{Nash} \phi_{\pi} \neq 1.1, \gamma_{l}^{g}=0.1011, \gamma_{l}^{* g}=0.4344$,

$$
\gamma_{l}^{n}=0.0211, \gamma_{l}^{* n}=0.0218, \gamma_{l}^{l}=\gamma_{l}^{* l}=\gamma_{l}^{c}=\gamma_{l}^{* c}=\gamma_{l}^{k}=\gamma_{l}^{* k}=0 \text { and } \rho^{\beta^{*}}=0
$$

(ii) We set $\eta \equiv 0.5$ in the bank's problem. (iii) Result's with cooperation in parentheses. (iv) Welfare gains/losses in terms of consumption equivalents.

Our solution implies that cooperation is superior to Nash in terms of lifetime utility and this is the case in each country. That is, cooperation is Pareto efficient eventually. On the other hand, the effects of cooperation are very small in magnitude in terms of consumption equivalents. These results are consistent with those delivered by similar models (see e.g. Mendoza and Tesar, 2005). ${ }^{53}$ What we think is novel here is that, when fiscal policies are set non-cooperatively, Italy finds it optimal to react less to its debt imbalances than in the case in which the same policies are set jointly $\left(\gamma_{l}^{* g}=0.4344\right.$ in the Nash equilibrium in Table 14 is less than $\gamma_{l}^{* g}=0.5619$ which was the case in Table 5 in the cooperative solution). Intuitively,

solution, i.e. the values of the time-invariant $\phi_{\pi}, \gamma$ and $\gamma^{*}$, is then given by the point of intersection of the three reaction functions.

${ }^{53}$ Okano (2014), on the other hand, finds zero gains from cooperation in the absence of utility-enhancing government consumption services (in our model, this happens when $\chi_{g}=0$ ). We report that here we continue to get welfare differences (although very small in magnitude) between Nash and cooperation even when we set $\chi_{g}=0$. This is not surprising. Okano (2014), as well as Beetsma and Jensen (2005), work with different models, which do not include, for instance, capital accumulation or distorting taxes, so they have a smaller menu of international externalities than we have here (for instance, here, as well as in Mendoza and Tesar, 2005, there are also externalities coming from national tax policies, which affect saving, investment, consumption and labor supply in both countries). 
since debt consolidation in one country works like an international public good (see e.g. the discussion in subsection 5.3 above), individual countries have an incentive to go for a milder debt consolidation in the absence of international cooperation or, equivalently, each country has an incentive to free ride on other countries' debt consolidation measures. Also notice that, without cooperation, the two countries need to use labor taxes too for debt consolidation, which can be explained by the fact that labor is an internationally immobile factor in our model.

\subsection{Would monetary policy independence matter?}

Finally, we resolve the model under the counter-factual scenario of flexible exchange rates and hence independent monetary policies in the two countries. In terms of modelling, the difference from the currency union model solved so far is that now the exchange rate between the two countries, $S_{t}$, becomes an endogenous variable. Thus, $S_{t}$ and $R_{t}^{*}$ exchange places: the latter was endogenous in the currency union regime studied so far (see the discussion in subsection 2.6.1), while now it is the former that becomes endogenous with the latter being free to follow, for instance, a national Taylor-type rule. In other words, with flexible exchange rates, we can have an independent Taylor-type rule for the national nominal interest rate in each country. Here, we postulate the rules:

$$
\begin{gathered}
\log \left(\frac{R_{t}}{R}\right)=\phi_{\pi} \log \left(\frac{\Pi_{t}}{\Pi}\right)+\phi_{y} \log \left(\frac{y_{t}^{H}}{y^{H}}\right)+\phi_{\epsilon} \log \left(\frac{\epsilon_{t}}{\epsilon}\right) \\
\log \left(\frac{R_{t}^{*}}{R^{*}}\right)=\phi_{\pi}^{*} \log \left(\frac{\Pi_{t}^{*}}{\Pi^{*}}\right)+\phi_{y}^{*} \log \left(\frac{y_{t}^{* H}}{y^{* H}}\right)+\phi_{\epsilon}^{*} \log \left(\frac{\epsilon_{t}}{\epsilon}\right)
\end{gathered}
$$

where $\phi_{\pi}, \phi_{y}, \phi_{e} \hat{\phi}_{\pi}^{*}, \phi_{y}^{*}, \phi_{\epsilon}^{*} \geq 0$ are respectively feedback monetary policy coefficients on inflation, output and exchange rate changes in each country (recall that $\epsilon_{t} \equiv S_{t} / S_{t-1}$ ). As above, for simple computational reasons (recall subsection 6.2), we will switch off the reaction to the output gap in the optimized policy rules. But now there are some differences. First, in (33)-(34), we also allow for reaction to exchange rate changes following e.g. Benigno et al. (2007). Also, as already said in subsection 4.3.2 above, now, if we want to ensure that the ZLB is not violated, we need to restrict the range of feedback coeffcients in the national monetary policy rules, $\phi_{\pi}, \phi_{\epsilon}, \phi_{\pi}^{*}, \phi_{\epsilon}^{*}$, so as $R_{t}, Q_{t}, R_{t}^{*}, Q_{t}^{*}>1$ (see at the end of this subsection for details). Thus, the results presented below will be constrained by the ZLB.

Since money is neutral in a steady state with zero inflation, the exchange rate regime does not affect the real allocation in the steady state solution, nor the calibration stage. Thus, 
possible differences would appear along the transition only. Using the same parameterization as above, results under flexible exchange rates are reported in Table 15. Numbers in parentheses report welfare levels in the benchmark case of a currency union as summarized in Table 5 , other things equal. Welfare gains/losses are again in terms of percentage consumption equivalents; a positive number means a gain vis-a-vis the case of a currency union and vice versa with a negative number.

Table 15: Flexible exchange rates versus a currency union (without premia in the reformed steady state)

\begin{tabular}{ccccc}
\hline \hline & 2 periods & 4 periods & 20 periods & lifetime \\
\hline \hline \multirow{2}{*}{ Home (Germany) } & 0.1247 & 0.2457 & 1.0615 & 3.053 \\
& $(0.1424)$ & $(0.2751)$ & $(1.0543)$ & $(2.8979)$ \\
\hline welfare gain/loss & -0.006 & -0.0061 & 0.0004 & 0.0026 \\
\hline \multirow{2}{*}{ Foreign (Italy) } & -0.0404 & -0.0291 & 0.4479 & 2.9163 \\
& $(-0.0421)$ & $(-0.0099)$ & $(0.4585)$ & $(2.765)$ \\
\hline welfare gain/loss & 0.0006 & -0.004 & -0.0006 & 0.0033
\end{tabular}

Notes: (i) Optimized policy coefficients under flexible exchange rates $\phi_{\pi}=1.2, \phi_{\pi}^{*}=1.9695$, $\phi_{\epsilon}=1.025, \phi_{\epsilon}^{*}=6.47, \gamma_{l}^{g}=0.0829, \gamma_{l}^{* g}=0.5583, \gamma_{l}^{l}=\gamma_{l}^{* l}=\gamma_{l}^{c}=\gamma_{l}^{k}=\gamma_{l}^{n}=0$, $\gamma_{l}^{* c}=\gamma_{l}^{* k}=\gamma_{l}^{* n}=0$ and $\rho^{\beta^{*}}=0$ (ii) We set $\eta \equiv 0.5$ (iii) Results in a currency union regime in parentheses. (iv) Welfare gains/losses are in terms of consumption equivalents.

The results reveal that a switch to flexible exchange rate could be beneficial in terms of lifetime utility in each country (simply because policymakers can now use more instruments), although the gains are small in both countries in terms of consumption equivalents. This is a typical result in this family of New Keynesian models (see e.g. Schmitt-Grohé and Uribe, 2016, who also review the related literature). Obviously, the arguments for monetary policy independence are expected to become even weaker, had we included policy credibility problems that naturally arise in the case of independent monetary policies (made possible by flexible exchange rate regimes) in inflation-prone countries like Italy. But, keeping these caveats in mind, the main messages do not change; for instance, the magnitude of most fiscal feedback policy coefficients remains close to that in Table 5, which again means that fiscal consolidation should take place via government consumption spending cuts. On the other hand, there are some new results for monetary policy. For instance, the optimal reaction of national policy interest rates to inflation, $\phi_{\pi}$ and $\phi_{\pi}^{*}$, is higher than in the currency union regime with a single 
policy interest rate (this is discussed in the next paragraph). Also, observe that the optimal reaction to exchange rate changes is relatively high in both countries, and especially in Italy (see the optimized value of $\phi_{\epsilon}^{*}$ ), meaning that active intervention in the foreign exchange rate is desirable.

We close this regime with some results coming from the response functions (available in Appendix 9). As a consequence of debt consolidation in Italy, nominal interest rates, as well as inflation rates, fall by more under flexible exchange rates than in a currency union and this happens in both countries; as Erceg and Lindé (2013) explain, the single currency-union central bank provides relatively little accommodation given its focus on union-wide averages. ${ }^{54}$ Our response functions also show that, in the debt consolidating country, the real interest rate is lower in a currency union than under flexible exchange rates, which induces a stronger crowding-in of capital and eventually a higher output over time; only, on impact, output is higher under flexible exchange rates in Italy. Recall that all this is with optimized policy rules.

\section{Conclusions, discussion of policy and extensions}

This paper has studied fiscal and monetary policy in a New Keynesian model consisting of two heterogeneous countries being part of a monetary union. We have used simple, implementable and optimized feedback policy rules for all main categories of taxes and public spending, as well as for the union-wide nominal interest rate, in order to study the general equilibrium implications of fiscal consolidation in a high-debt member country. A general result is that the fiscal policy mix is important for both countries. Another main result is that, although there is a conflict of national interests in shorter horizons, there is a common interest in the medium and longer term. This is with optimized policy rules. By contrast, debt consolidation is welfare inferior to non-consolidation for both countries and all the time, if it is implemented in an ad hoc way, like an increase in income taxes.

Regarding the way of modelling policy, here we adopted a rules-based approach. That is, we assumed that policy instruments follow simple, implementable and optimized policy rules, which means that their values deviate optimally from their trend values, where these

\footnotetext{
${ }^{54}$ Under independent monetary policies, national central banks have extra incentives to go for cuts in their policy rates (for instance, other things equal, an interest rate cut results in exchange rate depreciation that may improve competitiveness). In our model, this implies that if the optimal choice of $\phi_{\pi}, \phi_{\epsilon}, \phi_{\pi}^{*}, \phi_{\epsilon}^{*}$ is left unconstrained, the policy nominal interest rates have a tendency to violate their ZLB. In the results reported here, we have imposed restrictions upon the range of $\phi_{\pi}, \phi_{\epsilon}, \phi_{\pi}^{*}, \phi_{\epsilon}^{*}$ so this does not happen. Nevertheless, we report that our main normative results do not depend on whether we force the computations to respect the ZLB or not. See e.g. Erceg and Lindé (2013) for a detailed study of monetary policy, both constrained and unconstrained by the ZLB, in a currency union and under flexible exchange rates.
} 
trend values are set to the data averages. We realize that there are alternative approaches to modelling policy. They include Ramsey-Chamley-Judd type of policy (meaning completely optimal policy rules), Markov-perfect policy (meaning optimal policy in the absence of rules), or the type of policy pioneered by Mirrlees (1971) and extended more recently by the so-called New Dynamic Public Finance policy (meaning models of optimal taxation under asymmetric information). Here, in accordance with most of the related literature on debt consolidation (see the Introductory section above), we focused on optimized rules. We believe that this approach to policy can be justified given the institutional and political constraints that usually do not allow for a fully optimal policy, especially fiscal policy (see also Schmitt-Grohé and Uribe, 2005, and Kirsanova et al., 2007).

This work can be extended in several ways. Distributional implications of debt consolidation, like those mentioned in subsection 6.5, can be studied in more detail and by using other forms of agent heterogeneity. Also, we could add extra types of cross-border effects, like international public goods/bads and labor mobility (migration) and then reevaluate the possible benefits of international cooperation. We leave these extensions for future work. 


\section{References}

[1] Alesina A., De Broeck M., Prati A. and Tabellini G., 1992. Default risk, Economic Policy, $15,427-463$.

[2] Alesina A. and Perotti R., 1997. Fiscal adjustments in OECD countries: composition and macroeconomic effects, IMF Staff Papers, 44, 210-248.

[3] Alesina A. and Ardagna S., 1998. Tales of fiscal adjustment, Economic Policy, 13, 489-517.

[4] Alesina A., Favero C. and Giavazzi F., 2015. The output effect of fiscal consolidations, Journal of International Economics, 96, 19-42.

[5] Arellano C., 2008. Default risk and income fluctuations in emerging economies, American Economic Review, 98, 690-712.

[6] Almeida V., Castro G., Félix R.M. and Maria J.R., 2013. Fiscal consolidation in a small euro-area economy. International Journal of Central Banking, 9, 1-38.

[7] Batini N., Levine P. and Pearlman J., 2009. Monetary and fiscal rules in an emerging small open economy, IMF Working Paper, no 09/22, IMF.

[8] Baxter M. and King R., 1993, Fiscal policy in general equilibrium, American Economic Review, 83, 315-334.

[9] Becker G. and Mulligan C., 1997. The endogenous determination of time preference, Quarterly Journal of Economics, 112, 729-758.

[10] Beetsma R. and Jensen H., 2005. Monetary and fiscal policy interactions in a microfounded model of a monetary union, Journal of International Economics, 67, 320-352.

[11] Benigno G., Benigno P. and Ghironi F., 2007. Interest rate rules for fixed exchange regimes, Journal of Economic Dynamics and Control, 31, 2196-2211.

[12] Benigno G. and Benigno P., 2008. Exchange rate determination under interest rate rules, Journal of International Money and Finance, 27, 971-993.

[13] Benigno P. and Romei F., 2014. Debt deleveraging and the exchange rate, Journal of International Economics, 93, 1-16.

[14] Benigno P., Eggertsson G. and Romei F., 2014. Dynamic debt deleveraging and optimal monetary policy, NBER WP no. 20556, NBER. 
[15] Bi H., 2012. Sovereign default risk premia, fiscal limits and fiscal policy, European Economic Review, 56, 389-410.

[16] Bi H. and Kumhof M., 2011. Jointly optimal monetary and fiscal policy rules under liquidity constraints, Journal of Macroeconomics, 33, 373-389.

[17] Bi H., Leeper E. and Leith C., 2013. Uncertain fiscal consolidations, Economic Journal, 123, F31-F63.

[18] Blanchard O. and Giavazzi F., 2003. Macroeconomic effects of regulation and deregulation in goods and labor markets, Quarterly Journal of Economics, 879-907.

[19] Boissay F., Collard F. and Smets F.,, 2016. Booms and banking crises, Journal of Political Economy, 124, 489-538.

[20] Cantore C., Levine P., Melina G. and Pearlman J., 2017. Optimal fiscal and monetary policy, debt crisis and management, University of Surrey, School of Economics, Discussion Paper no. 0217.

[21] Checherita-Westphal C. and Rother P., 2012. The impact of high government debt on economic growth and its channels: An empirical investigation for the euro area, European Economic Review, 56, 1392-1405.

[22] Choi H., Mark N. and Sul D., 2008. Endogenous discounting, the world saving glut and the US current account, Journal of International Economics, 75, 30-53.

[23] Clinton K., Kumhof M., Laxton D. and Mursula S., 2011. Deficit reduction: short-term pain for long-term gain, European Economic Review, 55, 118-139.

[24] Coenen G., Mohr M. and Straub R., 2008. Fiscal consolidation in the euro area: Long-run benefits and short-run costs, Economic Modelling, 25, 912-932.

[25] Cøenen G., Erceg C., Freedman C., Furceri D., Kumhof M., Lalonde R., Laxton D., Lindé J., Mourougane A., Muir D., Mursula S., Resende de C.,, Roberts J., Roeger W., Snudden S., Tranbandt M. and Veld in't J., 2012. Effects of fiscal stimulus in structural models, American Economic Journal: Macroeconomics, 4, 22-68.

[26] Cogan J., Taylor J., Wieland V. and Wolters M., 2013. Fiscal consolidation strategy, Journal of Economic Dynamics and Control, 37, 404-421.

[27] Collard F. and Dellas H., 2006. Price rigidity and the selection of the exchange rate regime, Open Economies Review, 17, 5-26. 
[28] Corsetti G., Kuester K., Meier A. and Muller G., 2013. Sovereign risk, fiscal policy and macroeconomic stability, Economic Journal, 123, F99-F132.

[29] Cúrdia V. and Woodford M., 2010. Conventional and unconventional monetary policy, Federal Reserve Bank of St Louis Review, 92, 229-264.

[30] Cúrdia V. and Woodford M., 2011. The central bank balance-sheet as an instrument of monetary policy, Journal of Monetary Economics, 58, 54-79.

[31] D' Erasmo P., Mendoza E. and Zhang J., 2016. What is a sustainable public debt?, in Handbook of Macroeconomics, volume 2, edited by J. Taylor and H. Uhlig, North-Holland, Amsterdam.

[32] Dellas H. and Tavlas G., 2005. Wage rigidity and monetary union, Economic Journal, 115, 907-927.

[33] Doepke M. and Zilibotti F., 2008. Occupational choice and the spirit of capitalism, Quarterly Journal of Economics, 123, 747-793.

[34] Eaton J. and Gersovitz M., 1981. Debt with potential repudiation: Theoretical and empirical analysis, Review of Economic Studies, 48, 289-309.

[35] Economides G., Philippopoulos A. and Varthalitis P., 2016. Monetary union, even higher integration, or back to national currencies?, CESifo Economic Studies, 62, 232-255.

[36] EEAG Report on the European Economy, 2012, 2013, 2014, 2015, 2016, 2017. CESifo, Munich.

[37] EMU Public Finances, 2011, 2012, 2013, 2014, 2015, 2016. European Commission, Brussels.

[38] Ercèg C. and Lindé J., 2013. Fiscal consolidation in a currency union: Spending cuts vs. tax hikes, Journal of Economic Dynamics and Control, 37, 422-445.

[39] Fernández-Villaverde J., Gordon G., Guerron-Quintana P. and Rubio-Ramirez J., 2015. Nonlinear adventures at the zero lower bound, Journal of Economic Dynamics and Control, $57,182-204$.

[40] Forni L., Gerali A. and Pisani M., 2010. The macroeconomics of fiscal consolidation in euro area countries, Journal of Economic Dynamics and Control, 34, 1791-1812. 
[41] Galí J. and Monacelli T., 2005. Monetary policy and exchange rate volatility in a small open economy, Review of Economic Studies, 72, 707-734.

[42] Galí J. and Monacelli T., 2008. Optimal monetary and exchange rate policy in a currency union, Journal of International Economics, 76, 116-132.

[43] Galí J., 2008. Monetary Policy, Inflation and the Business Cycle: An Introduction to the New Keynesian Framework, Princeton University Press.

[44] Giavazzi F. and Pagano M., 1990. Can severe fiscal contractions be expansionary? Tales of two small European countries, in NBER Macroeconomics Annal, edited by Blanchard O. and Fischer S., MIT Press, Cambridge, 75-110.

[45] Kirsanova T., Satchi M., Vines D. and Wren-Lewis S., 2007. Optimal/fiscal policy rules in a monetary union, Journal of Money, Credit and Banking, 39, 1759-1784.

[46] Kirsanova T., Leith C. and Wren-Lewis S., 2009. Monetary and fiscal policy interaction: the current consensus assignment in the light of recent developments, Economic Journal, 119, F482-F495.

[47] Kirsanova T. and Wren-Lewis S., 2012. Optimal fiscal feedback on debt in an economy with nominal rigidities, Economic Journal, 122, 238-264.

[48] Kiyotaki N. and Moore J., 1997. Credit cycles, Journal of Political Economy, 105, 211-248.

[49] Kollmann R., 2008. Welfare-maximizing operational monetary and tax policy rules, Macroeconomic Dynamics, 12, 112-125.

[50] Leeper E., 1991. Equilibria under active and passive monetary and fiscal policies, Journal of Monetary Economics, 27, 129-147.

[51] Leeper-E., Plante M. and Traum N., 2009. Dynamics of fiscal financing in the United States, Journal of Econometrics, 156, 304-321.

[52] Leith C. and Wren-Lewis S., 2008. Interactions between monetary and fiscal policy under flexible exchange rates, Journal of Economic Dynamics and Control, 32, 2854-2882.

[53] Lucas R., 1990. Supply side economics: An analytical review, Oxford Economic Papers, 42, 293-316.

[54] Mendoza E. and Tesar L., 2005. Why hasn't tax competition triggered a race to the bottom? Some quantitative lessons from the EU, Journal of Monetary Economics, 52, 163-204. 
[55] Mirrlees J., 1971. An exploration in the theory of optimum income taxation, Review of Economic Studies, 38, 175-208.

[56] Okano E., 2014. How important is fiscal policy cooperation in a currency union?, Journal of Economic Dynamics and Control, 38, 266-286.

[57] Philippopoulos A., Varthalitis P. and Vassilatos V., 2015. On the optimal mix of monetary and fiscal policy actions in a closed economy, Economic Modelling, 48, 175-188.

[58] Philippopoulos A., Varthalitis P. and Vassilatos V., 2016. Fiscal consolidation in an open economy with sovereign premia, forthcoming in International Journal of Central Banking.

[59] Priftis R. and Vogel L., 2016, The portfolio balance mechanism and QE in the euro area, forthcoming in Manchester School.

[60] Reinhart C. and Rogoff K., 2010. Growth in a time of debt, American Economic Review, $100,573-578$.

[61] Schmitt-Grohé S. and Uribe M., 2003. Closing small open economies, Journal of International Economics, 61, 163-185.

[62] Schmitt-Grohé S. and Uribe M., 2004. Solving dynamic general equilibrium models using a second-order approximation to the policy function, Journal of Economic Dynamics and Control, 28, 755-775.

[63] Schmitt-Grohé S. and Uribe M., 2005. Optimal fiscal and monetary policy in a mediumscale macroeconomic model, in NBER Macroeconomics Annual, edited by Gertler M. and Rogoff K., MIT Press, Cambridge MA, 385-425.

[64] Schmitt-Grohe S. and Uribe M., 2007. Optimal simple and implementable monetary and fiscal rules, Journal of Monetary Economics, 54, 1702-1725.

[65] Schmitt-Grohé S. and Uribe M., 2016. Downward nominal wage rigidity, currency pegs and involuntary unemployment, Journal of Political Economy, 124, 1466-1514.

[66] Uribe M. and Yue V., 2006. Country spreads and emerging countries: who drives whom?, Journal of International Economics, 69, 6-36.

[67] Wren-Lewis S., 2010. Macroeconomic policy in light of the credit crunch: the return of counter-cyclical fiscal policy?, Oxford Review of Economic Policy, 26, 71-86. 
[68] Yun T., 1996. Nominal price rigidity, money supply endogeneity and business cylces, Journal of Monetary Economics, 37, 345-370.

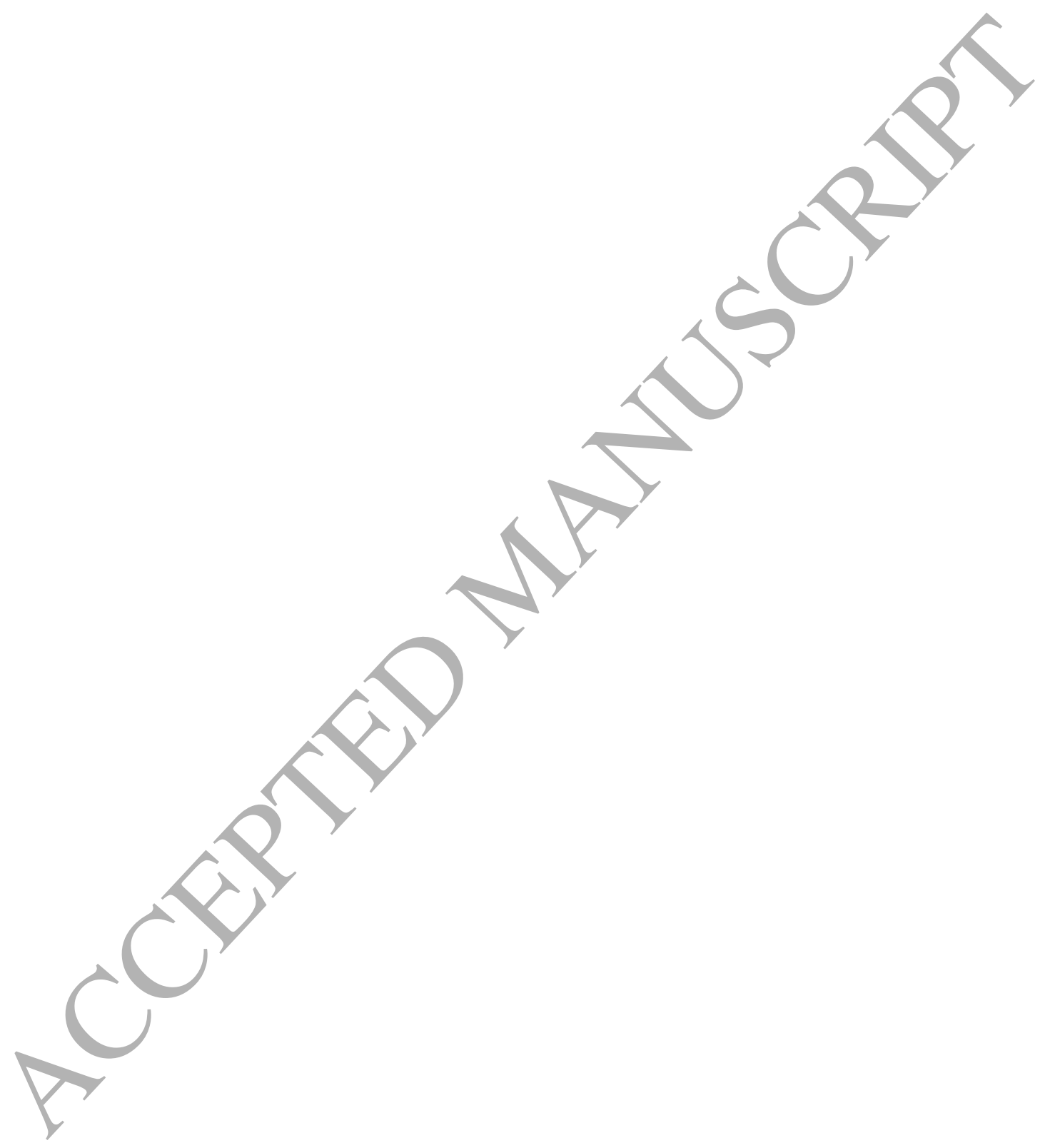




\section{Appendix 1: Households}

This Appendix presents the solution of the household's problem in the domestic country (the problem of the household in the foreign country is analogous except otherwise said). In each country, there are $i=1,2, \ldots, . N$ identical households who act competitively.

\subsection{Household's optimality conditions}

Each domestic household $i$ maximizes (7)-(8) subject to (1)-(6), (9)-(10) in the main text. The first-order conditions include the constraints plus:

$$
\begin{aligned}
& \frac{\partial u_{i, t}}{\partial c_{i, t}} \frac{\partial c_{i, t}}{\partial c_{i, t}^{H}} \frac{P_{t}}{P_{t}^{H}\left(1+\tau_{t}^{c}\right)}= \\
& =\beta E_{t} \frac{\partial u_{i, t+1}}{\partial c_{i, t+1}} \frac{\partial c_{i, t+1}}{\partial c_{i, t+1}^{H}} \frac{P_{t+1}}{P_{t+1}^{H}\left(1+\tau_{t+1}^{c}\right)} R_{t} \frac{P_{t}}{P_{t+1}} \\
& \frac{\partial u_{i, t}}{\partial c_{i, t}} \frac{\partial c_{i, t}}{\partial c_{i, t}^{H}} \frac{P_{t}}{P_{t}^{H}\left(1+\tau_{t}^{c}\right)} \frac{S_{t} P_{t}^{*}}{P_{t}}= \\
& =\beta E_{t} \frac{\partial u_{i, t+1}}{\partial c_{i, t+1}} \frac{\partial c_{i, t+1}}{\partial c_{t+1}^{H}} \frac{P_{t+1}}{P_{t+1}^{H}\left(1+\tau_{t+1}^{c}\right)} Q_{t} \frac{S_{t+1} P_{t+1}^{*}}{P_{t+1}} \frac{P_{t}^{*}}{P_{t+1}^{*}} \\
& \frac{\partial u_{i, t}}{\partial c_{i, t}} \frac{\partial c_{i, t}}{\partial c_{i, t}^{H}} \frac{1}{\left(1+\tau_{t}^{c}\right)}\left\{1+\xi\left(\frac{k_{i, t}}{k_{i, t}-1}-1\right)\right\}= \\
& =\beta E_{t} \frac{\partial u_{i, t+1}}{\partial c_{i, t+1}} \frac{\partial c_{i, t+1}}{\partial c_{i, t+1}^{H}} \frac{1}{\left(1+\tau_{t+1}^{c}\right)}\left\{\begin{array}{c}
(1-\delta)-\frac{\xi}{2}\left(\frac{k_{i, t+1}}{k_{i, t}}-1\right)^{2}+ \\
\xi\left(\frac{k_{i, t+1}}{k_{i, t}}-1\right) \frac{k_{i, t+1}}{k_{i, t}}+\left(1-\tau_{t+1}^{k}\right) r_{t+1}^{k}
\end{array}\right\} \\
& \chi_{m} \frac{\partial u_{i, t}}{\partial m_{i . t}}=\frac{\partial u_{i, t}}{\partial c_{i, t}} \frac{\partial c_{i, t}}{\partial c_{i, t}^{H}} \frac{P_{t}}{P_{t}^{H}\left(1+\tau_{t}^{c}\right)}-\beta E_{t} \frac{\partial u_{i, t+1}}{\partial c_{i, t+1}} \frac{\partial c_{i, t+1}}{\partial c_{i, t+1}^{H}} \frac{P_{t+1}}{P_{t+1}^{H}\left(1+\tau_{t+1}^{c}\right)} \frac{P_{t}}{P_{t+1}} \\
& -\chi_{n} \frac{\partial u_{i, t}}{\partial n_{i, t}}=\frac{\left(1-\tau_{t}^{n}\right)}{\left(1+\tau_{t}^{c}\right)} w_{t} \frac{\partial u_{i, t}}{\partial c_{i, t}} \frac{\partial c_{i, t}}{\partial c_{i, t}^{H}} \frac{P_{t}}{P_{t}^{H}} \\
& \frac{c_{i, t}^{H}}{c_{i, t}^{F}}=\frac{\nu}{1-\nu} \frac{P_{t}^{F}}{P_{t}^{H}} \\
& c_{i, t}^{H}(h)=\left[\frac{P_{t}^{H}(h)}{P_{t}^{H}}\right]^{-\phi} c_{i, t}^{H} \\
& c_{i, t}^{F}(f)=\left[\frac{P_{t}^{F}(f)}{P_{t}^{F}}\right]^{-\phi} c_{i, t}^{F}
\end{aligned}
$$

Equations (35)-(37) are respectively the Euler equations for domestic government bonds, foreign assets and domestic capital, (38) is the optimality condition for money balances and (39) is the optimality condition for work hours. Finally, (40) shows the optimal allocation between domestic goods $h$ and foreign goods $f$, while (41) and (42) show the optimal demand 
for each variety of domestic and foreign goods respectively.

\subsection{Implications for price bundles}

Equations (40), (41) and (42), combined with the household's budget constraints, imply that the three price indexes are:

$$
\begin{gathered}
P_{t}=\left(P_{t}^{H}\right)^{\nu}\left(P_{t}^{F}\right)^{1-\nu} \\
P_{t}^{H}=\left[\sum_{h=1}^{N}\left[P_{t}^{H}(h)\right]^{1-\phi}\right]^{\frac{1}{1-\phi}} \\
P_{t}^{F}=\left[\sum_{f=1}^{N}\left[P_{t}^{F}(f)\right]^{1-\phi}\right]^{\frac{1}{1-\phi}}
\end{gathered}
$$

\section{Appendix 2: Firms}

This Appendix presents the solution of the firm's problem in the domestic country (the problem of the firm in the foreign country is analogous except otherwise said). There are $h=1,2, \ldots, . N$ domestic firms. Each firm $h$ produces a differentiated good of variety $h$ under monopolistic competition facing Calvo-type nominal fixities.

\subsection{Demand for the firm's product}

Each domestic firm $h$ faces demand for its product, $y_{t}^{H}(h)$. The latter comes from domestic households' priyate consumption and investment, $C_{t}^{H}(h)$ and $X_{t}(h)$, where $C_{t}^{H}(h) \equiv$ $\sum_{i=1}^{N} c_{i, t}^{H}(h)$ and $X_{t}(h) \equiv \sum_{i=1}^{N} x_{i, t}(h)$, from the domestic government, denoted as $G_{t}(h)$, from the financial intermediary which is located in the domestic country, denoted as $\Upsilon_{t}(h),{ }^{55}$ and from foreign households' consumption of the domestic good, $C_{t}^{F *}(h)$, where $C_{t}^{F *}(h) \equiv$ $\sum_{i=1}^{N *} c_{i, t}^{F *}(h)$. Thus, aggregate demand for each good $h$ is:

$$
y_{t}^{H}(h)=C_{t}^{H}(h)+X_{t}(h)+G_{t}(h)+\Upsilon_{t}(h)+C_{t}^{F *}(h)
$$

\footnotetext{
${ }^{55}$ That is, as in e.g. Cúrdia and Woodford (2010 and 2011), any resources consumed by the bank for the monitoring of its financial operations will be part of the aggregate demand for the Dixit-Stiglitz composite good. The bank uses real resources in the period in which the loan is originated; see below for further details.
} 
Since we have:

$$
\begin{aligned}
c_{i, t}^{H}(h) & =\left[\frac{P_{t}^{H}(h)}{P_{t}^{H}}\right]^{-\phi} c_{i, t}^{H} \\
x_{i, t}(h) & =\left[\frac{P_{t}^{H}(h)}{P_{t}^{H}}\right]^{-\phi} x_{i, t} \\
G_{t}(h) & =\left[\frac{P_{t}^{H}(h)}{P_{t}^{H}}\right]^{-\phi} G_{t} \\
\Upsilon_{t}(h) & =\left[\frac{P_{t}^{H}(h)}{P_{t}^{H}}\right]^{-\phi} \Upsilon_{t} \\
c_{i, t}^{F *}(h) & =\left[\frac{P_{t}^{F *}(h)}{P_{t}^{F *}}\right]^{-\phi} c_{i, t}^{F *}
\end{aligned}
$$

we can rewrite it as:

$$
y_{t}^{H}(h)=\left[\frac{P_{t}^{H}(h)}{P_{t}^{H}}\right]^{-\phi}\left[C_{t}^{H}+X_{t}+G_{t}+\Upsilon_{t}+C_{t}^{F *}\right]
$$

where $C_{t}^{H} \equiv \sum_{i=1}^{N} e_{i, t}^{H}$ is total private consumption of home goods, $X_{t} \equiv \sum_{i=1}^{N} x_{i, t}$ is total private investment, $C_{t}^{F *} \equiv \sum_{i=1}^{N *} c_{i, t}^{F *}$ is total private consumption of home goods by households in the foreign country (i.e. domestic country's exports), $G_{t}$ denotes total government purchases of domestic output and $\Upsilon_{t}$ denotes total resources consumed by the financial intermediary. Also notice that the law of one price implies that in (51):

$$
\frac{P_{t}^{F *}(h)}{P_{t}^{F *}}=\frac{\frac{P_{t}^{H}(h)}{S_{t}}}{\frac{P_{t}^{H}}{S_{t}}}=\frac{P_{t}^{H}(h)}{P_{t}^{H}}
$$

Since aggregate demand, $Y_{t}^{H}$, is (see also Schmitt-Grohé and Uribe, 2007):

$$
Y_{t}^{H}=C_{t}^{H}+X_{t}+G_{t}+\Upsilon_{t}+C_{t}^{F *}
$$


aggregate demand for each good $h$ is rewritten as:

$$
y_{t}^{H}(h)=\left[\frac{P_{t}^{H}(h)}{P_{t}^{H}}\right]^{-\phi} Y_{t}^{H}
$$

\subsection{Firm's problem}

As said in the main text, each domestic firm $h$ maximizes real profits:

$$
\widetilde{\omega}_{t}(h) \equiv \frac{P_{t}^{H}(h)}{P_{t}} y_{t}^{H}(h)-\frac{P_{t}^{H}}{P_{t}} r_{t}^{k} k_{t-1}(h)-w_{t} n_{t}(h)
$$

where the maximization is subject to the production function:

$$
y_{t}^{H}(h)=A_{t}\left[k_{t-1}(h)\right]^{\alpha}\left[n_{t}(h)\right]^{1}
$$

and the demand function for each $h$ 's product as derived above:

$$
y_{t}^{H}(h)=\left[\frac{P_{t}^{H}(h)}{P_{t}^{H}}\right]^{-\phi} Y_{t}^{H}
$$

As said in the text, firms choose their prices facing a nominal fixity. In each period, firm $h$ faces an exogenous probability $\theta$ of not being able to reset its price. A firm $h$, which is able to reset its price, chooses its price $P_{t}^{\#}(h)$ to maximize the sum of discounted expected nominal profits for the next $k$ periods in which it may have to keep its price fixed.

\subsection{Firm's optimality conditions}

To solve the firm's problem, following most of the related literature, we work in two steps. We first solve a cost minimization problem, where each firm $h$ minimizes its cost by choosing factor input given technology and prices. In turn, given this cost function, each firm, if it is able to reset its price, solves a maximization problem by choosing its price.

The cost mimimization problem (written in real terms) is:

$$
r_{t}^{k} \frac{P_{t}^{H}}{P_{t}} k_{t-1}(h)+w_{t} n_{t}(h)+m c_{t}(h)\left[y_{t}(h)-A_{t}\left[k_{t-1}(h)\right]^{\alpha}\left[n_{t}(h)\right]^{1-\alpha}\right]
$$

where the production level, $y_{t}(h)$, is taken as given and $m c_{t}(h)$ denotes the real marginal cost or, equivalently, the multiplier associated with the production level. 
The solution gives the input demand functions:

$$
\begin{aligned}
& w_{t}=m c_{t}(h)(1-a) A_{t}\left[k_{t-1}(h)\right]^{\alpha}\left[n_{t}(h)\right]^{-\alpha} \\
& \frac{P_{t}^{H}}{P_{t}} r_{t}^{k}=m c_{t}(h) a A_{t}\left[k_{t-1}(h)\right]^{\alpha-1}\left[n_{t}(h)\right]^{1-\alpha}
\end{aligned}
$$

where, in equilibrium, with constant returns to scale to private inputs, the firm's marginal cost and the capital-to-labor ratio will not depend on firm-specific variables (see also Yun, 1996, and Schmitt-Grohé and Uribe, 2007).

In turn, the firm chooses its price, $P_{t}^{\#}(h)$, to maximize the expected sum of discounted nominal profits:

$$
E_{t} \sum_{k=0}^{\infty} \theta^{k} \Xi_{t, t+k}\left\{P_{t}^{\#}(h) y_{t+k}^{H}(h)-\Psi_{t+k} \hat{\left(y_{t+k}^{H}(h)\right)}\right\}
$$

where $\Xi_{t, t+k}$ is a discount factor taken as given by the firm and defined below, $y_{t+k}^{H}(h)=$ $\left[\frac{P_{t}^{\#}(h)}{P_{t+k}^{H}}\right]^{-\phi} Y_{t+k}^{H}$ is the demand function and $\Psi_{t}(h)$ denotes the minimum nominal cost function for producing $y_{t}^{H}(h)$ at $t$ so that $\Psi_{t}^{\prime}(h)$ is the associated marginal cost $\left(\Psi_{t}^{\prime}(h)=m c_{t}(h) P_{t}\right)$.

The first-order condition for $P_{t}^{\#}(h)$ gives (see also e.g. Galí (2008, p. 44):

$$
E_{t} \sum_{k=0}^{\infty} \theta^{k} \Xi_{t, t+k}\left[\frac{P_{t}^{\#}(h)}{P_{t+k}^{H}}\right]^{-\phi} Y_{t+k}^{H}\left\{P_{t}^{\#}(h)-\frac{\phi}{\phi-1} \Psi_{t+k}^{\prime}(h)\right\}=0
$$

or, dividing by the price index, $P_{t}^{H}$, we have:

$$
E_{t} \sum_{k=0}^{\infty} \theta^{k}\left[\Xi_{t, t+k}\left[\frac{P_{t}^{\#}(h)}{P_{t+k}^{H}}\right]^{-\phi} Y_{t+k}^{H}\left\{\frac{P_{t}^{\#}(h)}{P_{t}^{H}}-\frac{\phi}{\phi-1} m c_{t+k}(h) \frac{P_{t+k}}{P_{t}^{H}}\right\}\right]=0
$$

Therefore, the behaviour of each firm $h$ is summarized by (60), (61) and (63). A recursive expression of this problem is presented below.

Note that each firm $h$, which can reset its price in period $t$, solves an identical problem, so $P_{t}^{\#}(h)=P_{t}^{\#}$ is independent of $h$, and each firm $h$, which cannot reset its price, just sets its previous period price $P_{t}^{H}(h)=P_{t-1}^{H}(h)$. Thus, the evolution of the aggregate price level is given by (see also e.g. Galí (2008, p. 62)):

$$
\left(P_{t}^{H}\right)^{1-\phi}=\theta\left(P_{t-1}^{H}\right)^{1-\phi}+(1-\theta)\left(P_{t}^{\#}\right)^{1-\phi}
$$




\section{Appendix 3: Government budget constraint}

This Appendix presents the government budget constraint in some detail. We start by presenting the domestic government's budget constraint in nominal and aggregate terms:

$$
\begin{gathered}
B_{t}+S_{t} F_{t}^{g}+M_{t}=R_{t-1} B_{t-1}+Q_{t-1} S_{t} F_{t-1}^{g}+M_{t-1}+ \\
+P_{t}^{H} G_{t}-\tau_{t}^{c}\left(P_{t}^{H} C_{t}^{H}+P_{t}^{F} C_{t}^{F}\right)-\tau_{t}^{k}\left(r_{t}^{k} P_{t}^{H} K_{t-1}+P_{t} \widetilde{\Omega}_{t}\right)-\tau_{t}^{n} W_{t} \widetilde{N}_{t}-T_{t}^{l}
\end{gathered}
$$

where $B_{t}$ is the end-of-period nominal public debt held by domestic agents, $F_{t}^{g}$ is the end-ofperiod nominal public debt held by foreign agents and expressed in foreign currency, $M_{t}$ is the end-of-period stock of nominal money balances, $C_{t}^{H} \equiv \sum_{i=1}^{N} c_{i, t}^{H}, C_{t}^{F} \equiv \sum_{i=1}^{N} c_{i, t}^{F}, K_{t-1} \equiv$ $\sum_{i=1}^{N} k_{i, t-1}, \widetilde{\Omega}_{t} \equiv \sum_{i=1}^{N} \widetilde{\omega}_{i, t}, \widetilde{N}_{t} \equiv \sum_{i=1}^{N} n_{i, t}$ and $T_{t}^{l}$ denotes the nomimal value of lump-sum taxes/transfers to households (the rest of the variables have been defined above).

Then, dividing by the current CPI, $P_{t}$, and the constant population size, $N$, we get the government budget constraint in real and per capita terms:

$$
\begin{gathered}
b_{t}+\frac{S_{t} P_{t}^{*}}{P_{t}} f_{t}^{g}+m_{t}=R_{t-1} \frac{P_{t-1}}{P_{t}} b_{t}-1+Q_{t-1} \frac{S_{t} P_{t}^{*}}{P_{t}} \frac{P_{t-1}^{*}}{P_{t}^{*}} f_{t-1}^{g}+\frac{P_{t-1}}{P_{t}} m_{t-1}+ \\
+\frac{P_{t}^{H}}{P_{t}} g_{t}-\tau_{t}^{c}\left(\frac{P_{t}^{H}}{P_{t}} c_{t}^{H}+\frac{P_{t}^{F}}{P_{t}} c_{t}^{F}\right)-\tau_{t}^{k}\left(r_{t}^{k} \frac{P_{t}^{H}}{P_{t}} k_{t-1}+\widetilde{\omega}_{t}\right)-\tau_{t}^{n} w_{t} n_{t}-\tau_{t}^{l}
\end{gathered}
$$

where small letters denote real and per capita quantities, namely, $b_{t} \equiv \frac{B_{t}}{P_{t} N}, f_{t}^{g} \equiv \frac{F_{t}^{g}}{P_{t}^{*} N}$, $m_{t} \equiv \frac{M_{t}}{P_{t} N}, g_{t} \equiv \frac{G_{t}}{N}, c_{t}^{H} \equiv \frac{C_{t}^{H}}{N}, c_{t}^{F} \equiv \frac{C_{t}^{F}}{N}, k_{t-1} \equiv \frac{K_{t-1}}{N}, \widetilde{\omega}_{t} \equiv \frac{\widetilde{\Omega}_{t}}{N}, n_{t} \equiv \frac{\widetilde{N}_{t}}{N}$ and where $\tau_{t}^{l} \equiv \frac{T_{t}^{l}}{P_{t} N}$ denotes the lump-sum real tax/transfer given to each household (see the household's budget constraint).

For convenience, let $D_{t} \equiv B_{t}+S_{t} F_{t}^{g}$ denote the total nominal public debt issued by the domestic government. This debt can be held by domestic private agents, $\lambda_{t} D_{t}$, and by foreign private agents, $S_{t} F_{t}^{g}=\left(1-\lambda_{t}\right) D_{t}$, where $0 \leq \lambda_{t} \leq 1$. Then, the above government budget constraint is rewritten as:

$$
\begin{gathered}
d_{t}+m_{t}=R_{t-1} \lambda_{t-1} \frac{P_{t-1}}{P_{t}} d_{t-1}+\frac{P_{t-1}}{P_{t}} m_{t-1}+ \\
+Q_{t-1} \frac{S_{t} P_{t}^{*}}{P_{t}} \frac{P_{t-1}^{*}}{P_{t}^{*}} \frac{P_{t-1}}{P_{t-1}^{*} S_{t-1}}\left(1-\lambda_{t-1}\right) d_{t-1}+\frac{P_{t}^{H}}{P_{t}} g_{t}-\tau_{t}^{c}\left(\frac{P_{t}^{H}}{P_{t}} c_{t}^{H}+\frac{P_{t}^{F}}{P_{t}} c_{t}^{F}\right) \\
-\tau_{t}^{k}\left(r_{t}^{k} \frac{P_{t}^{H}}{P_{t}} k_{t-1}+\widetilde{\omega}_{t}\right)-\tau_{t}^{n} w_{t} n_{t}-\tau_{t}^{l}
\end{gathered}
$$

Thus, the liabilities of the domestic government as a share of output are (expressed in real 
and per capita terms):

$$
l_{t} \equiv \frac{R_{t} \lambda_{t} d_{t}+Q_{t} \frac{S_{t+1}}{S_{t}}\left(1-\lambda_{t}\right) d_{t}}{\frac{P_{t}^{H}}{P_{t}} y_{t}^{H}}
$$

Similarly, the government budget constraint in real and per capita terms in the foreign country is:

$$
\begin{gathered}
b_{t}^{*}+\frac{P_{t}}{P_{t}^{*} S_{t}} f_{t}^{* g}+m_{t}^{*}=R_{t-1}^{*} \frac{P_{t-1}^{*}}{P_{t}^{*}} b_{t-1}^{*}+Q_{t-1}^{*} \frac{P_{t}}{P_{t}^{*} S_{t}} \frac{P_{t-1}}{P_{t}} f_{t-1}^{* g}+\frac{P_{t-1}^{*}}{P_{t}^{*}} m_{t-1}^{*}+ \\
+\frac{P_{t}^{* H}}{P_{t}^{*}} g_{t}^{*}-\tau_{t}^{* c}\left(\frac{P_{t}^{* H}}{P_{t}^{*}} c_{t}^{* H}+\frac{P_{t}^{* F}}{P_{t}^{*}} c_{t}^{* F}\right)-\tau_{t}^{* k}\left(r_{t}^{* k} \frac{P_{t}^{* H}}{P_{t}^{*}} k_{t-1}^{*}+\widetilde{\omega}_{t}^{*}\right)-\tau_{t}^{* n} w_{t}^{*} n_{t}^{*}-\tau_{t}^{* l}
\end{gathered}
$$

Let denote $D_{t}^{*}$ to be the total foreign public debt in foreign currency. This can be held by foreign private agents, $B_{t}^{*}=\lambda_{t}^{*} D_{t}^{*}$, and by domestic private agents, $\frac{F_{t}^{* g}}{S_{t}}=\left(1-\lambda_{t}^{*}\right) D_{t}^{*}$. Then, we have:

$$
\begin{aligned}
& d_{t}^{*}+m_{t}^{*}=R_{t-1}^{*} \lambda_{t-1}^{*} \frac{P_{t-1}^{*}}{P_{t}^{*}} d_{t-1}^{*}+\frac{P_{t-1}^{*}}{P_{t}^{*}} m_{t-1}^{*}+ \\
& +Q_{t-1}^{*} \frac{P_{t}}{P_{t}^{*} S_{t}} \frac{P_{t-1}}{P_{t}} \frac{S_{t-1} P_{t-1}^{*}}{P_{t-1}}\left(1-\lambda_{t-1}^{*}\right) d_{t-1}^{*}+\frac{P_{t}^{* H}}{P_{t}^{*}} g_{t}^{*}-\tau_{t}^{* c}\left(\frac{P_{t}^{* H}}{P_{t}^{*}} c_{t}^{* H}+\frac{P_{t}^{* F}}{P_{t}^{*}} c_{t}^{* F}\right)- \\
& -\tau_{t}^{* k}\left(r_{t}^{* k} \frac{P_{t}^{* H}}{P_{t}^{*}} k_{t-1}^{*}+\widetilde{\omega}_{t}^{*}\right)-\tau_{t}^{* n} w_{t}^{*} n_{t}^{*}-\tau_{t}^{* l}
\end{aligned}
$$

Thus, the liabilities of the foreign government ăs a share of output are (expressed in real and per capita terms):

\section{Appendix 4: Financial intermediary}

The profit of the international financial intermediary from loans between $t-1$ and $t$ is distributed at time $t$. In nominal and aggregate terms, this profit is defined as: ${ }^{56}$

$$
Q_{t-1}^{*}\left[\left(F_{t-1}^{* g}-F_{t-1}^{* h}\right)-P_{t-1}^{H} \frac{\psi}{2}\left(f_{t-1}^{* g}-f_{t-1}^{* h}\right)^{2} N\right]-Q_{t-1} S_{t}\left(F_{t-1}^{h}-F_{t-1}^{g}\right)
$$

\footnotetext{
${ }^{56}$ Thus, at the beginning of period $t$, agents carry over assets and liabilities from period $t-1$. Borrowers honor their preexisting obligations to lenders. In particular, in the international capital market, where transactions take place via the bank, the bank receives interest income from borrowers and pays off the lenders. The latter is the interest payments that the bank promised at $t-1$ to pay at $t$. The bank also pays the monitoring cost associated with these transactions.
} 
where $F_{t-1}^{h} \equiv \sum_{i=1}^{N} F_{i, t-1}^{h}$ and $F_{t-1}^{* h} \equiv \sum_{i=1}^{N^{*}} F_{i, t-1}^{* h}$ are aggregate nominal international assets held by private agents in the domestic and foreign country respectively, $F_{t-1}^{g}$ and $F_{t-1}^{* g}$ are aggregate nominal foreign public debt in the domestic and foreign country respectively (see also Appendix 3 above), and $\frac{\psi}{2}\left(f_{t-1}^{* g}-f_{t-1}^{* h}\right)^{2}$ is a per capita real cost function, where $f_{t-1}^{* g}$ and $f_{t-1}^{* h}$ are respectively per capita and real foreign public debt and foreign private assets respectively and $\psi \geq 0$ is a cost parameter. That is, at any $t, f_{t}^{g} \equiv \frac{F_{t}^{g}}{P_{t}^{*} N}$ and $f_{t}^{h} \equiv \frac{\sum_{i=1}^{N} f_{i, t}^{h}}{N}$, where $f_{i, t}^{h} \equiv \frac{F_{i, t}^{h}}{P_{t}^{*}}$, and analogously for $f_{t}^{* g}$ and $f_{t}^{* h}$. Then, if $\left(F_{t-1}^{h}-F_{t-1}^{g}\right)$ is positive (resp. negative), it denotes the net asset (resp. liability) position of the domestic country in the world financial market, and similarly for $\left(F_{t-1}^{* h}-F_{t-1}^{* g}\right)$ in the foreign country. Notice that the real resources used by the bank are assumed to be consumed at the same time the interest payments/income are repaid/received, namely at time $t$, rather then when the loan contract was originated, namely at time $t-1$.

Then, dividing by the current CPI, $P_{t}$, and the constant population size, $N$, the real and per capita profit, defined as $\pi_{t}$, becomes:

$$
\pi_{t} \equiv Q_{t-1}^{*}\left[\frac{P_{t-1}}{P_{t}}\left(f_{t-1}^{* g}-f_{t-1}^{* h}\right)-\frac{P_{t}^{H}}{P_{t}} \frac{\psi}{2} \frac{P_{t-1}^{H}}{P_{t}^{H}}\left(f_{t-1}^{* g}-f_{t-1}^{* h}\right)^{2}\right]-Q_{t-1} \frac{S_{t} P_{t}^{*}}{P_{t}} \frac{P_{t-1}^{*}}{P_{t}^{*}}\left(f_{t-1}^{h}-f_{t-1}^{g}\right)
$$

Since, in equilibrium, international borrowing equals international lending at each $t$, namely, $F_{t}^{* g}-F_{t}^{* h}=S_{t}\left(F_{t}^{h}-F_{t}^{g}\right)$ in nominal and aggregate terms, or $f_{t}^{* g}-f_{t}^{* h}=\frac{S_{t} P_{t}^{*}}{P_{t}}\left(f_{t}^{h}-f_{t}^{g}\right)$ in real and per capita terms, so that $f_{t \rightarrow 1}^{* g}-f_{t-1}^{* h}=\frac{S_{t-1} P_{t-1}^{*}}{P_{t-1}}\left(f_{t-1}^{h}-f_{t-1}^{g}\right)$, this is rewritten as:

$$
\pi_{t}=Q_{t-1}^{*}\left[\frac{P_{t-1}}{P_{t}}\left(f_{t-1}^{* g}-f_{t-1}^{* h}\right)-\frac{P_{t}^{H}}{P_{t}} \frac{\psi}{2} \frac{P_{t-1}^{H}}{P_{t}^{H}}\left(f_{t-1}^{* g}-f_{t-1}^{* h}\right)^{2}\right]-Q_{t-1} \frac{S_{t}}{S_{t-1}} \frac{P_{t-1}}{P_{t}}\left(f_{t-1}^{* g}-f_{t-1}^{* h}\right)
$$

If the volume of the loan, $\left(f_{t-1}^{* g}-f_{t-1}^{* h}\right)$, is chosen optimally by the financial intermediary, the first-order condition is:

$$
Q_{t-1}^{*}=\frac{Q_{t-1} \frac{S_{t}}{S_{t-1}}}{1-\frac{P_{t-1}^{H}}{P_{t-1}} \psi\left(f_{t-1}^{* g}-f_{t-1}^{* h}\right)}
$$

In what follows, we define $Q_{t-1}^{*} \frac{\psi}{2} \frac{P_{t-1}^{H}}{P_{t}^{H}}\left(f_{t-1}^{* g}-f_{t-1}^{* h}\right)^{2} \equiv v_{t}$, where recall from above the GDP identity $Y_{t}^{H}=C_{t}^{H}+X_{t}+G_{t}+\Upsilon_{t}+C_{t}^{F *}$ in total terms or, equivalently, $y_{t}^{H}=c_{t}^{H}+x_{t}+g_{t}+v_{t}+c_{t}^{F *}$ in per capita terms. Recall that $S_{t}=1$ in a currency union regime. 


\section{Appendix 5: Equilibrium in the status quo economy}

This Appendix presents in detail the status quo equilibrium system, given feedback policy coefficients. We will work in steps.

\subsection{Market-clearing conditions and the balance of payments}

In the domestic economy, the market-clearing conditions in the capital market, the labor market, the money market, the domestic government bond market and the domestic dividend market are respectively (and similarly in the foreign country):

$$
\sum_{i=1}^{N} k_{i, t-1}=\sum_{h=1}^{N} k_{t-1}(h)
$$

$$
\sum_{i=1}^{N} n_{i, t}=\sum_{h=1}^{N} n_{t}(\hat{h})
$$

$$
\sum_{i=1}^{N} m_{i, t}=\frac{M_{t}}{P_{t}}
$$

The market-clearing condition for the profits made by the international financial intermediary (these profits are distributed to households in the domestic economy only who also bear the associated costs) is:

$$
\sum_{i=1}^{N} \pi_{i, t}=N \pi_{t}
$$

Regarding the balance of payments in each country, this is obtained by adding the con- 
straints of households, firms and the government in the country. Then, the balance of payments in the domestic country (written in real and per capita terms) is:

$$
\begin{aligned}
& \frac{P_{t}^{H}}{P_{t}}\left(c_{t}^{H}+x_{t}+g_{t}\right)+\frac{P_{t}^{F}}{P_{t}} c_{t}^{F}+Q_{t-1} \frac{S_{t} P_{t}^{*}}{P_{t}} \frac{P_{t-1}^{*}}{P_{t}^{*}}\left(f_{t-1}^{g}-f_{t-1}^{h}\right)= \\
& =\frac{S_{t} P_{t}^{*}}{P_{t}}\left(f_{t}^{g}-f_{t}^{h}\right)+\pi_{t}+\frac{\sum_{h=1}^{N} P_{t}^{H}(h) y_{t}^{H}(h)}{N P_{t}}
\end{aligned}
$$

where are variables have been defined above already.

It can be shown, by using the demand function for each firm's product, $y_{t}^{H}(h)=\left[\frac{P_{t}^{H}(h)}{P_{t}^{H}}\right]^{-\phi} Y_{t}^{H}$, and the Dixit-Stiglitz aggregation formula for aggregate absorption, $Y_{t}^{H} \equiv\left[\sum_{h=1}^{N}\left[y_{t}^{H}(h)\right]^{\frac{\phi-1}{\phi}}\right]^{\frac{\phi}{\phi-1}}$, that $\sum_{h=1}^{N} P_{t}^{H}(h) y_{t}^{H}(h)=P_{t}^{H} Y_{t}^{H}$. Hence, the last term on the RHS of the balance of payments above is $\frac{P_{t}^{H}}{P_{t}} y_{t}^{H}$, where $y_{t}^{H} \equiv \frac{Y_{t}^{H}}{N}$ is per capita domestic absorption. Therefore, the balance of payments in the domestic economy is:

$$
\begin{aligned}
& \frac{P_{t}^{H}}{P_{t}}\left(c_{t}^{H}+x_{t}+g_{t}-y_{t}^{H}\right)+\frac{P_{t}^{F}}{P_{t}} c_{t}^{F}+Q_{t-1} \frac{S_{t} P_{t}^{*}}{P_{t}^{*}} \frac{P_{t-1}^{*}}{P_{t}^{*}}\left(f_{t-1}^{g}-f_{t-1}^{h}\right)= \\
& =\frac{S_{t} P_{t}^{*}}{P_{t}}\left(f_{t}^{g}-f_{t}^{h}\right)+\pi_{t}
\end{aligned}
$$

where recall that the resources used by the financial intermediary, $v_{t} \equiv Q_{t-1}^{*} \frac{\psi}{2} \frac{P_{t-1}^{H}}{P_{t}^{H}}\left(f_{t-1}^{* g}-\right.$ $\left.f_{t-1}^{* h}\right)^{2}$, are paid by the domestic country (see Appendix 4), so that $y_{t}^{H}=c_{t}^{H}+x_{t}+g_{t}+v_{t}+c_{t}^{F *}$ (see also Appendix 2) and where (from Appendix 4) $\pi_{t} \equiv Q_{t-1}^{*} \frac{P_{t-1}}{P_{t}}\left(f_{t-1}^{* g}-f_{t-1}^{* h}\right)-\frac{P_{t}^{H}}{P_{t}} v_{t}-$ $Q_{t-1} \frac{S_{t} P_{t}^{*}}{P_{t}} \frac{P_{t-1}^{*}}{P_{t}^{*}}\left(f_{t-1}^{h}-f_{t-1}^{g}\right)$. If, in turn, we add $\frac{P_{t}^{H}}{P_{t}} v_{t}$ on both sides of the balance of payments above, we have $\frac{P_{t}^{H}}{P_{t}}\left(c_{t}^{H}+x_{t}+g_{t}+v_{t}-y_{t}^{H}\right)=-\frac{P_{t}^{H}}{P_{t}} c_{t}^{F *}$ so that the terms $-\frac{P_{t}^{H}}{P_{t}} c_{t}^{F *}+\frac{P_{t}^{F}}{P_{t}} c_{t}^{F}$ on the LHS is the trade balance.

Working similalry, we get the balance of payments in the foreign country:

$$
\begin{gathered}
\frac{P_{t}^{* H}}{P_{t}^{*}}\left(c_{t}^{* H}+x_{t}^{*}+g_{t}^{*}-y_{t}^{* H}\right)+\frac{P_{t}^{* F}}{P_{t}^{*}} c_{t}^{* F}+Q_{t-1}^{*} \frac{P_{t}}{S_{t} P_{t}^{*}} \frac{P_{t-1}}{P_{t}}\left(f_{t-1}^{* g}-f_{t-1}^{* h}\right)= \\
=\frac{P_{t}}{S_{t} P_{t}^{*}}\left(f_{t}^{* g}-f_{t}^{* h}\right)
\end{gathered}
$$

where now $y_{t}^{* H}=c_{t}^{* H}+x_{t}^{*}+g_{t}^{*}+c_{t}^{F}$.

Finally, as also said in Appendix 4 above, the market-clearing condition in the market of internationally traded assets is (written in real and per capita terms):

$$
\left(f_{t-1}^{* g}-f_{t-1}^{* h}\right)=\frac{S_{t} P_{t}^{*}}{P_{t}}\left(f_{t-1}^{h}-f_{t-1}^{g}\right)
$$

which means that net foreign liabilities in the foreign country (the LHS) are equal to net foreign assets in the domectic country (the RHS). 


\subsection{Equilibrium equations}

Given the above, equilibrium in the home country is summarized by the following equations (we omit the expectations operator in what follows):

$$
\begin{aligned}
& \frac{\partial u_{t}}{\partial c_{t}} \frac{\partial c_{t}}{\partial c_{t}^{H}} \frac{P_{t}}{P_{t}^{H}\left(1+\tau_{t}^{c}\right)}=\beta \frac{\partial u_{t+1}}{\partial c_{t+1}} \frac{\partial c_{t+1}}{\partial c_{t+1}^{H}} \frac{P_{t+1}}{P_{t+1}^{H}\left(1+\tau_{t+1}^{c}\right)} R_{t} \frac{P_{t}}{P_{t+1}} \\
& \frac{\partial u_{t}}{\partial c_{t}} \frac{\partial c_{t}}{\partial c_{t}^{H}} \frac{1}{\left(1+\tau_{t}^{c}\right)} \frac{P_{t}}{P_{t}^{H}} \frac{S_{t} P_{t}^{*}}{P_{t}}= \\
& =\beta \frac{\partial u_{t+1}}{\partial c_{t+1}} \frac{\partial c_{t+1}}{\partial c_{t+1}^{H}} \frac{1}{\left(1+\tau_{t+1}^{c}\right)} \frac{P_{t+1}}{P_{t+1}^{H}} Q_{t} \frac{S_{t+1} P_{t+1}^{*}}{P_{t+1}} \frac{P_{t}^{*}}{P_{t+1}^{*}} \\
& \frac{\partial u_{t}}{\partial c_{t}} \frac{\partial c_{t}}{\partial c_{t}^{H}} \frac{1}{\left(1+\tau_{t}^{c}\right)}\left\{1+\xi\left(\frac{k_{t}}{k_{t-1}}-1\right)\right\}= \\
& =\beta \frac{\partial u_{t+1}}{\partial c_{t+1}} \frac{\partial c_{t+1}}{\partial c_{t+1}^{H}} \frac{1}{\left(1+\tau_{t+1}^{c}\right)}\left\{(1-\delta)-\frac{\xi}{2}\left(\frac{k_{t+1}}{k_{t}}-1\right)^{2}+\xi\left(\frac{k_{t+1}}{k_{t}}-1\right) \frac{k_{t+1}}{k_{t}}+\left(1-\tau_{t+1}^{k}\right) r_{t+1}^{k}\right\} \\
& \frac{\partial u_{t}}{\partial m_{t}}=\frac{\partial u_{t}}{\partial c_{t}} \frac{\partial c_{t}}{\partial c_{t}^{H}} \frac{P_{t}}{P_{t}^{H}\left(1+\tau_{t}^{c}\right)}-\beta \frac{\partial u_{t+1}}{\partial c_{t+1}} \frac{\partial c_{t+1}}{\partial c_{t+1}^{H}} \frac{P_{t+1}}{P_{t+1}^{H}\left(1+\tau_{t+1}^{c}\right)} \frac{P_{t}}{P_{t+1}} \\
& -\frac{\partial u_{t}}{\partial n_{t}}=\left(1-\tau_{t}^{n}\right) w_{t} \frac{\partial u_{t}}{\partial c_{t}} \frac{\partial c_{t}}{\partial c_{t}^{H}} \frac{P_{t}}{P_{t}^{H}\left(1+\tau_{t}^{c}\right)} \\
& \frac{c_{t}^{H}}{c_{t}^{F}}=\frac{\nu}{1-\nu} \frac{P_{t}^{F}}{P_{t}^{H}} \\
& k_{t}=(1-\delta) k_{t-1}+x_{t}-\frac{\xi}{2}\left(\frac{k_{t}}{k_{t-1}}-1\right)^{2} k_{t-1} \\
& c_{t}=\frac{\left(c_{t}^{H}\right)^{\nu}\left(c_{t}^{F}\right)^{1-\nu}}{\nu^{\nu}(1-\nu)^{1-\nu}} \\
& w_{t}=m c_{t}(1-a) A_{t} k_{t-1}^{a} n_{t}^{-a} \\
& \frac{P_{t}^{H}}{P_{t}} r_{t}^{k}=m c_{t} a A_{t} k_{t-1}^{a-1} n_{t}^{1-a} \\
& \widetilde{\omega}_{t}=\frac{P_{t}^{H}}{P_{t}} y_{t}^{H}-\frac{P_{t}^{H}}{P_{t}} r_{t}^{k} k_{t-1}-w_{t} n_{t} \\
& \sum_{k=0}^{\infty} \theta^{k} \Xi_{t, t+k}\left[\frac{P_{t}^{\#}}{P_{t+k}^{H}}\right]^{-\phi} y_{t+k}^{H}\left\{\frac{P_{t}^{\#}}{P_{t}^{H}} \frac{P_{t}^{H}}{P_{t}} \frac{P_{t}}{P_{t-1}}-\frac{\phi}{(\phi-1)} m c_{t+k} \frac{P_{t}}{P_{t-1}} \ldots \frac{P_{t+k}}{P_{t+k-1}}\right\}=0 \\
& y_{t}^{H}=\frac{1}{\left(\frac{\widetilde{P}_{t}^{H}}{P_{t}^{H}}\right)^{-\phi}} A_{t} k_{t-1}^{a} n_{t}^{1-a} \\
& b_{t}+m_{t}+\frac{S_{t} P_{t}^{*}}{P_{t}} f_{t}^{g}=\frac{R_{t-1} b_{t-1}}{\Pi_{t}}+\frac{m_{t-1}}{\Pi_{t}}+Q_{t-1} \frac{S_{t} P_{t}^{*}}{P_{t}} \frac{P_{t-1}^{*}}{P_{t}^{*}} f_{t-1}^{g}+ \\
& +\frac{P_{t}^{H}}{P_{t}} g_{t}-\tau_{t}^{c}\left(\frac{P_{t}^{H}}{P_{t}} c_{t}^{H}+\frac{P_{t}^{F}}{P_{t}} c_{t}^{F}\right)-\tau_{t}^{k}\left(r_{t}^{k} \frac{P_{t}^{H}}{P_{t}} k_{t-1}+\widetilde{\omega}_{t}\right)-\tau_{t}^{n} w_{t} n_{t}-\tau_{t}^{l}
\end{aligned}
$$




$$
\begin{gathered}
y_{t}^{H}=c_{t}^{H}+x_{t}+g_{t}+v_{t}+c_{t}^{F *} \\
\frac{P_{t}^{H}}{P_{t}}\left(c_{t}^{H}+x_{t}+g_{t}-y_{t}^{H}\right)+\frac{P_{t}^{F}}{P_{t}} c_{t}^{F}+Q_{t-1} \frac{S_{t} P_{t}^{*}}{P_{t}} \frac{P_{t-1}^{*}}{P_{t}^{*}}\left(f_{t-1}^{g}-f_{t-1}^{h}\right)= \\
=\frac{S_{t} P_{t}^{*}}{P_{t}}\left(f_{t}^{g}-f_{t}^{h}\right)+\pi_{t} \\
\left(P_{t}^{H}\right)^{1-\phi}=\left[\theta\left(P_{t-1}^{H}\right)^{1-\phi}+(1-\theta)\left(P_{t}^{\#}\right)^{1-\phi}\right] \\
P_{t}=\left(P_{t}^{H}\right)^{\nu}\left(P_{t}^{F}\right)^{1-\nu} \\
P_{t}^{*}=\left(P_{t}^{* H}\right)^{-\phi}\left(P_{t}^{H} / S_{t}\right)^{1-\nu^{*}} \\
=\left[\theta\left(\widetilde{P}_{t-1}^{H}\right)^{-\phi}+(1-\theta)\left(P_{t}^{\#}\right)\right. \\
v_{t}^{F} \equiv Q_{t-1}^{*} \frac{\psi}{2} \frac{P_{t-1}^{H}}{P_{t}^{H}}\left(f_{t-1}^{* g}-f_{t-1}^{* h}\right)^{-} \\
\pi_{t} \equiv Q_{t-1}^{*}\left[\frac{P_{t-1}}{P_{t}}\left(f_{t-1}^{* g}-f_{t-1}^{* h}\right)-\frac{P_{t}^{H}}{P_{t}} \frac{\psi}{2} \frac{P_{t-1}^{H}}{P_{t}^{H}}\left(f_{t-1}^{* g}-f_{t-1}^{* h}\right)^{2}\right]-Q_{t-1} \frac{S_{t}}{S_{t-1}} \frac{P_{t-1}}{P_{t}}\left(f_{t-1}^{* g}-f_{t-1}^{* h}\right) \\
Q_{t-1}^{*}=\frac{P_{t-1}}{1-\frac{S_{t}^{H}}{P_{t-1}} \psi\left(f_{t-1}^{* g}-f_{t-1}^{* h}\right)}
\end{gathered}
$$

where $\Xi_{t, t+k} \equiv \beta^{k} \frac{c_{t+k}^{-\sigma}}{c_{t}^{-\sigma}} \frac{P_{t}}{P_{t+k}} \frac{\tau_{t}^{c}}{\tau_{t+k}^{c}}$ is the firm's discount rate, $S_{t} \equiv 1$ in a currency union model and $\frac{P_{t}^{H}}{P_{t}}=\left(\frac{P_{t}^{H}}{P_{t}^{F}}\right)^{1-\nu}$.

Notice that $y_{t}^{H}=\frac{1}{\left(\frac{\widetilde{P}_{t}^{H}}{P_{t}}\right)^{-\phi}} A_{t} k_{t-1}^{a} n_{t}^{1-a}$ follows from the firm's demand function $y_{t}^{H}(h)=$ $\left(\frac{\tilde{P}_{t}}{P_{t}^{H}}\right)$ $\left[\frac{P_{t}^{H}(h)}{P_{t}^{H}}\right]^{-\phi} Y_{t}^{H}$. An particular, if we take the sum over all firms, we have $\sum_{h=1}^{N} y_{t}^{H}(h)=$ $Y_{t}^{H} \sum_{h=1}^{N}\left[\frac{P_{t}^{H}(h)}{P_{t}^{H}}\right]^{-\phi}$. Using the firm's production function and since we have constant returns to private inputs, $\sum_{h=1}^{N} y_{t}^{H}(h)=\sum_{h=1}^{N} A_{t}\left[k_{t-1}(h)\right]^{\alpha}\left[n_{t}(h)\right]^{1-\alpha}=\sum_{h=1}^{N} A_{t}\left[\frac{k_{t-1}(h)}{n_{t}(h)}\right]^{\alpha} n_{t}(h)=$ $A_{t}\left(K_{t-1}\right)^{\alpha}\left(N_{t}\right)^{1-\alpha}$, where $K_{t-1}$ and $N_{t}$ denote firms' total capital and labor inputs. Also, we define the auxiliary variable $\widetilde{P}_{t}^{H} \equiv\left[\sum_{h=1}^{N}\left[P_{t}^{H}(h)\right]^{-\phi}\right]^{-\frac{1}{\phi}}$. Using all this, we then have $A_{t}\left(K_{t-1}\right)^{\alpha}\left(N_{t}\right)^{1-\alpha}=Y_{t}^{H} \frac{\left(\widetilde{P}_{t}^{H}\right)^{-\phi}}{\left(P_{t}^{H}\right)^{-\phi}}$ or $Y_{t}^{H}=\frac{1}{\left(\frac{\tilde{P}_{t}^{H}}{P_{t}^{H}}\right)^{-\phi}} A_{t}\left(K_{t-1}\right)^{\alpha}\left(N_{t}\right)^{1-\alpha}$, so that, by dividing both sides by the population size, we have in per capita terms $y_{t}^{H}=\frac{1}{\left(\frac{\tilde{P}_{t}^{H}}{P_{t}^{H}}\right)^{-\phi}} A_{t} k_{t-1}^{a} n_{t}^{1-a}$. See also e.g. Yun (1996) and Schmitt-Grohé and Uribe (2007).

Working similarly, the foreign country is summarized by the following equations: 


$$
\begin{aligned}
& \frac{\partial u_{t}^{*}}{\partial c_{t}^{*}} \frac{\partial c_{t}^{*}}{\partial c_{t}^{* H}} \frac{P_{t}^{*}}{P_{t}^{* H}\left(1+\tau_{t}^{* c}\right)}=\beta \frac{\partial u_{t+1}^{*}}{\partial c_{t+1}^{*}} \frac{\partial c_{t+1}^{*}}{\partial c_{t+1}^{* H}} \frac{P_{t+1}^{*}}{P_{t+1}^{* H}\left(1+\tau_{t+1}^{* c}\right)} R_{t}^{*} \frac{P_{t}^{*}}{P_{t+1}^{*}} \\
& \frac{\partial u_{t}^{*}}{\partial c_{t}^{*}} \frac{\partial c_{t}^{*}}{\partial c_{t}^{* H}} \frac{P_{t}^{*}}{P_{t}^{* H}\left(1+\tau_{t}^{* c}\right)} \frac{P_{t}}{S_{t} P_{t}^{*}}= \\
& =\beta \frac{\partial u_{t+1}^{*}}{\partial c_{t+1}^{*}} \frac{\partial c_{t+1}^{*}}{\partial c_{t+1}^{* H}} \frac{P_{t+1}^{*}}{P_{t+1}^{* H}\left(1+\tau_{t+1}^{* c}\right)} Q_{t}^{*} \frac{P_{t+1}}{S_{t+1} P_{t+1}^{*}} \frac{P_{t}}{P_{t+1}} \\
& \frac{\partial u_{t}^{*}}{\partial c_{t}^{*}} \frac{\partial c_{t}^{*}}{\partial c_{t}^{* H}} \frac{1}{\left(1+\tau_{t}^{* c}\right)}\left\{1+\xi^{*}\left(\frac{k_{t}^{*}}{k_{t-1}^{*}}-1\right)\right\}= \\
& =\beta \frac{\partial u_{t+1}^{*}}{\partial c_{t+1}^{*}} \frac{\partial c_{t+1}^{*}}{\partial c_{t+1}^{* H}} \frac{1}{\left(1+\tau_{t+1}^{* c}\right)}\left\{\left(1-\delta^{*}\right)-\frac{\xi^{*}}{2}\left(\frac{k_{t+1}^{*}}{k_{t}^{*}}-1\right)^{2}+\xi^{*}\left(\frac{k_{t+1}^{*}}{k_{t}^{*}}-1\right) \frac{k_{t+1}^{*}}{k_{t}^{*}}+\left(1-\tau_{t+1}^{* k}\right) r_{t+1}^{* k}\right\} \\
& \frac{\partial u_{t}^{*}}{\partial m_{t}^{*}}=\frac{\partial u_{t}^{*}}{\partial c_{t}^{*}} \frac{\partial c_{t}^{*}}{\partial c_{t}^{* H}} \frac{P_{t}^{*}}{P_{t}^{* H}\left(1+\tau_{t}^{* c}\right)}-\beta \frac{\partial u_{t+1}^{*}}{\partial c_{t+1}^{*}} \frac{\partial c_{t+1}^{*}}{\partial c_{t+1}^{* H}} \frac{P_{t+1}^{*}}{P_{t+1}^{* H}\left(1+\tau_{t+1}^{* c}\right)} \frac{P_{t}^{*}}{P_{t+1}^{*}} \\
& -\frac{\partial u_{t}^{*}}{\partial n_{t}^{*}}=\left(1-\tau_{t}^{* n}\right) w_{t} \frac{\partial u_{t}^{*}}{\partial c_{t}^{*}} \frac{\partial c_{t}^{*}}{\partial c_{t}^{H *}} \frac{P_{t}^{*}}{P_{t}^{* H}\left(1+\tau_{t}^{* c}\right)} \\
& \frac{c_{t}^{* H}}{c_{t}^{* F}}=\frac{\nu^{*}}{1-\nu^{*}} \frac{P_{t}^{* F}}{P_{t}^{* H}} \\
& k_{t}^{*}=\left(1-\delta^{*}\right) k_{t-1}^{*}+x_{t}^{*}-\frac{\xi^{*}}{2}\left(\frac{k_{t}^{*}}{k_{t-1}^{*}-1}-1\right)^{2} k_{t-1}^{*} \\
& c_{t}^{*}=\frac{\left(c_{t}^{* H}\right)^{\nu^{*}}\left(c_{t}^{* F}\right)^{1-\nu^{*}}}{{\nu^{*} \nu^{*}}^{*}\left(1-\nu^{*}\right)^{1-\nu^{*}}} \\
& w_{t}^{*}=m c_{t}^{*}\left(1-a^{*}\right) A_{t}^{*} k_{t-1}^{* a^{*}} n_{t}^{*-a^{*}} \\
& \frac{P_{t}^{* H}}{P_{t}^{*}} r_{t}^{* k}=m c_{t}^{*} a^{*} A_{t}^{*} k_{t-1}^{* a-1} n_{t}^{* 1-a} \\
& \widetilde{\omega}_{t}^{*}=\frac{P_{t}^{* H}}{P_{t}^{*}} y_{t}^{* H}-\frac{P_{t}^{* H}}{P_{t}^{*}} r_{t}^{* k} k_{t-1}^{*}-w_{t}^{*} n_{t}^{*}
\end{aligned}
$$

$\sum_{k=0}^{\infty}\left(\theta^{*}\right)^{k} \Xi_{t, t+k}^{*}\left[\frac{P_{t}^{* \#}}{P_{t+k}^{* H}}\right]^{-\phi} y_{t+k}^{* H}\left\{\frac{P_{t}^{* \#}}{P_{t}^{* H}} \frac{P_{t}^{* H}}{P_{t}^{*}} \frac{P_{t}^{*}}{P_{t-1}^{*}}-\frac{\phi}{(\phi-1)} m c_{t+k}^{*} \frac{P_{t}^{*}}{P_{t-1}^{*}} \ldots \frac{P_{t+k}^{*}}{P_{t+k-1}^{*}}\right\}=0$

$$
y_{t}^{H *}=\frac{1}{\left(\frac{\widetilde{P}_{t}^{H *}}{P_{t}^{H *}}\right)^{-\phi}} A_{t}^{*} k_{t-1}^{* a^{*}} n_{t}^{* 1-a^{*}}
$$

$$
\begin{gathered}
b_{t}^{*}+m_{t}^{*}+\frac{P_{t}}{S_{t} P_{t}^{*}} f_{t}^{* g}=R_{t-1}^{*} b_{t-1}^{*} \frac{P_{t-1}^{*}}{P_{t}^{*}}+m_{t-1}^{*} \frac{P_{t-1}^{*}}{P_{t}^{*}}+Q_{t-1}^{*} \frac{P_{t}}{S_{t} P_{t}^{*}} \frac{P_{t-1}}{P_{t}} f_{t-1}^{* g}+ \\
+\frac{P_{t}^{H *}}{P_{t}^{*}} g_{t}^{*}-\tau_{t}^{* c}\left(P_{t}^{* H} c_{t}^{* H}+P_{t}^{* F} c_{t}^{* F}\right)-\tau_{t}^{* k}\left(r_{t}^{* k} P_{t}^{* H} k_{t-1}^{*}+\widetilde{\omega}_{t}^{*}\right)-\tau_{t}^{* n} w_{t}^{*} n_{t}^{*}-\tau_{t}^{* l} \\
y_{t}^{* H}=c_{t}^{* H}+x_{t}^{*}+g_{t}^{*}+c_{t}^{F} \\
\frac{P_{t}^{* H}}{P_{t}^{*}}\left(c_{t}^{* H}+x_{t}^{*}+g_{t}^{*}-y_{t}^{* H}\right)+\frac{P_{t}^{* F}}{P_{t}^{*}} c_{t}^{* F}+Q_{t-1}^{*} \frac{P_{t}}{S_{t} P_{t}^{*}} \frac{P_{t-1}}{P_{t}}\left(f_{t-1}^{* g}-f_{t-1}^{* h}\right)= \\
= \\
\frac{P_{t}}{S_{t} P_{t}^{*}}\left(f_{t}^{* g}-f_{t}^{* h}\right)
\end{gathered}
$$




$$
\begin{aligned}
& \left(P_{t}^{* H}\right)^{1-\phi^{*}}=\left[\theta^{*}\left(P_{t-1}^{* H}\right)^{1-\phi^{*}}+\left(1-\theta^{*}\right)\left(P_{t}^{* \#}\right)^{1-\phi^{*}}\right] \\
& \left(\widetilde{P}_{t}^{* H}\right)^{-\phi^{*}}=\left[\theta^{*}\left(\widetilde{P}_{t-1}^{* H}\right)^{-\phi^{*}}+\left(1-\theta^{*}\right)\left(P_{t}^{* \#}\right)^{-\phi^{*}}\right]
\end{aligned}
$$

where see below for number of equations and variables in this system.

\subsection{Transformed variables}

As in most of the related literature (see e.g. Schmitt-Grohé and Uribe $(2005,2007)$ ), for algebraic simplicity, we transform some variables and introduce some new ones.

First, instead of price levels, we work with inflation rates and relative prices. Thus, we define $\Pi_{t} \equiv \frac{P_{t}}{P_{t-1}}, \Pi_{t}^{*} \equiv \frac{P_{t}^{*}}{P_{t-1}^{*}}, \Pi_{t}^{H} \equiv \frac{P_{t}^{H}}{P_{t-1}^{H}}, \Theta_{t} \equiv \frac{P_{t}^{\#}}{P_{t}^{H}}, \Delta_{t} \equiv\left(\frac{\widetilde{P}_{t}^{H}}{P_{t}^{H}}\right)^{-\phi}, \epsilon_{t} \equiv \frac{S_{t}}{S_{t-1}}$ and $T T_{t} \equiv \frac{P_{t}^{F}}{P_{t}^{H}}$. We also express some policy variables as shares of output. In particular, we define nominal domestic public debt as a share, $s_{t}^{b}$, of total nominal output, so that per capita real domestic public debt is $b_{t} \equiv \frac{B_{t}}{P_{t} N} \equiv \frac{s_{t}^{b} P_{t}^{H} Y_{t}^{H}}{P_{t} N} \equiv \frac{P_{t}^{H}}{P_{t}} s_{t}^{b} y_{t}^{H}=T T_{t}^{\nu-1} s_{t}^{b} y_{t}^{H}$, nominal total lump-sum taxes/transfers are defined as a share, $s_{t}^{l}$, of total nominal ouput, so that the per capita real lump-sum tax/transfer is $\tau_{t}^{l} \equiv \frac{T_{t}^{l}}{P_{t} N}=\frac{s_{t}^{l} P_{t}^{H} Y_{t}^{H}}{P_{t} N} \equiv \frac{P_{t}^{H}}{P_{t}} s_{t}^{l} y_{t}^{H}=T T_{t}^{\nu-1} s_{t}^{l} y_{t}^{H}$, while the quantity of goods/services provided by the government is defined as a share, $s_{t}^{g}$, of total realoutput produced, so that the per capita quantity of those goods/services is $g_{t} \equiv \frac{G_{t}}{N} \equiv \frac{s_{t}^{g} Y_{t}^{H}}{N} \equiv s_{t}^{g} y_{t}^{H}$. So, in what follows, we will use the variables $\Pi_{t}, \Pi_{t}^{*}, \Pi_{t}^{H}, \Theta_{t}, \Delta_{t}, \epsilon_{t}, T T_{t}, s_{t}^{g}, s_{t}^{l}$ instead of $P_{t}, P_{t}^{*}, P_{t}^{H}, P_{t}^{\#}, \widetilde{P}_{t}, S_{t}, P_{t}^{F}, g_{t}, \tau_{t}^{l}$ respectively. Note that we also make use of the notation, $f_{t}^{g} \equiv s_{t}^{f} y_{t}^{H} \frac{1}{T T_{t}^{\nu^{*}}}$.

Second, working as in Schmitt-Grohé and Uribe (2007), we rewrite the firm's optimality conditions in recursive form. In particular, instead of equation (97), we now use:

$$
z_{t}^{1}=\frac{\phi}{(\phi-1)} z_{t}^{2}
$$

where

$$
\begin{gathered}
z_{t}^{1}=\Theta_{t}^{1-\phi} y_{t}^{H} T T_{t}^{\nu-1}+\beta \theta \frac{c_{t+1}^{-\sigma}}{c_{t}^{-\sigma}} \frac{1+\tau_{t}^{c}}{1+\tau_{t+1}^{c}}\left(\frac{\Theta_{t}}{\Theta_{t+1}}\right)^{1-\phi}\left(\frac{1}{\Pi_{t+1}^{H}}\right)^{1-\phi} z_{t+1}^{1} \\
z_{t}^{2}=\Theta_{t}^{-\phi} y_{t}^{H} m c_{t}+\beta \theta \frac{c_{t+1}^{-\sigma}}{c_{t}^{-\sigma}} \frac{1+\tau_{t}^{c}}{1+\tau_{t+1}^{c}}\left(\frac{\Theta_{t}}{\Theta_{t+1}}\right)^{-\phi}\left(\frac{1}{\Pi_{t+1}^{H}}\right)^{-\phi} z_{t+1}^{2}
\end{gathered}
$$

thus, we add two more equations and two new endogenous variables, $z_{t}^{1}$ and $z_{t}^{2}$.

Third, again as in Schmitt-Grohé and Uribe (2007), in order to compute expected discounted lifetime utility, denoted as $V_{t}$, we add a new equation and a new endogenous variable, 
$V_{t}\left(\right.$ recall that $\left.g_{t} \equiv s_{t}^{g} y_{t}^{H}\right)$ :

$$
V_{t}=\frac{c_{t}^{1-\sigma}}{1-\sigma}-\chi_{n} \frac{n_{t}^{1+\varphi}}{1+\varphi}+\chi_{m} \frac{m_{t}^{1-\mu}}{1-\mu}+\chi_{g} \frac{\left(s_{t}^{g} y_{t}^{H}\right)^{1-\zeta}}{1-\zeta}+\beta V_{t+1}
$$

We work similarly for the foreign country. That is, first, we use $\Pi_{t}^{* H}, \Theta_{t}^{*}, \Delta_{t}^{*}, s_{t}^{* g}, s_{t}^{* l}$ instead of $P_{t}^{* H}, P_{t}^{* \#}, \widetilde{P}_{t}^{*}, g_{t}^{*}, \tau_{t}^{* l}$ respectively, second, we have for the foreign firm:

$$
\begin{gathered}
z_{t}^{* 1}=\frac{\phi}{(\phi-1)} z_{t}^{* 2} \\
=\Theta_{t}^{* 1-\phi^{*}} y_{t}^{* H} T T_{t}^{1-\nu^{*}}+\beta^{*} \theta^{*} \frac{c_{t+1}^{*-\sigma^{*}}}{c_{t}^{*-\sigma^{*}}} \frac{1+\tau_{t}^{* c}}{1+\tau_{t+1}^{* c}}\left(\frac{\Theta_{t}^{*}}{\Theta_{t+1}^{*}}\right)^{1-\phi^{*}}\left(\frac{1}{\Pi_{t+1}^{* H}}\right)^{1-\phi^{*}} z_{t+1}^{* 1} \\
z_{t}^{* 2}=\Theta_{t}^{*-\phi^{*}} y_{t}^{* H} m c_{t}^{*}+\beta^{*} \theta^{*} \frac{c_{t+1}^{*-\sigma^{*}}}{c_{t}^{*-\sigma^{*}}} \frac{1+\tau_{t}^{* c}}{1+\tau_{t+1}^{* c}}\left(\frac{\Theta_{t}^{*}}{\Theta_{t+1}^{*}}\right)^{-\phi^{*}}\left(\frac{1}{\Pi_{t+1}^{* H}}\right)^{-\phi^{*}} z_{t+1}^{* 2}
\end{gathered}
$$

and, thirdly, we have the new value function:

$$
V_{t}^{*}=\frac{c_{t}^{* 1-\sigma^{*}}}{1-\sigma^{*}}-\chi_{n}^{*} \frac{\eta_{t}^{* 1+\varphi^{*}}}{1+\varphi^{*}}+\chi_{m}^{*} \frac{m_{t}^{* 1-\mu^{*}}}{1-\mu^{*}}+\chi_{g}^{*} \frac{\left(s_{t}^{* g} y_{t}^{* H}\right)^{1-\zeta^{*}}}{1-\zeta^{*}}+\beta V_{t+1}^{*}
$$

Finally, given the above, notice that we make use of the following equations:

$$
\begin{gathered}
\frac{P_{t}}{S_{t} P_{t}^{*}}=T T_{t}^{1-\nu-\nu^{*}} \\
T T_{t}=\frac{P_{t}^{F}}{P_{t}^{H}}=\frac{\frac{P_{t}^{F}}{S_{t}}}{\frac{P_{t}^{H}}{S_{t}}}=\frac{P_{t}^{* H}}{P_{t}^{* F}} \\
\frac{P_{t}^{* H}}{P_{t}^{*}}=\frac{P_{t}^{* H}}{\left(P_{t}^{* H}\right)^{\nu^{*}}\left(P_{t}^{* F}\right)^{1-\nu^{*}}}=\left(\frac{P_{t}^{* H}}{P_{t}^{* F}}\right)^{1-\nu^{*}}=T T_{t}^{1-\nu^{*}}
\end{gathered}
$$




$$
\frac{P_{t}^{* F}}{P_{t}^{*}}=\frac{P_{t}^{* F}}{\left(P_{t}^{* H}\right)^{\nu^{*}}\left(P_{t}^{* F}\right)^{1-\nu^{*}}}=\left(\frac{P_{t}^{* F}}{P_{t}^{* H}}\right)^{\nu^{*}}=\left(\frac{1}{T T_{t}}\right)^{\nu^{*}}
$$

\subsection{Final equilibrium system in the status quo economy}

Using the above, we now present the final equilibrium system (given feedback policy coefficients).

The domestic country is summarized by the following equations:

$$
\begin{aligned}
& V_{t}=\frac{c_{t}^{1-\sigma}}{1-\sigma}-\chi_{n} \frac{n_{t}^{1+\varphi}}{1+\varphi}+\chi_{m} \frac{m_{t}^{1-\mu}}{1-\mu}+\chi_{g} \frac{\left(s_{t}^{g} y_{t}^{H}\right)^{1-\zeta}}{1-\zeta}+\beta V_{t+1} \\
& \beta \frac{c_{t+1}^{-\sigma}}{\left(1+\tau_{t+1}^{c}\right)} \frac{R_{t}}{\Pi_{t+1}}=\frac{c_{t}^{-\sigma}}{\left(1+\tau_{t}^{c}\right)} \\
& \beta \frac{c_{t+1}^{-\sigma}}{\left(1+\tau_{t+1}^{c}\right)} \frac{Q_{t} T T_{t+1}^{v^{*}+\nu-1}}{\Pi_{t+1}^{*}}=\frac{c_{t}^{-\sigma}}{\left(1+\tau_{t}^{c}\right)} T T_{t}^{v^{*}+\nu-1} \\
& \beta \frac{c_{t+1}^{-\sigma}}{\left(1+\tau_{t+1}^{c}\right)} T T_{t+1}^{\nu-1}\left\{1-\delta-\frac{\xi}{2}\left(\frac{k_{t+1}}{k_{t}}-1\right)^{2}+\xi\left(\frac{k_{t+1}}{k_{t}}-1\right) \frac{k_{t+1}}{k_{t}}+\left(1-\tau_{t+1}^{k}\right) r_{t+1}^{k}\right\}= \\
& =\frac{c_{t}^{-\sigma}}{\left(1+\tau_{t}^{c}\right)} T T_{t}^{\nu-1}\left[1+\xi\left(\frac{k_{t}}{k_{t-1}}-1\right)\right] \\
& \chi_{m} m_{t}^{-\mu}=\frac{c_{t}^{-\sigma}}{\left(1+\tau_{t}^{c}\right)}-\beta \frac{c_{t+1}^{-\sigma}}{\left(1+\tau_{t+1}^{c}\right)} \frac{1}{\Pi_{t+1}} \\
& \chi_{n} n_{t}^{\varphi}=\left(1-\tau_{t}^{n}\right) w_{t} \frac{c_{t}^{-\sigma}}{\left(1+\tau_{t}^{c}\right)} \\
& \frac{c_{t}^{H}}{c_{t}^{F}}=\frac{\nu}{1-\nu} T T_{t} \\
& k_{t}=(1-\delta) k_{t-1}+x_{t}-\frac{\xi}{2}\left(\frac{k_{t}}{k_{t-1}}-1\right)^{2} k_{t-1} \\
& c_{t}=\frac{\left(c_{t}^{H}\right)^{\nu}\left(c_{t}^{F}\right)^{1-\nu}}{(\nu)^{\nu}(1-\nu)^{1-\nu}} \\
& w_{t}=m c_{t}(1-a) A_{t} k_{t-1}^{a} n_{t}^{-a} \\
& \frac{1}{T T_{t}^{1-v}} r_{t}^{k}=m c_{t} a A_{t} k_{t-1}^{a-1} n_{t}^{1-a} \\
& \widetilde{\omega}_{t}=\frac{1}{T T_{t}^{1-v}} y_{t}^{H}-\frac{1}{T T_{t}^{1-v}} r_{t}^{k} k_{t-1}-w_{t} n_{t} \\
& z_{t}^{1}=\frac{\phi}{(\phi-1)} z_{t}^{2}
\end{aligned}
$$




$$
\begin{aligned}
& y_{t}^{H}=\frac{1}{\Delta_{t}} A_{t} k_{t-1}^{a} n_{t}^{1-a} \\
& d_{t}+m_{t}=\frac{R_{t-1}}{\Pi_{t}} \lambda_{t-1} d_{t-1}+\frac{Q_{t-1} T T_{t}^{v+v^{*}-1}}{\Pi_{t}^{*}} \frac{1}{T T_{t-1}^{v+v^{*}-1}}\left(1-\lambda_{t-1}\right) d_{t-1}+ \\
& +\frac{1}{\Pi_{t}} m_{t-1}+T T_{t}^{\nu-1} s_{t}^{g} y_{t}^{H}-\tau_{t}^{c}\left(\frac{1}{T T_{t}^{1-v}} c_{t}^{H}+T T_{t}^{v} c_{t}^{F}\right)- \\
& -\tau_{t}^{k}\left(r_{t-1}^{k} \frac{1}{T T_{t}^{1-v}} k_{t-1}+\widetilde{\omega}_{t}\right)-\tau_{t}^{n} w_{t} n_{t}-T T_{t}^{\nu-1} s_{t}^{l} y_{t}^{H} \\
& \left(1-\lambda_{t}\right) d_{t}-T T_{t}^{\nu^{*}+\nu-1} f_{t}^{h}+\pi_{t}+T T_{t}^{\nu-1} v_{t}=-T T_{t}^{\nu-1} c_{t}^{F *}+T T_{t}^{\nu} c_{t}^{H} \\
& +\frac{Q_{t-1} T T_{t}^{\nu^{*}+\nu-1}}{\Pi_{t}^{*}}\left(\frac{1}{T T_{t-1}^{v+v^{*}-1}}\left(1-\lambda_{t-1}\right) d_{t-1}-f_{t-1}^{h}\right) \\
& y_{t}^{H}=c_{t}^{H}+x_{t}+s_{t}^{g} y_{t}^{H}+v_{t}+c_{t}^{F *} \\
& \left(\Pi_{t}^{H}\right)^{1-\phi}=\theta+(1-\theta)\left(\Theta_{t} \Pi_{t}^{H}\right)^{1} \\
& \frac{\Pi_{t}}{\Pi_{t}^{H}}=\left(\frac{T T_{t}}{T T_{t-1}}\right)^{1-} \\
& \frac{T T_{t}}{T T_{t-1}}=\frac{\epsilon_{t} \Pi_{t}^{* H}}{\Pi_{t}^{H}} \\
& \frac{\Pi_{t}^{*}}{\Pi_{t}^{* H}}=\left(\frac{T T_{t-\gamma}}{T T_{t}}\right)^{1-\nu^{*}} \\
& \Delta_{t}=\theta \Delta_{t-1}\left(\Pi_{t}^{H}\right)^{\phi}+(1-\theta)\left(\Theta_{t}\right)^{-\phi} \\
& z_{t}^{1}=\Theta_{t}^{1-\phi} y_{t} T T_{t}^{\nu-1}+\beta \theta \frac{c_{t+1}^{-\sigma}}{c_{t}^{-\sigma}} \frac{1+\tau_{t}^{c}}{1+\tau_{t+1}^{c}}\left(\frac{\Theta_{t}}{\Theta_{t+1}}\right)^{1-\phi}\left(\frac{1}{\Pi_{t+1}^{H}}\right)^{1-\phi} z_{t+1}^{1} \\
& z_{t}^{2}=\Theta_{t}{ }^{\phi} y_{t} m c_{t}+\beta \theta \frac{c_{t+1}^{-\sigma}}{c_{t}^{-\sigma}} \frac{1+\tau_{t}^{c}}{1+\tau_{t+1}^{c}}\left(\frac{\Theta_{t}}{\Theta_{t+1}}\right)^{-\phi}\left(\frac{1}{\Pi_{t+1}^{H}}\right)^{-\phi} z_{t+1}^{2} \\
& v_{t}=Q_{t-1}^{*} \frac{\psi}{2} \frac{P_{t-1}^{H}}{P_{t}^{H}}\left(f_{t-1}^{* g}-f_{t-1}^{* h}\right)^{2} \\
& \pi_{t}=Q_{t-1}^{*}\left[\frac{P_{t-1}}{P_{t}}\left(f_{t-1}^{* g}-f_{t-1}^{* h}\right)-\frac{P_{t}^{H}}{P_{t}} \frac{\psi}{2} \frac{P_{t-1}^{H}}{P_{t}^{H}}\left(f_{t-1}^{* g}-f_{t-1}^{* h}\right)^{2}\right]-Q_{t-1} \frac{S_{t}}{S_{t-1}} \frac{P_{t-1}}{P_{t}}\left(f_{t-1}^{* g}-f_{t-1}^{* h}\right) \\
& Q_{t-1}^{*}=\frac{Q_{t-1} \frac{S_{t}}{S_{t-1}}}{1-\frac{P_{t-1}^{H}}{P_{t-1}} \psi\left(f_{t-1}^{* g}-f_{t-1}^{* h}\right)}
\end{aligned}
$$

Next, the foreign country is summarized by the following equations:

$$
V_{t}^{*}=\frac{c_{t}^{* 1-\sigma^{*}}}{1-\sigma^{*}}-\chi_{n}^{*} \frac{n_{t}^{* 1+\varphi^{*}}}{1+\varphi^{*}}+\chi_{m}^{*} \frac{m_{t}^{* 1-\mu^{*}}}{1-\mu^{*}}+\chi_{g}^{*} \frac{\left(s_{t}^{* g} y_{t}^{* H}\right)^{1-\zeta^{*}}}{1-\zeta^{*}}+\beta^{*} V_{t+1}^{*}
$$




$$
\begin{aligned}
& \beta^{*} \frac{c_{t+1}^{*-\sigma}}{\left(1+\tau_{t+1}^{* c}\right)} \frac{R_{t}^{*}}{\Pi_{t+1}^{*}}=\frac{c_{t}^{*-\sigma}}{\left(1+\tau_{t}^{* c}\right)} \\
& \beta^{*} \frac{c_{t+1}^{*-\sigma}}{\left(1+\tau_{t+1}^{* c}\right)} \frac{Q_{t}^{*} T T_{t+1}^{1-\nu-v^{*}}}{\Pi_{t+1}}=\frac{c_{t}^{*-\sigma}}{\left(1+\tau_{t}^{* c}\right)} T T_{t}^{1-\nu-v^{*}} \\
& \beta^{*} T T_{t+1}^{1-\nu^{*}} \frac{c_{t+1}^{*-\sigma}}{\left(1+\tau_{t+1}^{* c}\right)}\left\{1-\delta^{*}-\frac{\xi^{*}}{2}\left(\frac{k_{t+1}^{*}}{k_{t}^{*}}-1\right)^{2}+\xi^{*}\left(\frac{k_{t+1}^{*}}{k_{t}^{*}}-1\right) \frac{k_{t+1}^{*}}{k_{t}^{*}}+\left(1-\tau_{t+1}^{* k}\right) r_{t+1}^{* k}\right\}= \\
& =T T_{t}^{1-\nu^{*}} \frac{c_{t}^{*-\sigma}}{\left(1+\tau_{t}^{* *}\right)}\left[1+\xi^{*}\left(\frac{k_{t}^{*}}{k_{t-1}^{*}}-1\right)\right] \\
& \chi_{m}^{*} m_{t}^{*-\mu^{*}}=\frac{c_{t}^{*-\sigma}}{\left(1+\tau_{t}^{* c}\right)}-\beta^{*} \frac{c_{t+1}^{*-\sigma}}{\left(1+\tau_{t+1}^{* c}\right)} \frac{1}{\Pi_{t+1}^{*}} \\
& \chi_{n}^{*} n_{t}^{* \varphi^{*}}=\left(1-\tau_{t}^{* n^{*}}\right) w_{t}^{*} \frac{c_{t}^{*-\sigma}}{\left(1+\tau_{t}^{* c}\right)} \\
& \frac{c_{t}^{* H}}{c_{t}^{* F}}=\frac{\nu^{*}}{1-\nu^{*}} \frac{1}{T T_{t}} \\
& k_{t}^{*}=\left(1-\delta^{*}\right) k_{t-1}^{*}+x_{t}^{*}-\frac{\xi^{*}}{2}\left(\frac{k_{t}^{*}}{k_{t-1}^{*}}-1\right)^{2} k_{t-1}^{*} \\
& c_{t}^{*}=\frac{\left(c_{t}^{* H}\right)^{\nu^{*}}\left(c_{t}^{* F}\right)^{1-\nu^{*}}}{\left(\nu^{*}\right)^{\nu^{*}}\left(1-\nu^{*}\right)^{1-\nu^{*}}} \\
& w_{t}^{*}=m c_{t}^{*}\left(1-a^{*}\right) A_{t}^{*} k_{t-1}^{* a^{*}} n_{t}^{*-a^{*}} \\
& T T_{t}^{1-v^{*}} r_{t}^{* k}=m c_{t}^{*} a^{*} A_{t}^{*} k_{t-1}^{* a^{*}-1} n_{t}^{* 1-a^{*}} \\
& \left.\widetilde{\omega}_{t}^{*}=T T_{t}^{1}\right)^{v^{*}} y_{t}^{* H}-T T_{t}^{1-v^{*}} r_{t}^{* k} k_{t-1}^{*}-w_{t}^{*} n_{t}^{*} \\
& z_{t}^{* 1}=\frac{\phi^{*}}{\left(\phi^{*}-1\right)} z_{t}^{* 2} \\
& y_{t}^{* H}=\frac{1}{\Delta_{t}^{*}} A_{t}^{*} k_{t-1}^{* a^{*}} n_{t}^{* 1-a^{*}}
\end{aligned}
$$

$d_{t}^{*}+m_{t}^{*}=\frac{R_{t-1}^{*}}{\Pi_{t}^{*}} \lambda_{t-1}^{*} d_{t-1}^{*}+\frac{Q_{t-1}^{*} T T_{t}^{1-v-v^{*}}}{\Pi_{t}} \frac{1}{T T_{t-1}^{1-v-v^{*}}}\left(1-\lambda_{t-1}^{*}\right) d_{t-1}^{*}+$

$+\frac{1}{\Pi_{t}^{*}} m_{t-1}^{*}+T T_{t}^{1-\nu^{*}} s_{t}^{* g} y_{t}^{* H}-\tau_{t}^{* c}\left(T T_{t}^{1-v^{*}} c_{t}^{* H}+\frac{1}{T T_{t}^{v^{*}}} c_{t}^{* F}\right)-$$$
-\tau_{t}^{* k}\left(r_{t-1}^{* k} T T_{t}^{1-v^{*}} k_{t-1}^{*}+\widetilde{\omega}_{t}^{*}\right)-\tau_{t}^{* n} w_{t}^{*} n_{t}^{*}-s_{t}^{* l} y_{t}^{* H} T T_{t}^{1-\nu^{*}}
$$$$
y_{t}^{* H}=c_{t}^{* H}+x_{t}^{*}+s_{t}^{* g} y_{t}^{* H}+c_{t}^{F}
$$$$
\left(1-\lambda_{t}^{*}\right) d_{t}^{*}-T T_{t}^{1-\nu^{*}-\nu} f_{t}^{* h}=-T T_{t}^{1-\nu^{*}} c_{t}^{F}+T T_{t}^{-\nu^{*}} c_{t}^{F^{*}}
$$$$
+\frac{Q_{t-1}^{*} T T_{t}^{1-\nu^{*}-\nu}}{\Pi_{t}}\left(\frac{1}{T T_{t-1}^{1-v-v^{*}}}\left(1-\lambda_{t-1}^{*}\right) d_{t-1}^{*}-f_{t-1}^{h^{*}}\right)
$$$$
\left(\Pi_{t}^{* H}\right)^{1-\phi^{*}}=\theta^{*}+\left(1-\theta^{*}\right)\left(\Theta_{t}^{*} \Pi_{t}^{* H}\right)^{1-\phi^{*}}
$$ 


$$
\begin{gathered}
\Delta_{t}^{*}=\theta^{*} \Delta_{t-1}^{*}\left(\Pi_{t}^{* H}\right)^{\phi^{*}}+\left(1-\theta^{*}\right)\left(\Theta_{t}^{*}\right)^{-\phi^{*}} \\
z_{t}^{* 1}=\Theta_{t}^{* 1-\phi^{*}} y_{t}^{* H} T T_{t}^{1-\nu^{*}}+\beta^{*} \theta^{*} \frac{c_{t+1}^{*-\sigma^{*}}}{c_{t}^{*-\sigma^{*}}} \frac{1+\tau_{t}^{* c}}{1+\tau_{t+1}^{* c}}\left(\frac{\Theta_{t}^{*}}{\Theta_{t+1}^{*}}\right)^{1-\phi^{*}}\left(\frac{1}{\Pi_{t+1}^{* H}}\right)^{1-\phi^{*}} z_{t+1}^{* 1} \\
z_{t}^{* 2}=\Theta_{t}^{*-\phi^{*}} y_{t}^{* H} m c_{t}^{*}+\beta^{*} \theta^{*} \frac{c_{t+1}^{*-\sigma^{*}}}{c_{t}^{*-\sigma^{*}}} \frac{1+\tau_{t}^{* c}}{1+\tau_{t+1}^{* c}}\left(\frac{\Theta_{t}^{*}}{\Theta_{t+1}^{*}}\right)^{-\phi^{*}}\left(\frac{1}{\Pi_{t+1}^{* H}}\right)^{-\phi^{*}} z_{t+1}^{* 2}
\end{gathered}
$$

where $S_{t} F^{g}=\left(1-\lambda_{t}\right) D_{t}, F^{g}=\frac{\left(1-\lambda_{t}\right) D_{t}}{S_{t}}, \frac{F^{g}}{P_{t}^{*}}=\frac{\left(1-\lambda_{t}\right) D_{t}}{P_{t}^{*} S_{t}}, f_{t}^{g}=\left(1-\lambda_{t}\right) d_{t} \frac{P_{t}}{P_{t}^{*} S_{t}}=\left(1-\lambda_{t}\right) d_{t} \frac{1}{T T_{t}^{\nu^{*}+\nu-1}}$, $\frac{F^{* g}}{S_{t}}=\left(1-\lambda_{t}^{*}\right) D_{t}^{*}, F^{* g}=\left(1-\lambda_{t}\right) D_{t}^{*} S_{t}, \frac{F^{* g}}{P_{t}}=\frac{\left(1-\lambda_{t}^{*}\right) D_{t}^{*} S_{t}}{P_{t}}, f_{t}^{* g}=\left(1-\lambda_{t}^{*}\right) d_{t}^{*} \frac{S_{t} P_{t}^{*}}{P_{t}}=\left(1-\lambda_{t}^{*}\right) d_{t}^{*} T T_{t}^{\nu^{*}+\nu-1}$, $\frac{P_{t-1}^{H}}{P_{t-1}}=T T_{t-1}^{\nu-1}, \frac{S_{t} P_{t}^{*}}{P_{t}}=T T_{t}^{\nu^{*}+\nu-1}, \frac{P_{t}}{S_{t} P_{t}^{*}}=T T_{t+1}^{1-\nu-v^{*}}, \frac{P_{t}^{* H}}{P_{t}^{*}}=\left(\frac{P_{t}^{* H}}{P_{t}^{* F}}\right)^{1-\nu^{*}} T T_{t}=\frac{P_{t}^{F}}{P_{t}^{H}}=\frac{\frac{P_{t}^{F}}{S_{t}}}{\frac{P_{t}^{H}}{S_{t}}}=$ $\frac{P_{t}^{* H}}{P_{t}^{* F}}, \frac{P_{t}^{* F}}{P_{t}^{* H}}=\frac{1}{T T_{t}}, \epsilon_{t}=\frac{S_{t}}{S_{t-1}}$.

We finally have the feedback monetary and fiscal policy rules:

$$
\begin{aligned}
& \log \left(\frac{R_{t}}{R}\right)= \phi_{\pi}\left(\eta \log \left(\frac{\Pi_{t}}{\Pi}\right)+(1-\eta) \log \left(\frac{\Pi_{t}^{*}}{\Pi^{*}}\right)\right)+ \\
&+\phi_{y}\left(\eta \log \left(\frac{y_{t}^{H}}{y^{H}}\right)+(1-\eta) \log \left(\frac{y_{t}^{* H}}{y^{* H}}\right)\right) \\
& s_{t}^{g}-s^{g}=-\gamma_{l}^{g}\left(l_{t-1}-l\right)-\gamma_{y}^{g}\left(y_{t}^{H}-y^{H}\right) \\
& s_{t}^{l}-s^{l}=\gamma_{l}^{l}\left(l_{t-1}-l\right)+\gamma_{y}^{l}\left(y_{t}^{H}-y^{H}\right) \\
& \tau_{t}^{c}-\tau^{c}=\gamma_{l}^{c}\left(l_{t-1}-l\right)+\gamma_{y}^{c}\left(y_{t}^{H}-y^{H}\right) \\
& \tau_{t}^{k}-\tau^{k}=\gamma_{l}^{k}\left(l_{t-1}-l\right)+\gamma_{y}^{k}\left(y_{t}^{H}-y^{H}\right) \\
& \tau_{t}^{n}-\tau^{n}=\gamma_{l}^{n}\left(l_{t-1}-l\right)+\gamma_{y}^{n}\left(y_{t}^{H}-y^{H}\right) \\
& s_{t}^{* g}-s^{* g}=-\gamma_{l}^{* g}\left(l_{t-1}^{*}-l^{*}\right)-\gamma_{y}^{* g}\left(y_{t}^{* H}-y^{* H}\right) \\
& s_{t}^{* l}-s^{* l}=\gamma_{l}^{* l}\left(l_{t-1}^{*}-l^{*}\right)+\gamma_{y}^{* l}\left(y_{t}^{* H}-y^{* H}\right) \\
& \tau_{t}^{* c}-\tau^{* c}=\gamma_{l}^{* c}\left(l_{t-1}^{*}-l^{*}\right)+\gamma_{y}^{* c}\left(y_{t}^{* H}-y^{* H}\right) \\
& \tau_{t}^{* k}-\tau^{* k}=\gamma_{l}^{* k}\left(l_{t-1}^{*}-l^{*}\right)+\gamma_{y}^{* k}\left(y_{t}^{* H}-y^{* H}\right) \\
& \tau_{t}^{* n}-\tau^{* n}=\gamma_{l}^{* n}\left(l_{t-1}^{*}-l^{*}\right)+\gamma_{y}^{* n}\left(y_{t}^{* H}-y^{* H}\right) \\
& l_{t}=\frac{R_{t} \lambda_{t} d_{t}+Q_{t} \epsilon_{t+1}\left(1-\lambda_{t}\right) d_{t}}{T T_{t}^{\nu-1} y_{t}^{H}} \\
&
\end{aligned}
$$




$$
l_{t}^{*}=\frac{R_{t}^{*} \lambda_{t}^{*} d_{t}^{*}+Q_{t}^{*} \frac{1}{\epsilon_{t+1}}\left(1-\lambda_{t}^{*}\right) d_{t}^{*}}{T T_{t}^{1-\nu^{*}} y_{t}^{* H}}
$$

Therefore, we have 61 equations in total. We also have 61 endogenous variables, which are $\left\{V, y^{H}, c, c^{H}, c^{F}, n, x, k, f^{h}, m, T T, \Pi, \Pi^{H}, \Theta, \Delta, w, m c, \widetilde{\omega}, r^{k}, d, \Pi^{*}, z^{1}, z^{2}, Q, \pi\right.$, $q\}$ and $\left\{R, s^{g}, s^{l}, \tau^{c}, \tau^{k}, \tau^{n}, l\right\}$ for the home country, and $\left\{V^{*}, y^{* H}, c^{*}, c^{* H}, c^{* F}, n^{*}, x^{*}, k^{*}\right.$, $\left.f^{* h}, m^{*}, \Pi^{* H}, \Theta^{*}, \Delta^{*}, w^{*}, m c^{*}, \widetilde{\omega}^{*}, r^{* k}, d^{*}, z^{* 1}, z^{* 2}, Q^{*}, R^{*}\right\}$ and $\left\{s^{*} g, s^{* l}, \tau^{* c}, \tau^{* k}, \tau^{* n}, l^{*}\right\}$ for the foreign country. This is given given the exogenous variables, $\left\{\epsilon, \lambda, \lambda^{*}, A, A^{*}\right\}$, initial conditions for the state variables and the values of the feedback (monetary and fiseal) policy coefficients in the policy rules.

Notice that, since all market-clearing conditions have been already included, the above system also satisfies the international asset market-clearing condition, $\left(f^{* g}-f^{* h}\right)+\frac{S_{t} P_{t}^{*}}{P_{t}}\left(f^{g}-\right.$ $\left.f^{h}\right)=0$. This can be seen if we add up the two balance of payments above; this will give $\left(f^{* g}-f^{* h}\right)+\frac{S_{t} P_{t}^{*}}{P_{t}}\left(f^{g}-f^{h}\right)=0$ residually.

Notice also that net exports are exports minus imports. Thus, net exports of Germany as share of GDP are $N E_{t} \equiv \frac{P_{t}^{H} c_{t}^{F^{*}}-P_{t}^{F} c_{t}^{F}}{P_{t}^{H} y_{t}^{H}}=\frac{c_{t}^{F *}-T T_{t} c_{t}^{F}}{y_{t}^{H}}$, while net exports of Italy as share of GDP and denominated in domestic currency are $N E_{t}^{*} \equiv \frac{S_{t} P_{t}^{* H} c_{t}^{F}-P_{t}^{H} c_{t}^{* F}}{S_{t} P_{t}^{* H} y_{t}^{* H}}=\frac{P_{t}^{F} c_{t}^{F}-P_{t}^{H} c_{t}^{* F}}{P_{t}^{F} y_{t}^{* H}}=$ $\frac{c_{t}^{F}-\frac{1}{T T_{t}} c_{t}^{* F}}{y_{t}^{* H}}$.

\subsection{Steady state and transition}

The steady state system follows directly from the above defined system when variables do not change over time. At steady state, we set $\Pi=\Pi^{*}=1$ and let the nominal interest rates to follow residually from the Euler for bonds in each country. Regarding fiscal policy, the residual policy instrument is total public debt in each country. To get the transition path, we approximate the dynamic system around its steady state solution, as explained in the main text (see section 4).

\section{Appendix 6: Equilibrium in the reformed economy}

We study two cases as said in the main text.

\subsection{When premia are allowed in the new reformed steady state}

The equilibrium system in the reformed economy is the same as above (see the system of 61 equations above) except that now, in Italy, the debt target in the feedback policy rules in 
subsection 2.6.2 is set at 0.9. In the steady state of this reformed economy, with $\frac{d^{*}}{T T^{1-\nu^{*}} y^{* H}}$ set at 0.9 , the capital tax rate falls to 0.302 . Table A.1 reports the associated steady state solution.

Table A1: Reformed steady state with debt consolidation in Italy (with premia)

\begin{tabular}{|c|c|c|c|}
\hline Variables & Description & Home & Foreign \\
\hline$u, u^{*}$ & utility & 0.0397 & 0.0337 \\
\hline$y^{H}, y^{H *}$ & output & 0.3912 & 0.3569 \\
\hline$c, c^{*}$ & consumption & 0.2319 & 0.2283 \\
\hline$n, n^{*}$ & hours worked & 0.3116 & 0.3067 \\
\hline$k, k^{*}$ & capital & 0.6654 & 0.508 \\
\hline$w, w^{*}$ & real wage rate & 0.6904 & 0.7111 \\
\hline$r^{k}, r^{k *}$ & real return to capital & 0.147 & 0.1756 \\
\hline$T T$ & terms-of-trade & 1.098 & \\
\hline$Q^{*}-Q$ & interest rate premium & & 0.0055 \\
\hline$\frac{c}{y^{H} T T^{1-\nu}}, \frac{c^{*}}{y^{H *} T T_{t}^{\nu^{*}-1}}$ & $\begin{array}{l}\text { consumption as } \\
\text { share of GDP }\end{array}$ & 0.5656 & 0.6704 \\
\hline$\frac{k}{y^{H}}, \frac{k^{*}}{y^{H *}}$ & capital as share of GDP & 1.7 & 1.4236 \\
\hline$d$ & $\begin{array}{l}\text { total public debt } \\
\text { as share of GDP }\end{array}$ & 0.69 & 0.9 \\
\hline 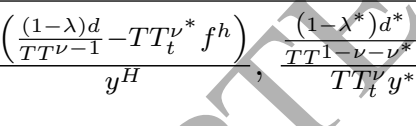 & $\begin{array}{l}\text { total foreign debt } \\
\text { as share of GDP* }\end{array}$ & -0.21 & 0.209 \\
\hline
\end{tabular}

\subsection{When premia are not allowed in the new reformed steady state}

The equilibrium system in the reformed economy is the same as above (see the system of 61 equations above) except that now, in Italy, not only the debt target in the feedback policy rules in subsection 2.6.2 is set at 0.9 , but also the discount factor, $\beta^{*}$, follows the $\operatorname{AR}(1)$ rule:

$$
\beta_{t}^{*}=\rho^{\beta^{*}} \beta_{t-1}^{*}+\left(1-\rho^{\beta^{*}}\right) \beta
$$

where variables' definitions are in the main text and, as said, the value of $\rho^{\beta^{*}}$ is chosen optimally.

In the steady state of this reformed economy: (a) In Italy, since the public debt-to-GDP ratio is set at an exogenously given value, one of the other fiscal variables becomes endogenous. 
As said, we report results when it is the capital tax rate that plays that role. (b) Sovereign premia are eliminated by setting $Q^{*}=Q$. This, in turn, implies $\beta^{*}=\beta$ via the Euler equations for the international asset in the two countries written at the steady state. It also implies that that we lose one equation (the two Euler equations for the international asset become identical), but, at the same time, in order to have $Q^{*}=Q$, we also have a new equation, $f^{* g}-f^{* h}=0$, so the steady state system remains well defined in terms of equations and unknowns. The associated steady state solution is in Table A2.

Table A2: Reformed steady state with debt consolidation in Italy (without premia)

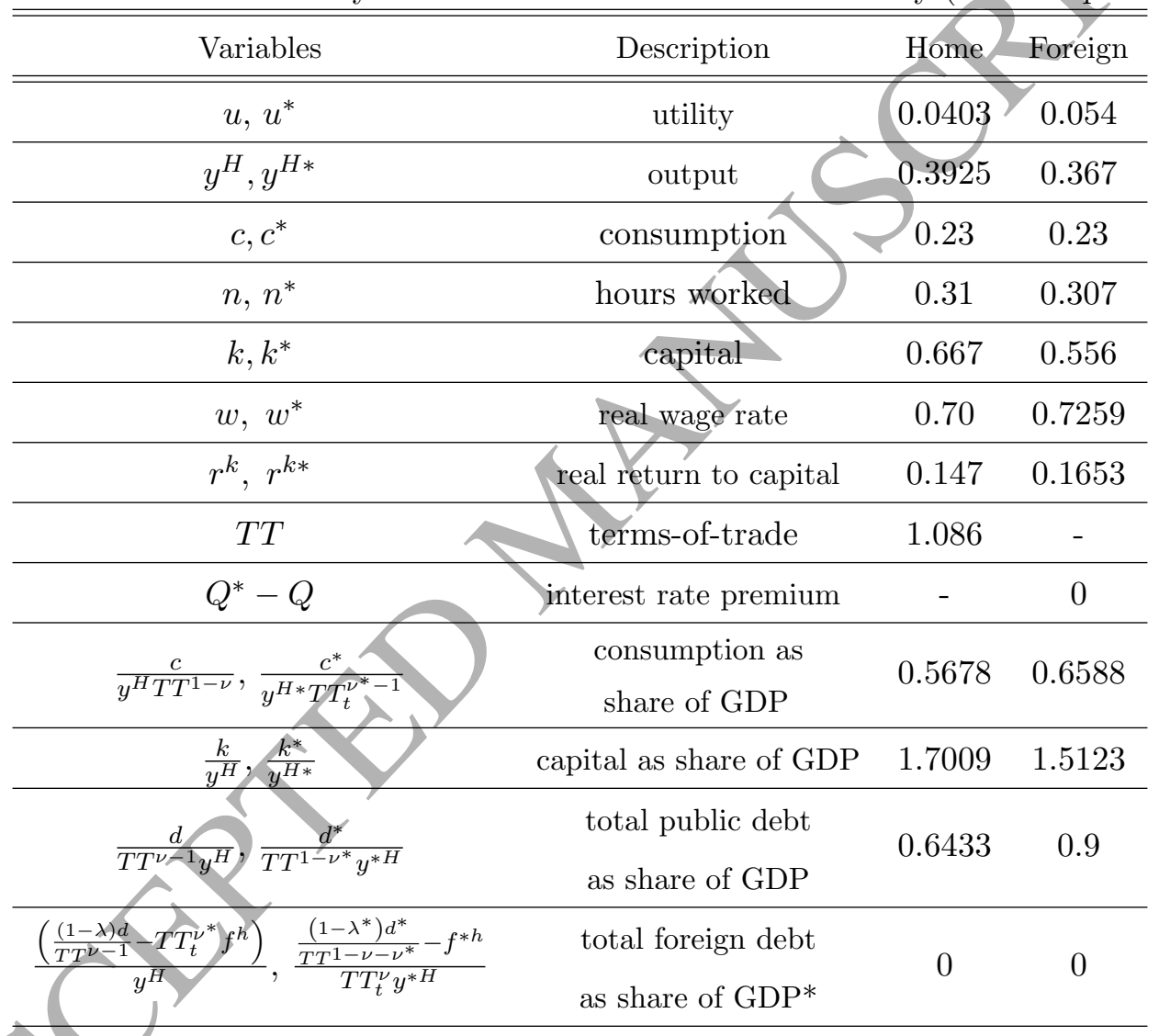

\section{Appendix 7: Response functions under other policy scenar-} ios

In this Appendix, we present the response functions in three more cases.

\subsection{Adding TFP shocks to Figures 1-3}

In Figures 1-3 in the main text, transition dynamics was driven by deterministic policy reforms in Italy only. Here, we enrich these figures by adding a temporary adverse shock to TFP in 
Italy. The red and blue lines show the same policy scenarios as in Figures 1-3, while now the green lines show the case in which policy is optimally chosen in both countries but Italy does not reduce its debt in the new steady state (that is, in this scenario, we start from and end up at the same status quo steady state solution and deviations from this solution are produced by temporary shocks). Recall that this non-consolidation scenario was described in subsection 4.2 and has served as benchmark for the computation of welfare differences in terms of consumption equivalents.

Figure F1: Response functions of public debt to GDP and fiscal instruments in Italy (in levels)
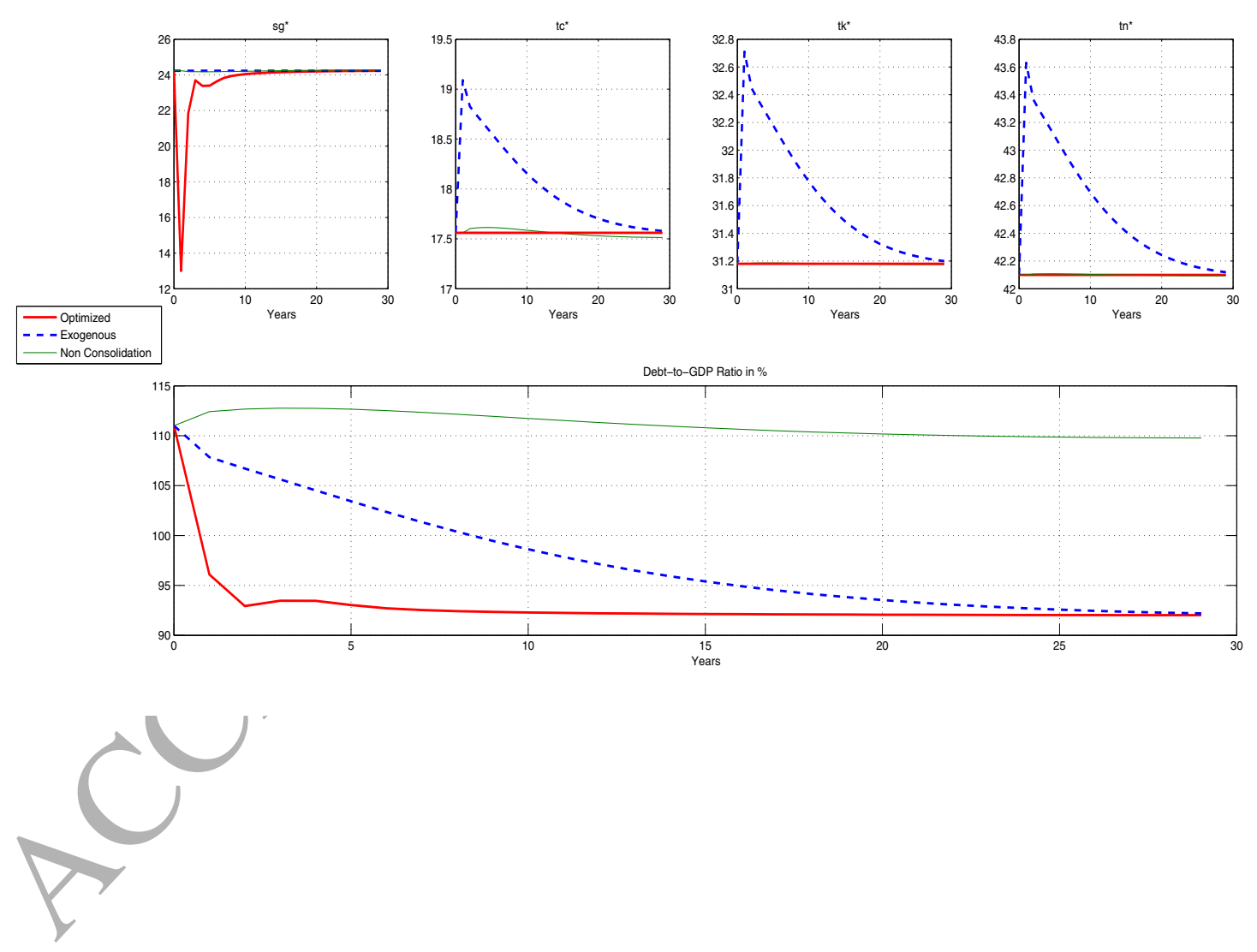
Figure F2: Response functions of main macro variables in Germany and Italy (in percentage deviations from status-quo steady state)
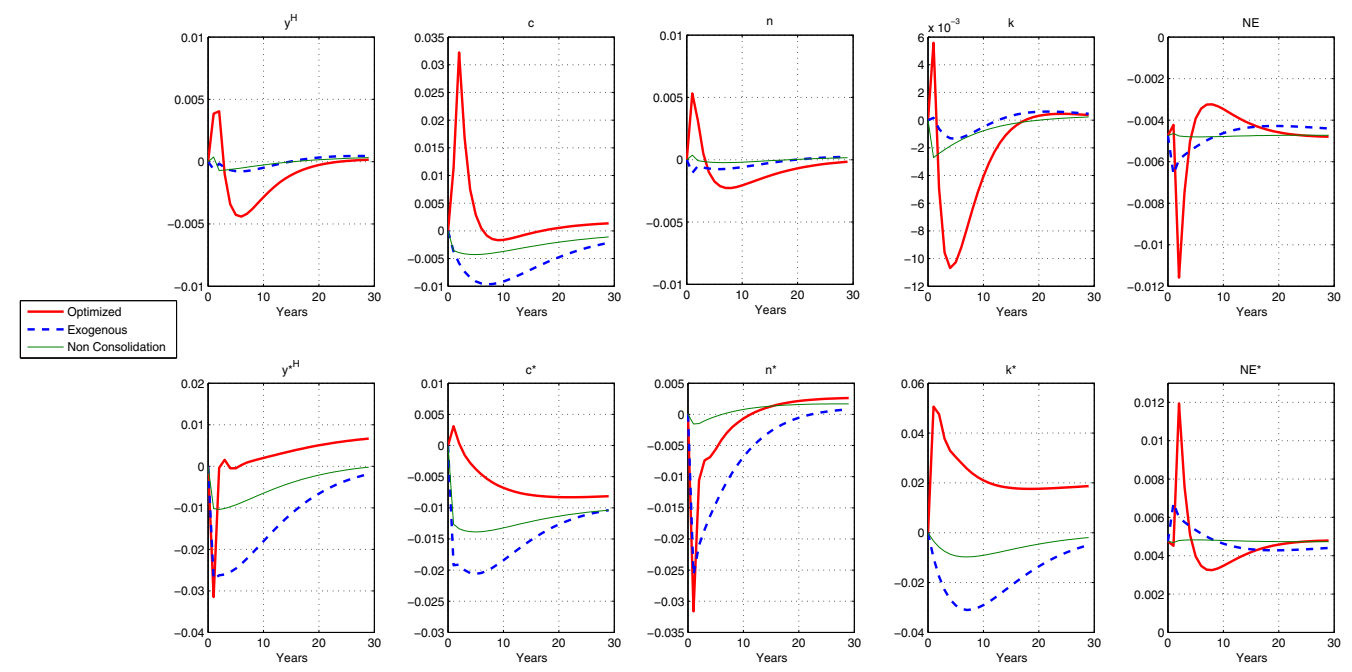

Figure F3: Response functions of main price indices in Germany and Italy (in levels)
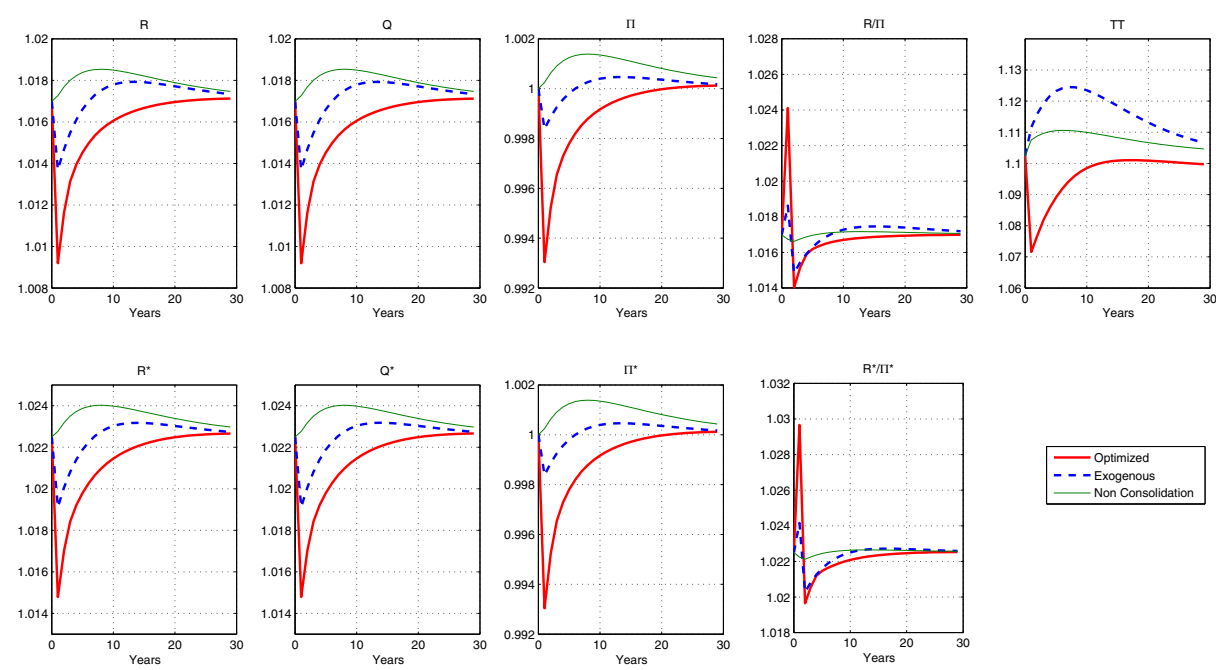

\subsection{Fiscal consolidation without premia in the new reformed steady}

Figures 1-3 in the text have allowed for premia in the new reformed steady state (see subsection 5.1.1). We now present the response functions in the more ambitious case in which, not only public debt is reduced, but also premia are eliminated, in the new reformed steady state (see 
subsection 5.1.2 for this scenario). Since the responses of policy instruments and prices remain qualitatively the same as in Figures 1 and 3 respectively, here we just present the simulated paths of the main macro variables. This is in Figure F4 which should be compared to Figure 2 in the text.

Figure F4: Response functions of main macro variables in Germany and Italy without premia in the reformed steady state (in percentage deviations from status-quo steady state)
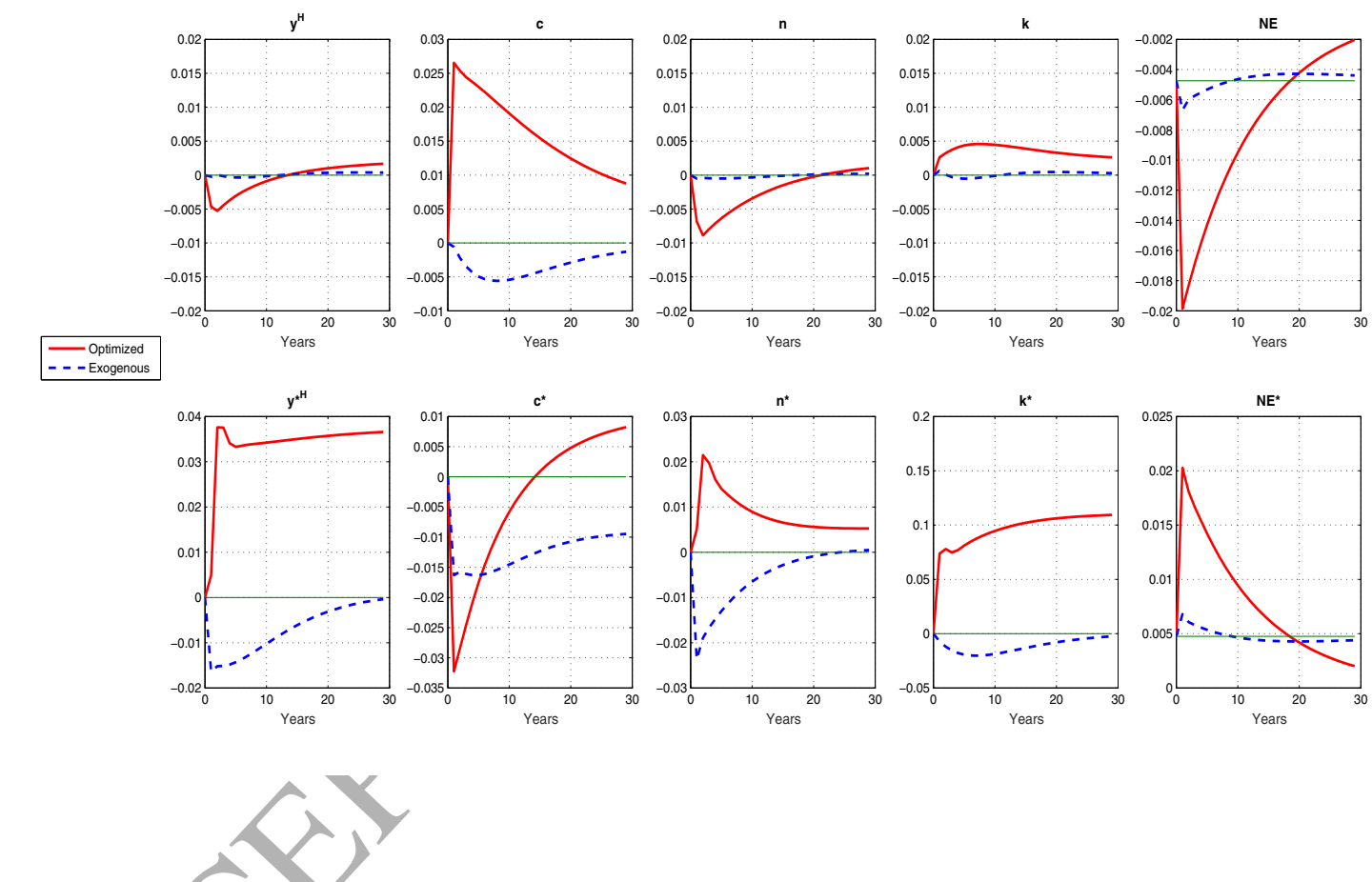

\subsection{Fiscal consolidation via ad hoc cuts in transfers}

Here, we present the response functions in the case in which debt consolidation would take place via ad hoc cuts in transfers (see the blue lines). For comparison, we include the same response functions in the case in which debt consolidation takes place via optimal cuts in government consumpion spending as in Figures 1-3 in the main text (see the red lines). Thus, Figures F5-F7 should be compared to Figures 1-3 in the text. 
Figure F5: Response functions of public debt to GDP and fiscal instruments in Italy with ad hoc cuts in transfers (in levels)

- optimized
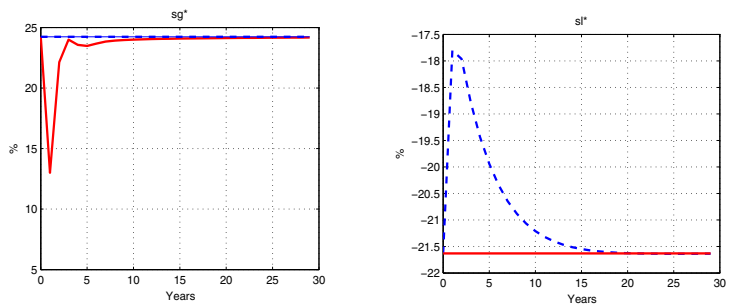

- - - Exog. Transters

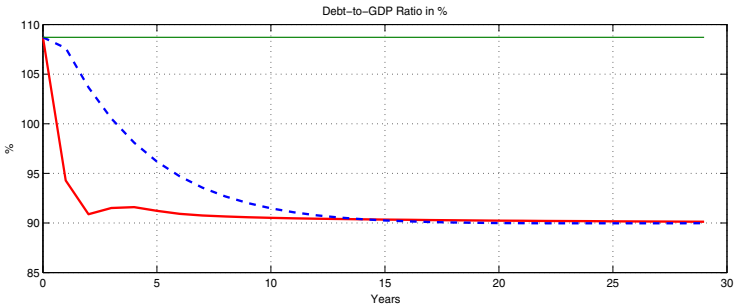

Figure F6: Response functions of main macro variables in Germany and Italy with ad hoc cuts in transfer (in percentage deviations from status-quo steady state)

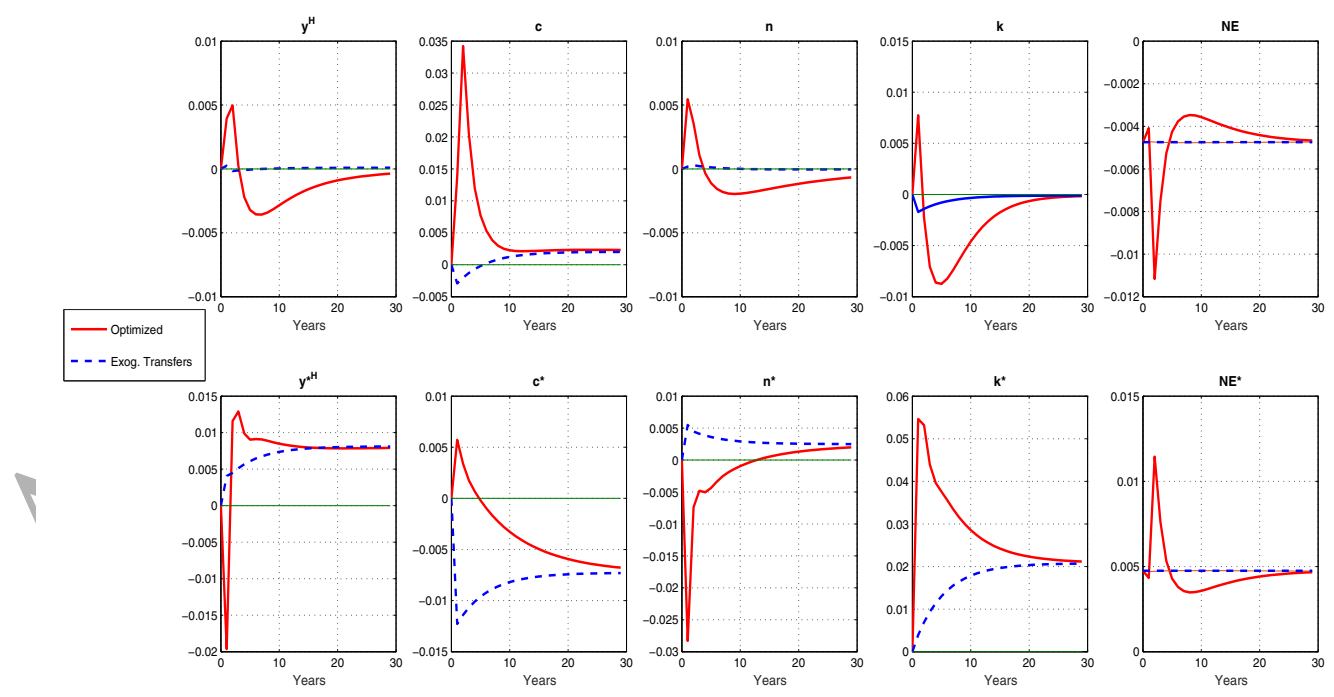


Figure F7: Response functions of main price indices in Germany and Italy with ad hoc cuts in transfer (in levels)
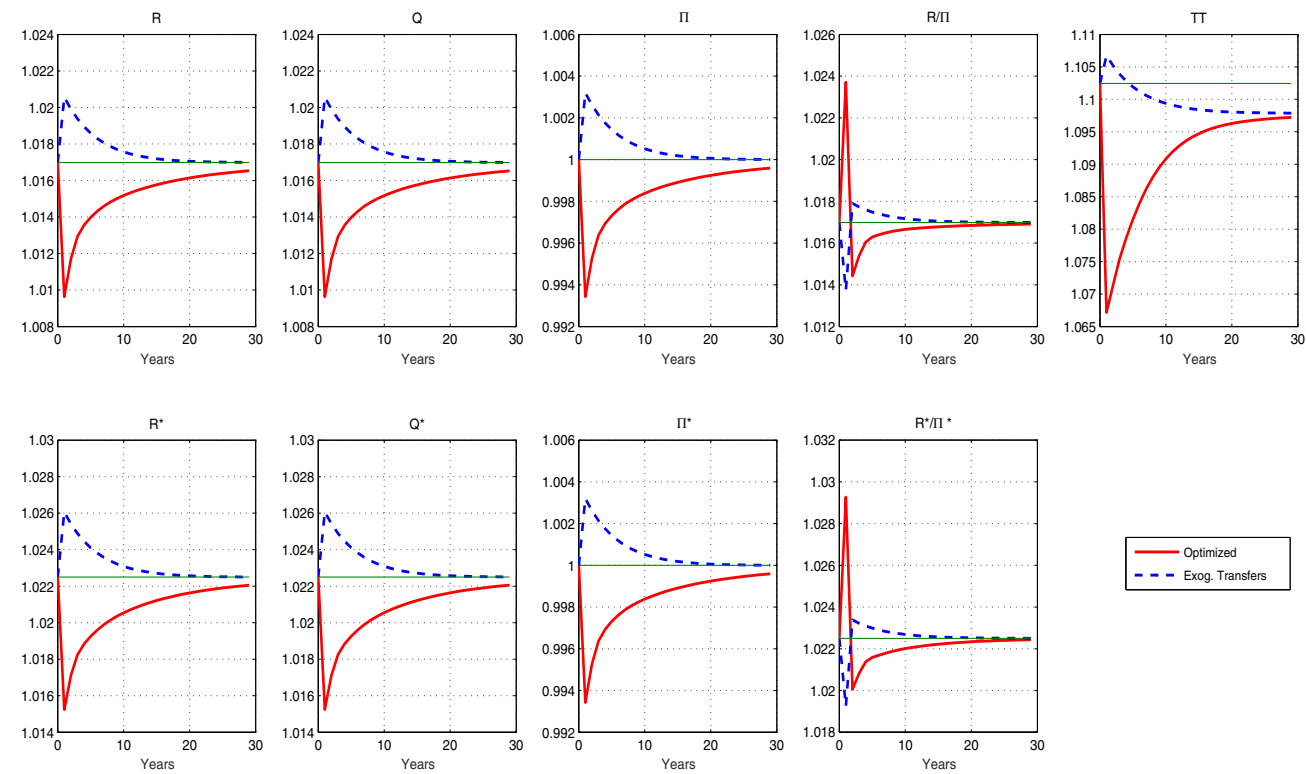

\section{Appendix 8: Adding non-Ricardian agents and public in- vestment}

In this Appendix, we add non-Ricardian households and productivity-enhancing public spending. To save on space, we add both model extensions at the same time by building upon the model developed in section 2 in the main text (although, in the numerical solutions, we report results for one extension at a time).

\subsection{Adding non-Ricardian households}

In each country, instead of having $i=1,2, \ldots, N$ identical households as assumed so far, there are $N_{r}$ Ricardian houselholds who behave as the households $i$ modelled above (these households are now denoted by the subscript $\left.r=1,2, \ldots, N_{r}\right)$ and $N_{n r}$ non-Ricardian households, where $N_{n r}=N-N_{r}$, who do not participate in financial and capital markets (these new households are denoted by the subscript $\left.n r=1,2, \ldots, N_{n r}\right)$. Their corresponding population shares are $\nu_{r}$ and $\nu_{n r}=1-\nu_{r}$. We assume that, in each country, the number of private firms equals the number of Ricardian households (this is for simplicity). 
The constraints of each non-Ricardian household are as in equations (1)-(6) in the main text while its budget constraint is a simplified version of equation (9), namely:

$$
\begin{aligned}
& \left(1+\tau_{t}^{c}\right)\left[\frac{P_{t}^{H}}{P_{t}} c_{n r, t}^{H}+\frac{P_{t}^{F}}{P_{t}} c_{n r, t}^{F}\right]+m_{n r, t}= \\
& =\left(1-\tau_{t}^{n}\right) w_{t} n_{n r, t}+\frac{P_{t-1}}{P_{t}} m_{n r, t-1}-\tau_{i, t}^{l}
\end{aligned}
$$

that is, this new household does not save in physical capital, government bonds or international assets and does not get any profits distributed by firms.

The objective function is like equations (7)-(8) in the main text. The optimality conditions of the new agent, as well as the full new equilbrium system, are presented in detail below.

\subsection{Adding government investment}

Now, the firm's production function changes from equation (13) in the main text to:

$$
y_{t}^{H}(h)=A_{t}\left(g_{t}^{i}\right)^{\varkappa}\left[k_{t-1}(h)\right]^{\alpha}\left[n_{t}(h)\right]^{1-\alpha}
$$

where $g_{t}^{i}$ is the per capita quantity of productivity-enhancing public goods/services and $0 \leq$ $\varkappa \leq 1$ is a technology parameter. Notice that, as in Baxter and King (1993), we keep the assumption of CRS over private inputs.

In equilibrium, $g_{t}^{i}=s_{t}^{i} y_{t}^{H}$, in other words, public investment is a share of output and this share is set as in the data. We thus have a new fiscal policy instrument, $s_{t}^{i}$, which is allowed to follow (like the other policy/instruments) the feedback rule:

$$
s_{t}^{i}-s^{i}=-\gamma_{l}^{i}\left(l_{t-1}-l\right)-\gamma_{y}^{i}\left(y_{t}^{H}-y^{H}\right)
$$

and similalry in the foreign country:

$$
s_{t}^{* i}-s^{* i}=-\gamma_{l}^{* i}\left(l_{t-1}^{*}-l^{*}\right)-\gamma_{l}^{* i}\left(y_{t}^{* H}-y^{* H}\right)
$$

where $\gamma_{l}^{i}, \gamma_{y}^{i}, \gamma_{l}^{* i}, \gamma_{l}^{* i} \geq 0$ are feedback policy coefficients like those in equations 18-21 in the main text.

The full new equilbrium system is presented in detail in what follows.

\subsection{The extended final equilibrium system in the status quo economy}

Given the above extensions, the domestic country is summarized by the equation system presented in detail below. Notice that this system includes government investment, non-Ricardian 
agents and rules for all main fiscal policy instruments in both countries. We also allow for different transfers between Ricardian and non-Ricardian households in each country. In particular, if $s_{t}^{l}$ is total transfers as share of GDP as above, then a fraction $0 \leq \varrho \leq 1$ of this goes to non-Ricardian households and the rest goes to Ricardian households and this happens in both countries (we have experimented with different values of $\varrho$ ).

Ricardian households:

$$
\begin{aligned}
& V_{r, t}=\frac{\left(c_{r, t}\right)^{1-\sigma}}{1-\sigma}-\chi_{n} \frac{\left(n_{r, t}\right)^{1+\varphi}}{1+\varphi}+\chi_{m} \frac{\left(m_{r, t}\right)^{1-\mu}}{1-\mu}+\chi_{g} \frac{\left(s_{t}^{g} y_{t}^{H}\right)^{1-\zeta}}{1-\zeta}+\beta V_{r, t+1} \\
& \beta \frac{\left(c_{r, t+1}\right)^{-\sigma}}{\left(1+\tau_{t+1}^{c}\right)} \frac{R_{t}}{\Pi_{t+1}}=\frac{\left(c_{r, t}\right)^{-\sigma}}{\left(1+\tau_{t}^{c}\right)} \\
& \beta \frac{\left(c_{r, t+1}\right)^{-\sigma}}{\left(1+\tau_{t+1}^{c}\right)} \frac{Q_{t} T T_{t+1}^{v^{*}+\nu-1}}{\Pi_{t+1}^{*}}=\frac{\left(c_{r, t}\right)^{-\sigma}}{\left(1+\tau_{t}^{c}\right)} T T_{t}^{v^{*}+\nu-1} \\
& \beta \frac{\left(c_{r, t+1}\right)^{-\sigma}}{\left(1+\tau_{t+1}^{c}\right)} T T_{t+1}^{\nu-1}\left\{1-\delta-\frac{\xi}{2}\left(\frac{k_{t+1}}{k_{t}}-1\right)^{2}+\xi\left(\frac{k_{t+1}}{k_{t}}-1\right) \frac{k_{t+1}}{k_{t}}+\left(1-\tau_{t+1}^{k}\right) r_{t+1}^{k}\right\}= \\
& =\frac{\left(c_{r, t}\right)^{-\sigma}}{\left(1+\tau_{t}^{c}\right)} T T_{t}^{\nu-1}\left[1+\xi\left(\frac{k_{t}}{k_{t}-1}-1\right)\right] \\
& \chi_{m}\left(m_{r, t}\right)^{-\mu}=\frac{\left(c_{r, t}\right)^{-\sigma}}{\left(1+\tau_{t}^{c}\right)}-\beta \frac{\left(c_{r, t+1}^{c}\right)^{-\sigma}}{\left(1+\tau_{t+1}^{c}\right)} \frac{1}{\Pi_{t+1}} \\
& \chi_{n}\left(n_{r, t}\right)^{\varphi}=\left(1-\tau_{t}^{n}\right) w_{t} \frac{\left(c_{r, t}\right)^{-\sigma}}{\left(1+\tau_{t}^{c}\right)} \\
& \frac{c_{r, t}^{H}}{c_{r, t}^{F}}=\frac{\nu}{1-\nu} T T_{t} \\
& k_{r, t}=(1-\delta) k_{r, t-1}+x_{r, t}-\frac{\xi}{2}\left(\frac{k_{r, t}}{k_{r, t-1}}-1\right)^{2} k_{r, t-1} \\
& c_{r, t}=\frac{\left(c_{r, t}^{H}\right)^{\nu}\left(c_{r, t}^{F}\right)^{1-\nu}}{(\nu)^{\nu}(1-\nu)^{1-\nu}}
\end{aligned}
$$

Non-Ricardian households (in the new system, we have the 6 new equations right below and 6 new endogenous variables, $\left.c_{n r, t}^{H}, c_{n r, t}^{F}, c_{n r, t}, n_{n r, t}, m_{n r, t}, V_{n r, t}\right)$ :

$$
\begin{gathered}
\left(1+\tau_{t}^{c}\right)\left[\frac{P_{t}^{H}}{P_{t}} c_{n r, t}^{H}+\frac{P_{t}^{F}}{P_{t}} c_{n r, t}^{F}\right]+m_{n r, t}= \\
=\left(1-\tau_{t}^{n}\right) w_{t} n_{n r, t}+\frac{P_{t-1}}{P_{t}} m_{n r, t-1}-T T_{t}^{\nu-1} s_{t}^{l} y_{t}^{H} \frac{\varrho}{\nu_{n r}} \\
V_{n r, t}=\frac{\left(c_{n r, t}\right)^{1-\sigma}}{1-\sigma}-\chi_{n} \frac{\left(n_{n r, t}\right)^{1+\varphi}}{1+\varphi}+\chi_{m} \frac{\left(m_{n r, t}\right)^{1-\mu}}{1-\mu}+\chi_{g} \frac{\left(s_{t}^{g} y_{t}^{H}\right)^{1-\zeta}}{1-\zeta}+\beta V_{n r, t+1}
\end{gathered}
$$




$$
\begin{gathered}
\chi_{n}\left(n_{n r, t}\right)^{\varphi}=\left(1-\tau_{t}^{n}\right) w_{t} \frac{\left(c_{n r, t}\right)^{-\sigma}}{\left(1+\tau_{t}^{c}\right)} \\
\chi_{m}\left(m_{n r, t}\right)^{-\mu}=\frac{\left(c_{n r, t}\right)^{-\sigma}}{\left(1+\tau_{t}^{c}\right)}-\beta \frac{\left(c_{n r, t+1}\right)^{-\sigma}}{\left(1+\tau_{t+1}^{c}\right)} \frac{1}{\Pi_{t+1}} \\
\frac{c_{n r, t}^{H}}{c_{n r, t}^{F}}=\frac{\nu}{1-\nu} T T_{t} \\
c_{n r, t}=\frac{\left(c_{n r, t}^{H}\right)^{\nu}\left(c_{n r, t}^{F}\right)^{1-\nu}}{(\nu)^{\nu}(1-\nu)^{1-\nu}}
\end{gathered}
$$

Firms:

$$
\begin{gathered}
w_{t}=m c_{t}(1-a) A_{t}\left(s_{t}^{i} y_{t}^{H}\right)^{\varkappa}\left(\nu_{r} k_{r, t-1}\right)^{\alpha}\left(\nu_{r} n_{r, t}+\nu_{n r} n_{n r, t}\right)^{-a} \\
\frac{1}{T T_{t}^{1-v}} r_{t}^{k}=m c_{t} a A_{t}\left(s_{t}^{i} y_{t}^{H}\right)^{\varkappa}\left(\nu_{r} k_{r, t-1}\right)^{\alpha-1}\left(\nu_{r} n_{r, t}+\nu_{n r} n_{n r, t}\right)^{1-a} \\
\widetilde{\omega}_{r, t}=\frac{1}{T T_{t}^{1-v}} y_{t}^{H}-\frac{1}{T T_{t}^{1-v}} r_{t}^{k} \nu_{r} k_{r, t-1}-w_{t}\left(\nu_{r} n_{r, t}+\nu_{n r} n_{n r, t}\right) \\
y_{t}^{H}=\frac{1}{\Delta_{t}} A_{t}\left(s_{t}^{i} y_{t}^{H}\right)^{\varkappa}\left(\nu_{r} k_{r, t-1}\right)^{\alpha}\left(\nu_{r} n_{r, t}+\nu_{n r} n_{n r, t}\right)^{1-a} \\
z_{t}^{1}=\frac{\phi}{(\phi-1)} z_{t}^{2}
\end{gathered}
$$

Constraints:

$$
\begin{gathered}
d_{t}+\left(\nu_{r} m_{r, t}+\nu_{n r} m_{r n, t}\right)=\frac{R_{t-1}}{\Pi_{t}} \lambda_{t-1} d_{t-1}+\frac{Q_{t-1} T T_{t}^{v+v^{*}-1}}{\Pi_{t}^{*}} \frac{1}{T T_{t-1}^{v+v^{*}-1}}\left(1-\lambda_{t-1}\right) d_{t-1}+ \\
+\frac{1}{\Pi_{t}}\left(\nu_{r} m_{r, t-1}+\nu_{n r} m_{r n, t-1}\right)+T T_{t}^{\nu-1}\left(s_{t}^{g}+s_{t}^{i}\right) y_{t}^{H}- \\
-\tau_{t}^{c}\left[\frac{1}{T T_{t}^{1-v}}\left(\nu_{r} c_{r, t}^{H}+\nu_{n r} c_{n r, t}^{H}\right)+T T_{t}^{v}\left(\nu_{r} c_{r, t}^{F}+\nu_{n r} c_{n r, t}^{F}\right)\right]- \\
-\tau_{t}^{k} \nu_{r}\left(r_{t}^{k} \frac{1}{T T_{t}^{1-v}} k_{r, t-1}+\widetilde{\omega}_{r, t}\right)-\tau_{t}^{n} w_{t}\left(\nu_{r} n_{r, t}+\nu_{n r} n_{n r, t}\right)-T T_{t}^{\nu-1} s_{t}^{l} y_{t}^{H} \\
\left(1-\lambda_{t}\right) d_{t}-T T_{t}^{\nu^{*}+\nu-1} \nu_{r} f_{t}^{h}+\nu_{r} \pi_{t}+T T_{t}^{\nu-1} v_{t}=-T T_{t}^{\nu-1}\left(\nu_{r} c_{r, t}^{F *}+\nu_{n r} c_{n r, t}^{F *}\right)+ \\
+T T_{t}^{\nu}\left(\nu_{r} c_{r, t}^{F}+\nu_{n r} c_{n r, t}^{F}\right)+ \\
\quad+\frac{Q_{t-1} T T_{t}^{\nu^{*}+\nu-1}}{\Pi_{t}^{*}}\left(\frac{1}{T T_{t-1}^{v+v^{*}-1}}\left(1-\lambda_{t-1}\right) d_{t-1}-\nu_{r} f_{t-1}^{h}\right) \\
y_{t}^{H}=\left(\nu_{r} c_{r, t}^{H}+\nu_{n r} c_{n r, t}^{H}\right)+\nu_{r} x_{r, t}+\left(s_{t}^{g}+s_{t}^{i}\right) y_{t}^{H}+v_{t}+\left(\nu_{r} c_{r, t}^{F *}+\nu_{n r} c_{n r, t}^{F *}\right)
\end{gathered}
$$

Prices: 


$$
\begin{aligned}
& \left(\Pi_{t}^{H}\right)^{1-\phi}=\theta+(1-\theta)\left(\Theta_{t} \Pi_{t}^{H}\right)^{1-\phi} \\
& \frac{\Pi_{t}}{\Pi_{t}^{H}}=\left(\frac{T T_{t}}{T T_{t-1}}\right)^{1-\nu} \\
& \frac{T T_{t}}{T T_{t-1}}=\frac{\epsilon_{t} \Pi_{t}^{* H}}{\Pi_{t}^{H}} \\
& \frac{\Pi_{t}^{*}}{\Pi_{t}^{* H}}=\left(\frac{T T_{t-1}}{T T_{t}}\right)^{1-\nu^{*}} \\
& \Delta_{t}=\theta \Delta_{t-1}\left(\Pi_{t}^{H}\right)^{\phi}+(1-\theta)\left(\Theta_{t}\right)^{-\phi} \\
& z_{t}^{1}=\Theta_{t}^{1-\phi} y_{t}^{H} T T_{t}^{\nu-1}+\beta \theta \frac{c_{t+1}^{-\sigma}}{c_{t}^{-\sigma}} \frac{1+\tau_{t}^{c}}{1+\tau_{t+1}^{c}}\left(\frac{\Theta_{t}}{\Theta_{t+1}}\right)^{1-\phi}\left(\frac{1}{\Pi_{t+1}^{H}}\right)^{1-\phi} z_{t+1}^{1} \\
& z_{t}^{2}=\Theta_{t}^{-\phi} y_{t}^{H} m c_{t}+\beta \theta \frac{c_{t+1}^{-\sigma}}{c_{t}^{-\sigma}} \frac{1+\tau_{t}^{c}}{1+\tau_{t+1}^{c}}\left(\frac{\Theta_{t}}{\Theta_{t+1}}\right)^{-\phi}\left(\frac{1}{\Pi_{t+1}^{H}}\right)^{-\phi} z_{t+1}^{2}
\end{aligned}
$$

Financial intermediary:

$$
\begin{gathered}
v_{t}=Q_{t-1}^{*} \frac{\psi}{2} \frac{P_{t-1}^{H}}{P_{t}^{H}}\left(f_{t-1}^{* g}-\nu_{r} f_{t-1}^{* h}\right)^{2} \\
\pi_{t}=Q_{t-1}^{*}\left[\frac{P_{t-1}}{P_{t}}\left(f_{t-1}^{* g}-\nu_{r} f_{t-1}^{* h}\right)-\frac{P_{t}^{H}}{P_{t}} \frac{\psi}{2} \frac{P_{t-1}^{H}}{P_{t}^{H}}\left(f_{t-1}^{* g}-\nu_{r} f_{t-1}^{* h}\right)^{2}\right]-Q_{t-1} \frac{S_{t}}{S_{t-1}} \frac{P_{t-1}}{P_{t}}\left(f_{t-1}^{* g}-\nu_{r} f_{t-1}^{* h}\right) \\
Q_{t-1}^{*}=\frac{Q_{t-1} \frac{S_{t}}{S_{t-1}}}{1-\frac{P_{t-1}^{H}}{P_{t-1}} \psi\left(f_{t-1}^{* g}-\nu_{r} f_{t-1}^{* h}\right)}
\end{gathered}
$$

Next, the foreign country is summarized by the following equations:

Ricardian households:

$$
\begin{gathered}
V_{r, t}^{*}=\frac{c_{r, t}^{* 1-\sigma^{*}}}{1-\sigma^{*}}-\chi_{n}^{*} \frac{n_{r, t}^{* 1+\varphi^{*}}}{1+\varphi^{*}}+\chi_{m}^{*} \frac{m_{r, t}^{* 1-\mu^{*}}}{1-\mu^{*}}+\chi_{g}^{*} \frac{\left(s_{t}^{* g} y_{t}^{* H}\right)^{1-\zeta^{*}}}{1-\zeta^{*}}+\beta^{*} V_{r, t+1}^{*} \\
\beta^{*} \frac{c_{r, t+1}^{*-\sigma}}{\left(1+\tau_{t+1}^{* c}\right)} \frac{R_{t}^{*}}{\Pi_{t+1}^{*}}=\frac{c_{r, t}^{*-\sigma}}{\left(1+\tau_{t}^{* c}\right)} \\
\beta^{*} \frac{c_{r, t+1}^{*-\sigma}}{\left(1+\tau_{t+1}^{* c}\right)} \frac{Q_{t}^{*} T T_{t+1}^{1-\nu-v^{*}}}{\Pi_{t+1}}=\frac{c_{r, t}^{*-\sigma}}{\left(1+\tau_{t}^{* c}\right)} T T_{t}^{1-\nu-v^{*}}
\end{gathered}
$$




$$
\begin{aligned}
& \beta T T_{t+1}^{1-\nu^{*}} \frac{c_{r, t+1}^{*}-\sigma}{\left(1+\tau_{t+1}^{* c}\right)}\left\{1-\delta^{*}-\frac{\xi^{*}}{2}\left(\frac{k_{t+1}^{*}}{k_{t}^{*}}-1\right)^{2}+\xi^{*}\left(\frac{k_{t+1}^{*}}{k_{t}^{*}}-1\right) \frac{k_{t+1}^{*}}{k_{t}^{*}}+\left(1-\tau_{t+1}^{* k}\right) r_{t+1}^{* k}\right\} \\
& =T T_{t}^{1-\nu^{*}} \frac{c_{r, t}^{*-\sigma}}{\left(1+\tau_{t}^{* c}\right)}\left[1+\xi^{*}\left(\frac{k_{t}^{*}}{k_{t-1}^{*}}-1\right)\right] \\
& \chi_{m}^{*} m_{r, t}^{*-\mu^{*}}=\frac{c_{r, t}^{*-\sigma}}{\left(1+\tau_{t}^{* c}\right)}-\beta^{*} \frac{c_{r, t+1}^{*-\sigma}}{\left(1+\tau_{t+1}^{* c}\right)} \frac{1}{\Pi_{t+1}^{*}} \\
& \chi_{n}^{*} n_{r, t}^{* \varphi^{*}}=\left(1-\tau_{t}^{* n^{*}}\right) w_{t}^{*} \frac{c_{r, t}^{*-\sigma}}{\left(1+\tau_{t}^{* c}\right)} \\
& \frac{c_{r, t}^{* H}}{c_{r, t}^{* F}}=\frac{\nu^{*}}{1-\nu^{*}} \frac{1}{T T_{t}} \\
& k_{r, t}^{*}=\left(1-\delta^{*}\right) k_{r, t-1}^{*}+x_{r, t}^{*}-\frac{\xi^{*}}{2}\left(\frac{k_{r, t}^{*}}{k_{r, t-1}^{*}}-1\right)^{2} k_{r, t-1}^{*} \\
& c_{r, t}^{*}=\frac{\left(c_{r, t}^{* H}\right)^{\nu^{*}}\left(c_{r, t}^{* F}\right)^{1-\nu^{*}}}{\left(\nu^{*}\right)^{\nu^{*}}\left(1-\nu^{*}\right)^{1-\nu^{*}}}
\end{aligned}
$$

Non-Ricardian households:

$$
\begin{gathered}
\left(1+\tau_{t}^{c *}\right)\left[\frac{P_{t}^{* H}}{P_{t}^{* *}} c_{n r, t}^{* H}+\frac{P_{t}^{*} F}{P_{t}^{*}} c_{n r, t}^{* F}\right]+m_{n r, t}^{*}= \\
=\left(1-\tau_{t}^{n *}\right) w_{t}^{*} n_{n r, t}^{*}+\frac{P_{t-1}^{*}}{P_{t}^{*}} m_{n r, t-1}^{*}-T T_{t}^{1-\nu^{*}} s_{t}^{* l} y_{t}^{* H} \frac{\varrho^{*}}{\nu_{n r}^{*}} \\
V_{n r, t}^{*}=\frac{c_{n r, t}^{* 1-\sigma^{*}}}{1-\sigma^{*}}-\chi_{n}^{*} \frac{n_{n r, t}^{* 1+\varphi^{*}}}{1+\varphi^{*}}+\chi_{m}^{*} \frac{m_{n r, t}^{* 1-\mu^{*}}}{1-\mu^{*}}+\chi_{g}^{*} \frac{\left(s_{t}^{* g} y_{t}^{* H}\right)^{1-\zeta^{*}}}{1-\zeta^{*}}+\beta^{*} V_{n r, t+1}^{*} \\
\chi_{n}^{*}\left(n_{n r, t}^{*}\right)^{\varphi^{*}}=\left(1-\tau_{t}^{* n}\right) w_{t}^{*} \frac{\left(c_{n r, t}^{*}\right)^{-\sigma *}}{\left(1+\tau_{t}^{c *}\right)} \\
\chi_{m}^{*}\left(m_{n r, t}^{*}\right)^{-\mu *}=\frac{\left(c_{n r, t}^{*}\right)^{-\sigma}}{\left(1+\tau_{t}^{c *}\right)}-\beta \frac{\left(c_{n r, t+1}^{*}\right)^{-\sigma *}}{\left(1+\tau_{t+1}^{c *}\right)} \frac{1}{\Pi_{t+1}^{*}} \\
\frac{c_{n r, t}^{* H}}{c_{n r, t}^{* F}}=\frac{\nu^{*}}{1-\nu^{*}} \frac{1}{T T} t \\
c_{n r, t}^{*}=\frac{\left(c_{n r, t}^{* H}\right)^{\nu^{*}}\left(c_{n r, t}^{* F}\right)^{1-\nu^{*}}}{\left(\nu^{*}\right)^{\nu^{*}}\left(1-\nu^{*}\right)^{1-\nu^{*}}}
\end{gathered}
$$

Firms:

$$
\begin{gathered}
w_{t}^{*}=m c_{t}^{*}\left(1-a^{*}\right) A_{t}^{*}\left(s_{t}^{* i} y_{t}^{* H}\right)^{\varkappa}\left(\nu_{r}^{*} k_{r, t-1}^{*}\right)^{a^{*}}\left(\nu_{r}^{*} n_{r, t}^{*}+\nu_{n r}^{*} n_{n r, t}^{*}\right)^{-a^{*}} \\
T T_{t}^{1-v^{*}} r_{t}^{* k}=m c_{t}^{*} a^{*} A_{t}^{*}\left(s_{t}^{* i} y_{t}^{* H}\right)^{\varkappa}\left(\nu_{r}^{*} k_{r, t-1}^{*}\right)^{a^{*}-1}\left(\nu_{r}^{*} n_{r, t}^{*}+\nu_{n r}^{*} n_{n r, t}^{*}\right)^{1-a^{*}}
\end{gathered}
$$




$$
\begin{gathered}
\widetilde{\omega}_{t}^{*}=T T_{t}^{1-v^{*}} y_{t}^{* H}-T T_{t}^{1-v^{*}} r_{t}^{* k} \nu_{r}^{*} k_{r, t-1}^{*}-w_{t}^{*}\left(\nu_{r}^{*} n_{r, t}^{*}+\nu_{n r}^{*} n_{n r, t}^{*}\right) \\
y_{t}^{* H}=\frac{1}{\Delta_{t}^{*}} A_{t}\left(s_{t}^{* i} y_{t}^{* H}\right)^{\varkappa}\left(\nu_{r}^{*} k_{r, t-1}^{*}\right)^{a^{*}}\left(\nu_{r}^{*} n_{r, t}^{*}+\nu_{n r}^{*} n_{n r, t}^{*}\right)^{1-a^{*}} \\
z_{t}^{* 1}=\frac{\phi^{*}}{\left(\phi^{*}-1\right)} z_{t}^{* 2}
\end{gathered}
$$

Constraints:

$$
\begin{gathered}
d_{t}^{*}+\nu_{r}^{*} m_{r, t}^{*}+\nu_{n r}^{*} m_{n r, t}^{*}=\frac{R_{t-1}^{*}}{\Pi_{t}^{*}} \lambda_{t-1}^{*} d_{t-1}^{*}+\frac{Q_{t-1}^{*} T T_{t}^{1-v-v^{*}}}{\Pi_{t}} \frac{1}{T T_{t-1}^{1-v-v^{*}}}\left(1-\lambda_{t-1}^{*}\right) d_{t-1}^{*}+ \\
+\frac{1}{\Pi_{t}^{*}}\left(\nu_{r}^{*} m_{r, t-1}^{*}+\nu_{n r}^{*} m_{n r, t-1}^{*}\right)+T T_{t}^{1-\nu^{*}}\left(s_{t}^{* g}+s_{t}^{* i}\right) y_{t}^{* H}- \\
-\tau_{t}^{* c} \nu_{n r}^{*}\left(T T_{t}^{1-v^{*}} c_{n r, t}^{* H}+\frac{1}{T T_{t}^{v^{*}}} c_{n r, t}^{* F}\right)-\tau_{t}^{* c} \nu_{r}^{*}\left(T T_{t}^{1-v^{*}} c_{r, t}^{* H}+\frac{1}{\left.T T_{t}^{* *} c_{r, t}^{* F}\right)-}\right. \\
-\tau_{t}^{* k} \nu_{r}^{*}\left(r_{t-1}^{* k} T T_{t}^{1-v^{*}} k_{r, t-1}^{*}+\widetilde{\omega}_{r, t}^{*}\right)-\tau_{t}^{* n} w_{t}^{*}\left(\nu_{r}^{*} n_{r, t}^{*}+\nu_{n r}^{*} n_{n r, t}^{*}\right)-s_{t}^{* l} y_{t}^{* H} T T_{t}^{1-\nu^{*}} \\
\left(1-\lambda_{t}^{*}\right) d_{t}^{*}-T T_{t}^{1-\nu^{*}-\nu} \nu_{r}^{*} f_{t}^{* h}=-T T_{t}^{1-\nu}\left(\nu_{r}^{*} c_{r, t}^{F}+\nu_{n r}^{*} c_{n r, t}^{F}\right)+ \\
+T T_{t}^{-\nu^{*}}\left(\nu_{r}^{*} c_{r, t}^{F_{r}^{*}}+\nu_{n r}^{*} c_{n r, t}^{F^{*}}\right) \\
+\frac{Q_{t-1}^{*} T T_{t}^{1-\nu^{*}-\nu}}{\Pi_{t}}\left(\frac{1}{T T_{t-1}^{1-v}-v^{*}}\left(1-\lambda_{t-1}^{*}\right) d_{t-1}^{*}-\nu_{r}^{*} f_{t-1}^{h^{*}}\right) \\
y_{t}^{* H}=\nu_{r}^{*} c_{r, t}^{* H}+\nu_{n r}^{*} c_{n r, t}^{* H}+\nu_{r}^{*} x_{r, t}^{*}+\left(s_{t}^{* g}+s_{t}^{* i}\right) y_{t}^{* H}+\nu_{r}^{*} c_{r, t}^{F}+\nu_{n r}^{*} c_{n r, t}^{F}
\end{gathered}
$$

Prices:

$$
\begin{gathered}
\left(\Pi_{t}^{* H}\right)^{1-\phi^{*}}=\theta^{*}+\left(1-\theta^{*}\right)\left(\Theta_{t}^{*} \Pi_{t}^{* H}\right)^{1-\phi^{*}} \\
\Delta_{t}^{*}=\theta^{*} \Delta_{t-1}^{*}\left(\Pi_{t}^{* H}\right)^{\phi^{*}}+\left(1-\theta^{*}\right)\left(\Theta_{t}^{*}\right)^{-\phi^{*}} \\
z_{t}^{* 1}=\Theta_{t}^{* 1-\phi^{*}} y_{t}^{* H} T T_{t}^{1-\nu^{*}}+\beta^{*} \theta^{*} \frac{c_{t+1}^{*-\sigma^{*}}}{c_{t}^{*-\sigma^{*}}} \frac{1+\tau_{t}^{* c}}{1+\tau_{t+1}^{* c}}\left(\frac{\Theta_{t}^{*}}{\Theta_{t+1}^{*}}\right)^{1-\phi^{*}}\left(\frac{1}{\Pi_{t+1}^{* H}}\right)^{1-\phi^{*}} z_{t+1}^{* 1} \\
z_{t}^{* 2}=\Theta_{t}^{*-\phi^{*}} y_{t}^{* H} m c_{t}^{*}+\beta^{*} \theta^{*} \frac{c_{t+1}^{*-\sigma^{*}}}{c_{t}^{*-\sigma^{*}}} \frac{1+\tau_{t}^{* c}}{1+\tau_{t+1}^{* c}}\left(\frac{\Theta_{t}^{*}}{\Theta_{t+1}^{*}}\right)^{-\phi^{*}}\left(\frac{1}{\Pi_{t+1}^{* H}}\right)^{-\phi^{*}} z_{t+1}^{* 2}
\end{gathered}
$$

where we have used $S_{t} F^{g}=\left(1-\lambda_{t}\right) D_{t}, F^{g}=\frac{\left(1-\lambda_{t}\right) D_{t}}{S_{t}}, \frac{F^{g}}{P_{t}^{*}}=\frac{\left(1-\lambda_{t}\right) D_{t}}{P_{t}^{*} S_{t}}, f_{t}^{g}=\left(1-\lambda_{t}\right) d_{t} \frac{P_{t}}{P_{t}^{*} S_{t}}=$ $\left(1-\lambda_{t}\right) d_{t} \frac{1}{T T_{t}^{\nu^{*}+\nu-1}}, \frac{F^{* g}}{S_{t}}=\left(1-\lambda_{t}^{*}\right) D_{t}^{*}, F^{* g}=\left(1-\lambda_{t}\right) D_{t}^{*} S_{t}, \frac{F^{* g}}{P_{t}}=\frac{\left(1-\lambda_{t}^{*}\right) D_{t}^{*} S_{t}}{P_{t}}, f_{t}^{* g}=\left(1-\lambda_{t}^{*}\right) d_{t}^{*} \frac{S_{t} P_{t}^{*}}{P_{t}}=$ $\left(1-\lambda_{t}^{*}\right) d_{t}^{*} T T_{t}^{\nu^{*}+\nu-1}, \frac{P_{t-1}^{H}}{P_{t-1}}=T T_{t-1}^{\nu-1}, \frac{S_{t} P_{t}^{*}}{P_{t}}=T T_{t}^{\nu^{*}+\nu-1}, \frac{P_{t}}{S_{t} P_{t}^{*}}=T T_{t+1}^{1-\nu-v^{*}}, \frac{P_{t}^{* H}}{P_{t}^{*}}=\left(\frac{P_{t}^{* H}}{P_{t}^{* F}}\right)^{1-\nu^{*}}$, $T T_{t}=\frac{P_{t}^{F}}{P_{t}^{H}}=\frac{\frac{P_{t}^{F}}{S_{t}}}{\frac{P_{t}^{H}}{S_{t}}}=\frac{P_{t}^{* H}}{P_{t}^{* F}}, \frac{P_{t}^{* F}}{P_{t}^{* H}}=\frac{1}{T T_{t}}, \epsilon_{t}=\frac{S_{t}}{S_{t-1}}$. 
We finally have the feedback policy rules:

$$
\begin{aligned}
& \log \left(\frac{R_{t}}{R}\right)=\phi_{\pi}\left(\eta \log \left(\frac{\Pi_{t}}{\Pi}\right)+(1-\eta) \log \left(\frac{\Pi_{t}^{*}}{\Pi^{*}}\right)\right)+ \\
& +\phi_{y}\left(\eta \log \left(\frac{y_{t}^{H}}{y^{H}}\right)+(1-\eta) \log \left(\frac{y_{t}^{* H}}{y^{* H}}\right)\right) \\
& s_{t}^{g}-s^{g}=-\gamma_{l}^{g}\left(l_{t-1}-l\right)-\gamma_{y}^{g}\left(y_{t}^{H}-y^{H}\right) \\
& s_{t}^{i}-s^{i}=-\gamma_{l}^{i}\left(l_{t-1}-l\right)-\gamma_{y}^{i}\left(y_{t}^{H}-y^{H}\right) \\
& s_{t}^{l}-s^{l}=\gamma_{l}^{l}\left(l_{t-1}-l\right)+\gamma_{y}^{l}\left(y_{t}^{H}-y^{H}\right) \\
& \tau_{t}^{c}-\tau^{c}=\gamma_{l}^{c}\left(l_{t-1}-l\right)+\gamma_{y}^{c}\left(y_{t}^{H}-y^{H}\right) \\
& \tau_{t}^{k}-\tau^{k}=\gamma_{l}^{k}\left(l_{t-1}-l\right)+\gamma_{y}^{k}\left(y_{t}^{H}-y^{H}\right) \\
& \tau_{t}^{n}-\tau^{n}=\gamma_{l}^{n}\left(l_{t-1}-l\right)+\gamma_{y}^{n}\left(y_{t}^{H}-y^{H}\right) \\
& s_{t}^{* g}-s^{* g}=-\gamma_{l}^{* g}\left(l_{t-1}^{*}-\eta^{*}\right)-\gamma_{y}^{* g}\left(y_{t}^{* H}-y^{* H}\right) \\
& s_{t}^{* i}-s^{* i}=-\gamma_{l}^{* i}\left(l_{t-1}^{*}-l^{*}\right)-\gamma_{y}^{* i}\left(y_{t}^{* H}-y^{* H}\right) \\
& s_{t}^{* l}-s^{* l}=\gamma_{l}^{* l}\left(l_{t-1}^{*}-l^{*}\right)+\gamma_{y}^{* l}\left(y_{t}^{* H}-y^{* H}\right) \\
& \tau_{t}^{* c}-\tau^{* c}=\gamma_{l}^{* c}\left(l_{t-1}^{*}-l^{*}\right)+\gamma_{y}^{* c}\left(y_{t}^{* H}-y^{* H}\right) \\
& \gamma_{t}^{* k}-\tau^{* k}=\gamma_{l}^{* k}\left(l_{t-1}^{*}-l^{*}\right)+\gamma_{y}^{* k}\left(y_{t}^{* H}-y^{* H}\right) \\
& \tau_{t}^{* n}-\tau^{* n}=\gamma_{l}^{* n}\left(l_{t-1}^{*}-l^{*}\right)+\gamma_{y}^{* n}\left(y_{t}^{* H}-y^{* H}\right) \\
& l_{t}=\frac{R_{t} \lambda_{t} d_{t}+Q_{t} \epsilon_{t+1}\left(1-\lambda_{t}\right) d_{t}}{T T_{t}^{\nu-1} y_{t}^{H}} \\
& l_{t}^{*}=\frac{R_{t}^{*} \lambda_{t}^{*} d_{t}^{*}+Q_{t}^{*} \frac{1}{\epsilon_{t+1}}\left(1-\lambda_{t}^{*}\right) d_{t}^{*}}{T T_{t}^{1-\nu^{*}} y_{t}^{* H}}
\end{aligned}
$$

Welfare functions:

Home weighted average:

$$
V_{t} \equiv \nu_{r} V_{r, t}+\left(1-\nu_{r}\right) V_{n r, t}
$$

Foreign weighted average:

$$
V_{t}^{*} \equiv \nu_{r}^{*} V_{r, t}^{*}+\left(1-\nu_{r}^{*}\right) V_{n r, t}^{*}
$$


World weighted average:

$$
W_{t}=\eta V_{t}+(1-\eta) V_{t}^{*}
$$

\subsection{Steady state solution with non-Ricardian households}

Table A3: Status quo steady state solution with non-Ricardian agents

\begin{tabular}{|c|c|c|c|}
\hline Variables & Description & Home & Foreign \\
\hline$u_{r}, u_{r}^{*}$ & utility Ricardian & 0.2918 & 0.2893 \\
\hline$u_{n r}, u_{n r}^{*}$ & utility non-Ricardian & 0.0115 & -0.0032 \\
\hline$y^{H}, y^{H *}$ & output & 0.3975 & 0.3603 \\
\hline$c_{r}, c_{r}^{*}$ & consumption Ricardian & & 0.2735 \\
\hline$c_{n r}, c_{n r}^{*}$ & consumption non-Ricardian & 0.1937 & 0.1896 \\
\hline$Q^{*}-Q$ & interest rate premiu & - & 0.0055 \\
\hline$\frac{d}{T T^{\nu-1} y^{H}}, \frac{d^{*}}{T T^{1-\nu^{*}} y^{* H}}$ & $\begin{array}{l}\text { total pub } \\
\text { as share }\end{array}$ & 0.6842 & 1.08 \\
\hline$\frac{\left(\frac{(1-\lambda) d}{T T^{\nu-1}}-T T_{t}^{\nu^{*}} f^{h}\right)}{y^{H}}, \frac{\frac{\left(1-\lambda^{*}\right) d^{*}}{T T^{1-\nu-\nu^{*}}-f^{* h}}}{T T_{t}^{\nu} y^{* H}}$ & $\begin{array}{l}\text { total foreign debt } \\
\text { as share of GDP* }\end{array}$ & -0.2274 & 0.2107 \\
\hline
\end{tabular}

Notes: Parameters and policy variables as in Tables 1a-b and as discussed in the text.

\section{Appendix 9: Flexible exchange rates}

In this appendix, we present response functions for some key variables in the case of independent monetary policies meaning flexible exchange rates. As discussed in the text, the range of feedback monetary policy coefficients is restricted so as, in equilibrium, nominal interest rates do not violate their ZLB. Below, we present the response functions in a currency union (red solid lines) and under flexible exchange rates (brown dashed lines). For reasons of comparison with Figures 2 and 3 in the text, we focus on the case in which premia remain in the new reformed steady state. 
Figure F8: Response functions of main macro variables in Germany and Italy under flexible exchange rates (in percentage deviations from status-quo steady state)
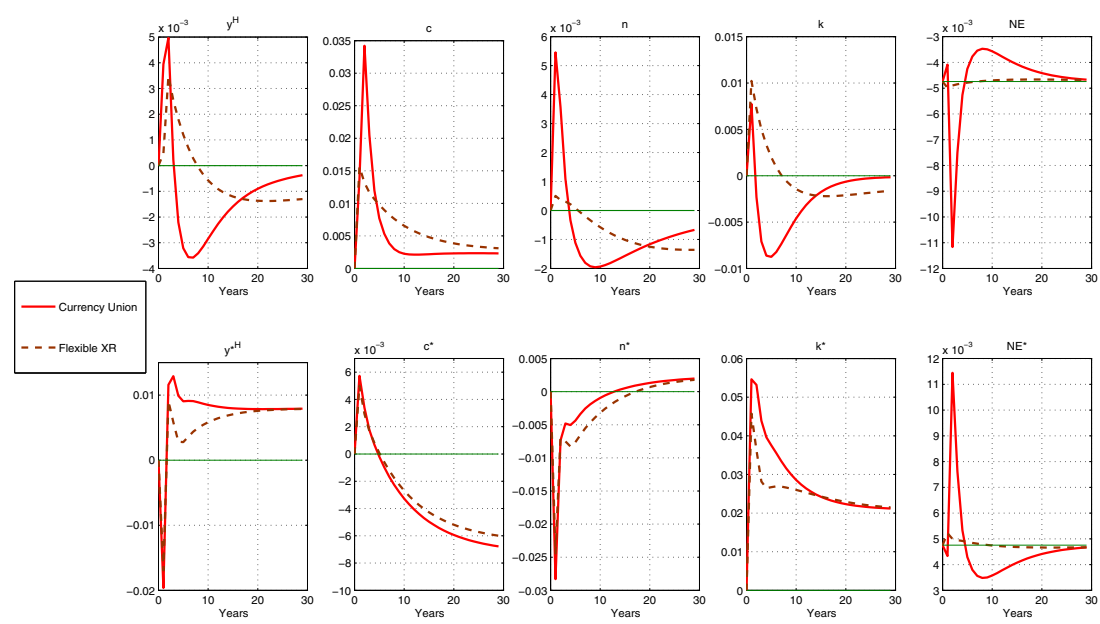

Figure F9: Response functions of main price indices in Germany and Italy under flexible exchange rates (in levels)
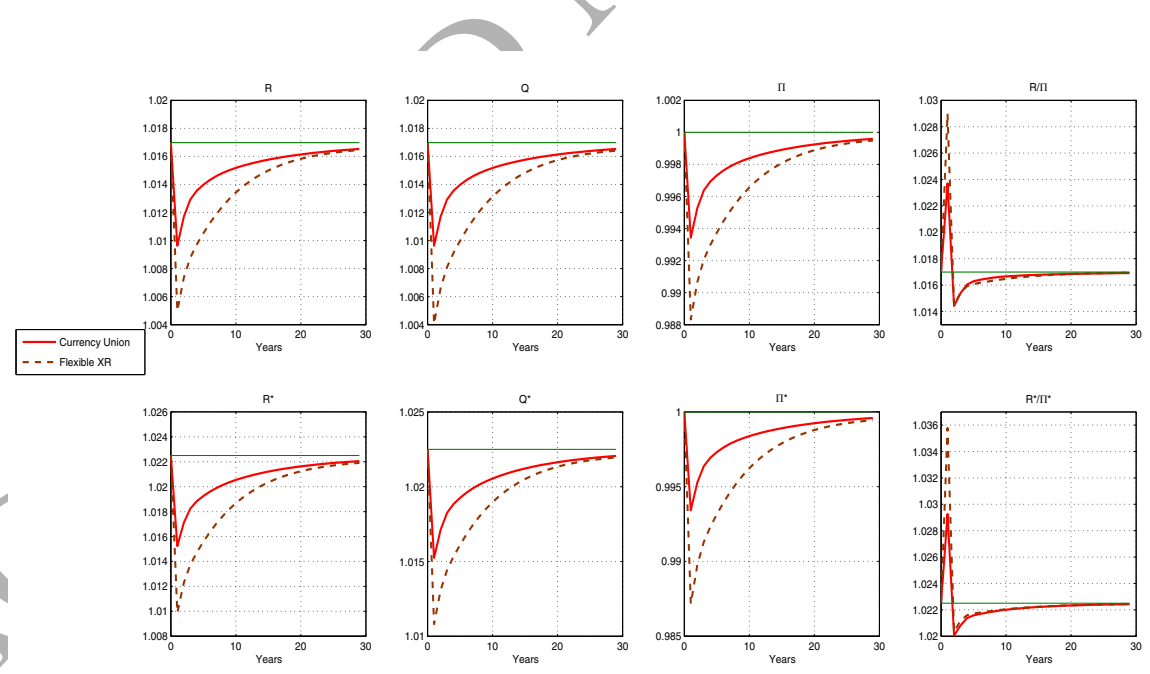